Universidad Autónoma Metropolitana

Widad Stapalapa

Idónea Comunicación de Resultados para obtener el grado de maestra en Humanidades

Línea Lingüística

\title{
Campaña presidencial 2006 en la prensa mexicana. Un estudio discursivo
}

Presenta: Lic. Claudia Jalife Montalvo Asesora: Dra. Irene Fonte Zarabozo

ABRIL DE 2012

Índice 
Capítulo I: Antecedentes, objetivos y metodología 3

Introducción: Antecedentes, objetivos y metodología 4

Los medios y la campaña política 2006

Objetivos 6

$\begin{array}{ll}\text { Metodología } & 7\end{array}$

Titulares y lead $\quad 7$

Citas referidas 9

El significado en contexto 10

Antecedentes 14

$\begin{array}{ll}\text { El periódico y su relación con el poder político } & 14\end{array}$

$\begin{array}{ll}\text { Capitulado } & 20\end{array}$

Capítulo II: $\quad 22$

Aspectos Teóricos $\quad 23$

1 La ideología en los periódicos 23

2 La Teoría de la Valoración 26

2.1 Los fundamentos $\quad 26$

2.2 Los subtipos de valoración $\quad 32$

2.2.1 Categorizaciones semánticas $\quad 34$

2.2.1.1 Actitud 34

2.2.1.1.1 El afecto $\quad 35$

2.2.1.1.2 El juicio 37

2.2.1.1.3 Apreciación $\quad 39$

2.2.1.2 Compromiso 40

2.1.3.3 Gradación 42

Capítulo III: $\quad 44$

La evaluación en los periódicos

Inicio de campaña:

Inicio de campaña de Andrés Manuel López Obrador (La Jornada) 45

Inicio de campaña de Andrés Manuel López Obrador (El Universal) 48

Inicio de campaña de Felipe Calderón Hinojosa (La Jornada) 54

Inicio de campaña de Felipe Calderón Hinojosa (El Universal) 56

Inicio de campaña de Roberto Madrazo Pintado (La jornada) 58

Inicio de campaña de Roberto Madrazo Pintado (El Universal) 60 
Segundo día de campaña:

\section{Índice}

21 de enero de 2006: Andrés Manuel López Obrador (La Jornada) 62

21 de enero de 2006: Andrés Manuel López Obrador (El Universal) 64

21 de enero de 2006: Felipe Calderón Hinojosa (La Jornada) 65

21 de enero de 2006: Felipe Calderón Hinojosa (El Universal) 67

21 de enero de 2006: Roberto Madrazo Pintado (La Jornada) 68

21 de enero de 2006: Roberto Madrazo Pintado (El Universal) 71

Tercer día de campaña:

22 de enero de 2006: Andrés Manuel López Obrador (La Jornada) 72

22 de enero de 2006: Andrés Manuel López Obrador (El Universal) 74

22 de enero de 2006: Felipe Calderón Hinojosa (La Jornada) 76

22 de enero de 2006: Felipe Calderón Hinojosa (El Universal) 78

22 de enero de 2006: Roberto Madrazo Pintado (La Jornada) 79

22 de enero de 2006: Roberto Madrazo Pintado (El Universal) 81

Cuarto día de campaña:

23 de enero de 2006: Andrés Manuel López Obrador (La Jornada) 82

23 de enero de 2006: Andrés Manuel López Obrador (El Universal) 84

23 de enero de 2006: Felipe Calderón Hinojosa (La Jornada) 87

23 de enero de 2006: Felipe Calderón Hinojosa (El Universal) 89

23 de enero de 2006: Roberto Madrazo Pintado (La Jornada) 90

23 de enero de 2006: Roberto Madrazo Pintado (El Universal) 92

Cierre de campaña:

29 de junio de 2006: Andrés Manuel López Obrador (La Jornada) 94

29 de junio de 2006: Andrés Manuel López Obrador (El Universal) 96

26 de junio de 2006: Felipe Calderón Hinojosa (La Jornada) 98

26 de junio de 2006: Felipe Calderón Hinojosa (El Universal) 100

28 de junio de 2006: Roberto Madrazo Pintado (La Jornada) 102

28 de junio de 2006: Roberto Madrazo Pintado (El Universal) 104

Capítulo IV: Conclusiones

$\begin{array}{ll}\text { Ideología desde la evaluación } & 106\end{array}$

$\begin{array}{ll}\text { Obras citadas } & 115\end{array}$

Apéndices 


\section{Antecedentes, objetivos y metodología \\ Capítulo I}




\section{Introducción}

\section{Antecedente, objetivos y metodología}

En esta investigación tengo la inquietud de conocer el papel ideológico que jugó la prensa escrita en la narración de las campañas de los candidatos presidenciales del 2006. Esto es, planteo estudiar cómo el periódico muestra o presenta a los candidatos presidenciales en términos de la evaluación positiva o negativa y a través de ello identificar la postura ideológica de los prensa con relación a los candidatos presidenciales.

La problemática que aquí expondré alude al rol que jugó la prensa mexicana escrita frente a la presentación de los candidatos presidenciales del 2006, en un clima enrarecido y viciado por los demás medios de comunicación que en su afán por acaparar la atención de más audiencia u otros intereses, acusaron públicamente a algunos personajes políticos sin que, en algunos casos, pudiera comprobarse la imputación.

Los medios fueron espacios de denuncias; estos mostraron ante la audiencia grabaciones de actos ilícitos, etcétera. Los políticos fueron sorprendidos en su quehacer cotidiano realizando operaciones o negocios de corrupción. Sin embargo, no se llegó a denuncias formales.

Se produjo tanto una creación como una destrucción de la imagen de los políticos a través de la guerra de discursos. Esta función, usual en la tarea de los medios, fue muy marcada en este periodo preelectoral. Sobre todo, las televisoras que crearon coalición con ciertos grupos de poder y la pelea por el mismo, se tornó más difícil y escandalosa.

Los medios y la campaña política del 2006.

La relación de la prensa y campañas presidenciales en nuestro país tiene una historia reciente en comparación con las naciones que gozan de 
"elecciones democráticas"; es decir, donde los partidos políticos contienden por la presidencia y exhiben, en la prensa o demás medios de comunicación, sus propuestas y éstas quedan expuestas para ser valoradas.

En México, en el año 2000 se comenzó a observar, influenciados por la ilusión de alternancia, en los medios de comunicación una "primitiva" contienda política que literalmente se convirtió en guerra de discursos, dichos y acusaciones de unos candidatos contra otros, y terminada la contienda, de políticos contra políticos. Esto alcanzó su máxima expresión entre los años 2004 y el 2006 con los video-escándalos y grabaciones ${ }^{1}$; los continuos altercados entre el entonces presidente Vicente Fox y el jefe de gobierno del Distrito Federal, Andrés Manuel López Obrador, etcétera. La prensa se convirtió en el medio eficaz para denunciar hechos corruptos que fueron expuestos a la opinión pública para valorarlos.

Por tal motivo ante la llegada de otras elecciones presidenciales (2006) se hizo evidente la necesidad de regular la excesiva postura democrática, por llamarla de alguna manera, de los medios de comunicación para frenar el modo en cómo se presentan a los candidatos presidenciales, así no fueran objeto de valoración.

Por lo que se especificó en el Régimen Electoral y Mexicano y Las Elecciones del 2006, un apartado donde con más precisión se definió la función de los medios de comunicación frente a la campaña proselitista. Este apartado defiende la equidad en la competencia electoral, y al mismo tiempo delimita las funciones y el papel que se supone deberían jugar los medios de

\footnotetext{
${ }^{1}$ A inicios de marzo de 2004 en la televisión mexicana se proyectaron videos que exhibían a servidores públicos, en su mayoría, del partido de izquierda en actos de corrupción; el primero fue del Secretario de Finanzas del Distrito Federal, Gustavo Ponce Meléndez, quien destinó dinero del erario para viajar y apostar cantidades millonarias en el casino del hotel Bellagio de las Vegas. El video muestra al político jugando en tal casino; posteriormente, en el programa televisivo titulado "El mañanero", se mostró al presidente de la asamblea, René Bejarano, recibiendo dinero del empresario Argentino, Carlos Ahumanda Kurt; el monto ascendía a 45,000 dólares. Este video fue uno de los golpes más certeros para desprestigiar al partido de izquierda. Por último el de Carlos Ímaz Gispert quien antes de ocupar la delegacional de Tlalpan recibió de ese mismo empresario, Ahumada, la cantidad de 500,000 pesos para viajar a Europa con su esposa, Claudia Sheinbaum, quien a su vez fue responsable de todas las obras viales del jefe de gobierno y ahora candidato presidencial del partido de izquierda, Andrés Manuel López Obrador.
} 
comunicación: el manejo y la cobertura, los juicios de valoración y de la información sobre las campañas y los candidatos:

Los lineamientos generales aplicables al proceso electoral federal 2006 fueron presentados por el IFE a la Cámara Nacional de la Industria de Radio y Televisión en diciembre de 2005. En la misma tesitura de los lineamientos presentados en ocasiones precedentes, los relativos a las elecciones 2006 enfatizan que los medios precisen al auditorio, de manera expresa, clara y contundente, los casos en que la información transmitida constituya una inserción pagada por los partidos 0 coaliciones; que en los noticiarios se distinga claramente entre las notas informativas y los géneros periodísticos en que se emiten juicios de valor o se editorialicen los contenidos; que se satisfagan los derechos de aclaración y réplica de partidos y candidatos; que exista equidad en la cobertura informativa de las campañas de acuerdo con la actividad de cada candidato, que se respete su vida privada. (IFE, 2006:15)

El apartado lleva como título Disposiciones Adicionales Sobre La Cobertura y El Uso de Los Medios. El resaltado con negritas nos muestra que el fenómeno refleja una crisis en los principios que, hasta ese entonces, regulaban las posturas, los sentimientos y críticas sobre los políticos en las notas periodísticas.

Ante tal escenario, resulta relevante el estudio del discurso de las noticas de los periódicos en términos de la evaluación que reflejaron. Esto ofrece respuesta a qué papel jugaron algunos diarios durante la presentación de los candidatos presidenciales del 2006.

\section{Objetivos}

- El objetivo general de esta investigación es conocer por medio del análisis del discurso la postura ideológica de algunos periódicos que presentaron a los candidatos presidenciales de la contienda del 2006.

Objetivo particular: 
- Conocer si se cumplió con las restricciones impuestas por el Instituto Federal Electoral (IFE).

\section{Metodología}

Mi colección de notas está centrada en los tres candidatos presidenciales de la contienda política mexicana del 2006: Roberto Madrazo, Partido de la Revolución Institucional (PRI); Andrés Manuel López Obrador, Partido Revolucionario Democrático (PRD), y Felipe Calderón Hinojosa, Partido Acción Nacional (PAN). El análisis del corpus comprende los primeros cuatro días del inicio de campaña y el cierre que consideré sólo un día; en total el corpus está compuesto de 30 notas del periódico La Jornada y El Universal.

Estos dos diarios, según mi percepción, sostienen posturas distintas: La Jornada posee tendencia hacia el pensamiento de izquierda y El Universal de centro. Por tanto, me hace suponer que habrá diferencias en cómo cada uno presenta la noticia de las campañas presidenciales desde su ideología.

El criterio que consideré para el análisis fue el siguiente: Ubiqué en titulares y el lead, las oraciones, frases o el léxico considerados como evaluativos de acuerdo a la Teoría de la Valoración: personas, objetos, sentimientos, comportamiento (compromiso), así como la gradación (la fuerza en las oraciones, palabras) y los recursos empleados para evaluar: cláusulas, el léxico, la sintaxis, etcétera. También creí pertinente, por la naturaleza de las notas, utilizar como referente las citas textuales dentro de los titulares y al lead para analizar la presentación de quién evaluaba y su impacto.

- Titulares y el lead

Con lo que respecta a los titulares diré que para fines de la evaluación de notas es un recurso imprescindible puesto que en ellos encontramos, ya sea el resumen del tema de la noticia o, como bien indica Vasilachis, se alude implícitamente al tema con metáforas, ironías, etcétera, esto con una determinada finalidad, ubicar al lector "en el sistema cognitivo de referencia seleccionado por el autor del titular y con ello detonar una posible evaluación. 
También porque es frecuente encontrarnos con titulares que omiten el verbo y los artículos para aminorar la acción del sujeto trayendo como resultado una posible evaluación; asimismo, cuando el sujeto se elide por el uso de nominalizaciones y "de la predicación de la acción respecto de objetos que ocupan el lugar del sujeto (por ejemplo: 'La flexibilización laboral es mala' o 'La ley de accidentes seguirá 'cajoneada' ")... es frecuente el uso de las estrategias de calificar a dichos objetos con atributos aplicables al sujeto que aparece elidido" (Vasilachis, 1998:37). En resumen, los titulares pueden dirigir o estructurar "explícita o implícitamente la interpretación de los textos de la noticia en el sentido propuesto por la evaluación". (38).

Con lo que respecta al lead Van Dijk nos comenta que éste muestra un resumen de los hechos. De igual manera estipula la hora, "el lugar, las situaciones y los personajes principales expresados en pocas frases por lo regular se muestra en cursivas, negritas o con la letra más grande. "Más concretamente, el lead puede contener los resultados o consecuencias principales de las acciones y acontecimiento o reacciones (verbales) de los portavoces importantes". (86).

A continuación Van Dijk nos resume la función de los titulares y el lead:

Expresan la información más importante, más pertinente o más "sorprendente" del relato de la noticia; resumen el sumario ofrecido en el lead. Al mismo tiempo son una interpretación de los acontecimientos o acciones desde el punto de vista del periodista (o del periódico). Su función más importante es atraer la atención al relato mencionado el (los) tema(s) que puede(n) interesar al lector. Muchas veces los titulares se dividirán en un titular principal, uno o dos subtitulares y un supratitular (châpeau)...Más adelante veremos que tanto los titulares como el lead son el lugar preferido para las opiniones implícitas: el resumen exige una valoración de lo que es "importante", "interesante" o "pertinente", y tal juicio depende, naturalmente, de la interpretación y valoración que hace el periodista de los acontecimientos, de modo que el resultado puede ser la "parcialidad (Van Dijk, 1983:85-86 ). 
En efecto, los titulares, al igual que el lead, serán uno de los lugares para localizar las estrategias lingüísticas de la valoración.

Otro recurso para evaluar, en las noticias, son los discursos citados que pueden formar una escena enunciativa que es también ideológica.

\section{- Las citas referidas}

En las notas periodísticas podemos encontrar una escena enunciativa, esto es, la confluencia de discursos sobre un mismo asunto "procedentes de diversos enunciadores insertos en una misma coyuntura socio-histórica, forma una escena virtual de diálogo entre éstos". (Fonte 2002: 28)

Las citas o los discursos referidos pueden ser evaluados, así lo explica Fonte "El discurso ajeno cumple determinadas funciones en el discurso que lo cita. Al mismo tiempo resulta evaluado: puede ser presentado de manara positiva o negativa". (Fonte 2002:29). Por ejemplo, una de las funciones que cumplen el discurso referido es la de dialogar con el lector, aquí el locutor aprovecha la voz del otro para evaluar el grado de compromiso que establece con su interlocutor.

En ese contexto, Williamson y Zúñiga (2005), nos dicen que la polifonía es un recurso útil para el periodista. No sólo se comunica narrativamente un hecho, también el locutor trae a su discurso múltiples voces para construir un hecho noticioso. Estas voces constituyen no sólo el hecho, sino también de manera indirecta, establecen la forma en cómo el periodista presenta su nota y a los personajes que forman parte de la historia.

Las citas referidas, de acuerdo a la clasificación de Fonte, están representadas por el discurso directo, supone la reproducción literal o textual de lo dicho por el enunciador. La voz del locutor y enunciador se mantienen, por lo regular, separada entre comillas y después de dos puntos (Fonte, 2008). El dicho del otro se distingue perfectamente. 
En el caso del discurso indirecto, el locutor se procura preservar el contenido, el sentido, el significado, etcétera de la voz del otro, pero mantiene la forma literal, es decir su estructura gramatical presenta los ajustes pertinente para incorporar el discurso enunciado (Ídem).

Con las voces narradas, otra forma de citación (antes trabajadas por Leech y Short y conocidas con otro nombre: reporte narrativo del acto verbal) el lector da cuenta del acto verbal o del evento comunicativo en forma global y sintética. Hay mayor control aún del locutor de lo dicho por el enunciador, cuya figura apenas se dibuja en la escena; su discurso está casi del todo incorporado al del locutor. (Ídem).

Los otros dos discursos son más complejos. Por ejemplo, el seudodirecto que Irene Fonte retoma de Toolan 2001, explica que esta es una forma de reelaboración que hace el periódico del discurso citado. El discurso puede ser presentado como textual; sin embargo, es una síntesis, mientras que los deícticos y los tiempos verbales son de la enunciación original. Este tipo de cita las encontramos comúnmente en los titulares, aunque también puede localizarse en el cuerpo de la noticia. (2008). Por último, las citas mixtas, éstas, de acuerdo al texto de Williamson y Zuñiga, son formas de citación explícitamente selectivas, en las que la prominencia variable de lo citado puede reflejar también un proceso de distanciamiento entre ello y el periodista que lo citas. Las citas mixtas resultan eficaces en casos de conflicto, ironía o desaprobación. Como recurso retórico del periodismo, parecen ser un fenómeno moderno debido a su aparición relativamente reciente (Williamson y Zúñiga 2005).

El objetivo es tratar de revisar en general los espacios sensibles a ser evaluados en las notas y con ello dar cuenta del significado, del sentido del decir del locutor. Para ello contamos con el contexto.

- El significado en contexto

Lo explícito y lo implícito en los textos ideológicos 
El significado en contexto es un recurso metodológico necesario para el análisis del tema de esta investigación, ya que el corpus elegido contiene textos en situaciones reales, como las notas periodísticas de las campañas presidenciales.

Asimismo, el corpus presenta información evaluativa en su gran mayoría implícita y la información valorativa explícita que es mostrada está justificada por el contexto para no trasgredir las restricciones impuestas por el Instituto Federal Electoral.

Lo explícito e implícito de los enunciados en los textos cargados de ideología son muy comunes porque refieren a un indicador ideológico, así lo expresa Van Dijk: "Al hacer estas proposiciones explícitas tenemos un medio para la reconstrucción de las creencias (ideológicas) de un emisor o autor... La información implícita de un texto no sirve únicamente para definir su coherencia global o local, sino también puede estar señalada en el texto mismo. El análisis de estas señales, por lo tanto puede ser revelador. Las señales globales típicas son títulos, sumarios, oraciones temáticas, etc. Un título, por la tanto, puede ser una expresión de una 'predisposición' global de un texto." (1980, p.47)

En los textos: "Hay proposiciones que no se expresan directamente, pero que pueden ser inferidas de otras proposiciones que han sido expresadas" (1993:169) y existen otras que han sido enunciadas previamente en el texto. Todas estas pueden estar manifestadas a través de conjunciones, pronombres o a nivel oracional, ésta última por la jerarquía que establecen las mismas para expresar relaciones de presuposición o de importancia. (1983).

Para el análisis de las proposiciones explícitas e implícitas de la evaluación de los candidatos, el análisis quedará a cargo del contexto, el significado en contexto y su parámetro será la Teoría de la Valoración.

El estudio del significado en contexto deviene de una larga tradición, la cual comienza con Malinowski en 1923, cuando llega a la conclusión de que es difícil traducir la forma en que los hablantes "nativos" utilizan su lengua fuera de su contexto cultural, al ignorar esto simplemente se hace que la lengua se 
convierten en una ficción. Resalta que lo situacional es un referente básico que debe incluirse en el análisis lingüístico. Este autor llama contexto situacional a una serie de factores del ambiente en el cual se desarrolla la comunicación.

Posteriormente, con la hipótesis Sapir-Worf ([1941] 1956) la lengua cobra una noción más compleja porque ellos advierten que "el mundo es presentado como un flujo caleidoscópico el cual está organizado por nuestra mente... Separamos los elementos naturales, los organizamos en conceptos y les asignamos significados según un modo de organización que es común en nuestra comunidad de habla y está codificado en los patrones lingüísticos". (212-213).

Los hablantes comparten un referente cultural y social en sus comunidades, esto permite referirnos a una cosmovisión del mundo, su lengua así lo organiza y ésta, a su vez, a la realidad social.

Halliday (1982) retoma algunas reflexiones de Firth ${ }^{2}$, discípulo de Malinowski, y comparte "que el lenguaje sólo surge a la existencia cuando funciona en algún medio... se relaciona con algún escenario" (p. 42) Halliday relaciona tres componentes del contexto de situación con las funciones semánticas del lenguaje, definiendo así el significado social o lenguaje como semiótica.

Las funciones semánticas del lenguaje son: campo, tenor y modo. El primero se refiere al tipo de lenguaje utilizado de acuerdo al tema de la situación, esto es, "el campo se refiere a lo que los participantes en el contexto de situación están haciendo verdaderamente" (Halliday 1982:288), también incluye, los propósitos o las intenciones del hablante.

El tenor se refiere a la relación entre los participantes, más bien, el papel que desarrolla cada uno porque de ello depende el grado de formalidad o de tecnificación de los mensajes (Ídem).

\footnotetext{
${ }^{2}$ Del contexto situacional de Firth considera los siguientes elementos: La posición de los hablantes y su rol; la acción verbal y no; la acción con la situación espacial y los objetos que lo rodean, y los efectos de esta acción.
} 
Por último, el modo es el medio utilizado para comunicar lo que se desea; por ejemplo, por el canal escrito o hablado.

El significado como red de codificaciones tiende a proporcionar información del mundo real, cognoscitivo, social, entre otras. La información social, a diferencia de las otras, es polisistema, es decir, proporciona una serie de significados de los cuales se referirán a un contexto. (Ídem).

Por ejemplo, las notas periodísticas de campañas políticas compartirán a través de los significados codificados, la evaluación de los candidatos presidenciales, es decir la ideología ${ }^{3}$, con un número considerable de lectores. El escritor/periodista/locutor se anticipa a sus lectores/interlocutores porque crean a partir del contexto social (el tema) y del situacional, la semántica adecuada que deberá exponerse en un texto o conversación.

Esta anticipación que mencionaba corresponde a la noción de registro, la cual se define "como "la configuración de recursos semánticos que el miembro de una cultura asocia típicamente a un tipo de situación; es el potencial de significado asequible en un contexto social dado." (Halliday, 1982:146).

Van Dijk (1998) nos dice que "los contextos, o, más bien, los modelos de contextos, explican las variaciones personales, situacionales y sociales en las formas que la ideologías subyacen pueden afectar o no al texto...Por tanto, ninguna teoría discursiva de la expresión y reproducción ideológicas puede ser adecuada sin un análisis detallado del contexto" (286).

Más adelante afirma que la función y la variación del contexto no se restringen solamente a las estructuras oracionales de la gramática, sino también a las estructuras formales del discurso, "como estructuras esquemáticas de la narración, de la argumentación o las estructuras canónicas

\footnotetext{
${ }^{3}$ A propósito del contexto ideológico, Van Dijk expresa que las ideologías pueden intervenir en la construcción o las interpretaciones sociales de las categorías contextuales que, a su vez, restringen (o están influenciados o constituidas por el texto) el texto y la conversación". (Van Dijk, 1998:290). Una de esas categorías justamente son las creencias sociales, éstas corresponden a la ideología de los participantes. Por ello, si hablamos del control ideológico no es externo, sino interno porque se produce por medio de las creencias de los mismos participantes. Tal como puede ocurrir en las notas periodísticas.
} 
convencionalizadas de otros géneros (la conversación, la noticia, el artículo científico)." (p.70).

\section{ANTECEDENTES}

En este apartado explicaré por qué es relevante el estudio de la prensa mexicana en las campañas presidenciales.

La importancia del estudio de los periódicos en esta coyuntura en nuestro país, radica en la estrecha relación que se establece entre las campañas políticas y los medios de comunicación.

A continuación haré un pequeño recorrido para mostrar cómo se dio esta relación en determinados momentos históricos y como ha ido adquiriendo mayor relevancia.

\section{El periódico y su relación con el poder político}

Haciendo un poco de historia recordaremos que las campañas presidenciales y el seguimiento de la sucesión del poder no tenían mucha trascendencia en la sociedad mexicana, porque el presidente en turno designaba a su sucesor del mismo partido. Esto fue la práctica del partido que institucionalizó la Revolución Mexicana, el Partido Revolucionario Institucional (PRI).

La prensa en el periodo posrevolucionario no se caracterizó por ser crítico al contrario sólo fue un medio eficaz para medir el poder del presidente:

La política periodística del Estado en la fase poste-revolucionaria, sobre todo después de la fundación del PNR ha mantenido a los diarios dóciles al gobierno y carentes de crítica por medio de la centralización de informaciones, la prerrogativas fiscales y desde Alemán, la corrupción de los periodistas de prensa. Sólo en algunas revistas marginales se mantuvo un periodismo de opinión decidido. En lo que respeta a los grandes órganos de difusión de la capital, se puede decir como constante que todos vivieron "momentos políticos" que, por lo general, 
coincidieron con el apoyo de una fracción político o de un presidente. No hubo diario que sirviera de vocero de uno de los partidos de oposición poco desarrollados. El gobierno actuó haciendo con severas represalias contra las pocas voces disidentes. (Karam, 2000:s.p.).

Más adelante, en los años cuarenta podemos resumir que la prensa escrita en nuestro país, como en muchas ciudades latinoamericanas fue el instrumento del poder. Por ello entre más poder político y económico, más control sobre la prensa se tenía. Rossana Fuentes-Berain (2001), nos menciona lo siguiente: "Tres décadas enteras la prensa escrita mexicana no fue un contrapoder fue un instrumento más del poder, que lo ayudaba a cabalidad a cumplir con la tercera dimensión de Lukes: La legitimización, es este caso, de la agenda priista". (s.p.)

Más tarde en el gobierno de Luis Echeverría se controló a la iniciativa privada y fomentó la inversión estatal en los medios de comunicación para recuperar la tutela sobre la cultura y la ideología del pueblo. ${ }^{4}$ Durante su gobierno se compró un canal televisivo y se creó una organización pública para controlar la información y la publicidad política. De esa manera se llegó a determinar qué era bueno, culturalmente hablando, para la población.

Un hecho impactante durante su gobierno fue el del periódico Excélsior. Éste poseía una postura crítica ante los acontecimientos del país y las decisiones del gobierno, por tal motivo lo neutralizó ${ }^{5}$ el Estado. Así, se suscitó una lucha de sometimiento del gobierno federal hacia los periódicos privados. Para muchos periodistas el golpe al Excélsior fue un golpe a la libertad de expresión.

\footnotetext{
${ }^{4}$ Véase en Caletti Kaplan, Rubén, “Las políticas de comunicación en México: Una paradoja históricas en palabras y en actos", en Medios de comunicación y política en América Latina, Elizabeth Fox (Ed.), México, 1989.

${ }^{5}$ Después de que Excélsior emitiera una fuerte crítica contra la masacre de Tlatelolco en 1968 poco tiempo después se cometió un atentado dinamitero contra el edificio del periódico. El gobierno adjudicó el ataque a la izquierda, pero se supone que fue él mismo el responsable. Karam, Tanius, “Comunicación y democracia en México: una introducción general”, en Razón y Palabra, mayo-julio de 2000.
} 
Después de lo ocurrido en el 1968 cierto sector de la sociedad mexicana comenzó a cambiar su manera de percibir la política y a los políticos y a exigir más claridad e imparcialidad en las notas periodísticas, sentando las bases para propiciar una reforma en los medios de comunicación. Asimismo, Rosalba Cruz Soto, muestra que los investigadores de los años sesenta y setenta que trabajaron entorno a la prensa mexicana como L. McGowan (1978), Wold, Ruth (1970), entre otros, llegaron a la conclusión de que ésta funcionaba como un instrumento de coerción y de consenso al servicio del poder político.

En 1977 se suscitó otra reforma política con Jesús Reyes Heroles ${ }^{6}$ quien abrió la posibilidad de concebir a la prensa como un espacio democrático, moderno y pluralista en donde las ideologías y los partidos de corrientes políticas diferentes defendían sus posturas. Rossana Fuentes-Berain (2001), sostiene que el cambio de esta relación entre prensa y los políticos se produjo justamente con las reformas a finales de los setentas (llamadas por ella, inmateriales) y con el fin del monopolio en la creación de papel periódico (hechos materiales). Estos dos factores, comenta, fueron los promotores de tal cambio:

...En el sexenio de José López Portillo, políticos y periodistas, se vieron exhibidos frente al gran público ante una frase célebre "no te pago para que me pegues", que permitió a la ciudadanía otear el resquebrajamiento de una relación entre y el poder político y la prensa escrita. Con esa sentencia, López Portillo verbalizó una norma no escrita de la relación prensa-poder' (Ídem, 2001: s.p.)

\footnotetext{
${ }^{6}$ Las reformas de 1977 promovidas por el entonces secretario de gobernación, Jesús Reyes Heroles, consistían en un cambio básicamente electoral porque renovó el sistema de partidos para legitimar la aparente democracia promovida por el gobierno de José López Portillo; entre estas reformas se localiza la efectuada en los medios de comunicación, por ejemplo, se decretó otorgar espacio en radio y televisión a los partidos contendientes para presentar propaganda proselitista, esto fue para los medios la primera oportunidad para convertirse en un espacio plural. Estas reformas pretendían en lo general, legitimar al estado, a su política económica, a su autoridad, y fortalecer el poder del presidente frente al congreso. (Fernández, 1978).
} 
Para 1988 se registra por primera vez en la historia de México un intento de contienda política en donde se presuponía un sistema de elecciones con alternancia política.

Estas elecciones presidenciales presentaron a cinco candidatos ${ }^{7}$, de los cuales tres sobresalían de los demás: Cuauhtémoc Cárdenas Solórzano del Partido de la Revolución Democrática e hijo del ex presidente Lázaro Cárdenas; Jesús Manuel Clouthier del Rincón del Partido Acción Nacional e industrial muy reconocido en el norte del país y, por último, Carlos Salinas de Gortari del Partido Revolucionario Institucional, el cual había transitado por varios puestos políticos de alta jerarquía como Secretario de Programación y Presupuesto en el gobierno de Miguel de la Madrid, entre otros.

Lo relevante de todo ello es que se comenzaron a vislumbrar condiciones electorales diferentes, en donde los candidatos de diversos partidos promovían sus propuestas de gobierno por toda la República Mexicana y convocaban a la ciudadanía al voto. ${ }^{8}$ La prensa y otros medios de comunicación realizaron un papel importante en la propagación de las campañas políticas.

La sospecha de fraude electoral en las elecciones presidenciales de 1988 motivó a algunos periódicos a manifestar una postura crítica frente a los hechos, lo que marcó el inicio de un debate en los medios.

Así lo revela Fuentes:

\footnotetext{
${ }^{7}$ Los cinco candidatos representaban a las siguientes fracciones: Rosario Ibarra de Piedra por el PRT (Partido Revolucionario de los Trabajadores), Gumersindo Magaña, por el PDM (Partido Democrático Mexicano); Carlos Salinas de Gortari, por el PRI (Partido Revolucionario Institucional), Manuel de Jesús Clouthier del Rincón, por el PAN (Partido Acción Nacional); Cuauhtémoc Cárdenas Solórzano, por el Frente Democrático Nacional que incluía a los siguientes partidos: Partido Popular Socialista, PPS; Partido del Frente Cardenista de Reconstrucción Nacional, PFCRN; Partido Auténtico de la Revolución Mexicana,, PARM y Partido Mexicano Socialista, PMS).

8 Como contraste en 1964 Díaz Ordaz ganó sin rivales la presidencia con el Partido Revolucionario Institucional (PRI).
} 
La disputa respecto a los resultados de la elección presidencial de 1988 fue para la ciudadanía y para la prensa nacional otro espacio de definición. El memorable encabezado de "El Financiero" el 7 de julio "Nada para nadie", marcó que el diario de Rogelio Cárdenas padre e hijo franqueara las barreras de su nombre e ingresara al debate político nacional... (2001, s.p.).

En 1994, otro suceso cimbró la relación prensa y campaña presidencial: el asesinato de un pre-candidato presidencial del Partido Revolucionario Institucional, Luis Donaldo Colosio. La muerte de este candidato acaparó el proceso electoral del 94, propiciando que diversos grupos entraran al debate y postura política al exigir mediante la prensa cuantas de lo ocurrido.

En el año 1999, nuevamente se vislumbra una posibilidad de alternancia política en las próximas elecciones. Dice Fuentes (2001, s.p.) que esto ya se venía gestando en el gobierno de Ernesto Zedillo: "Cuando el Presidente Ernesto Zedillo presentó su Plan Nacional de Desarrollo 1995/2000, el "destape" de la prensa mexicana era ya un hecho consumado y el empoderamiento de la sociedad también. La rendición de cuentas, sin embargo, tardó más en llegar y lo hizo de manera paulatina a medida que la posibilidad de la alternancia política se estableció como una vertiente real de la política nacional".

Los medios de comunicación, en especial la prensa escrita, le dieron un seguimiento especial a este incipiente evento "democrático".

Por ello, el 2000 es un parteaguas en la prensa mexicana y su relación con las campañas políticas. Efectivamente con la elección del candidato Vicente Fox Quezada como presidente de México, se proyecta un nuevo episodio, tanto en la "aparente nueva vida democrática en México.

Asimismo, recodemos las victorias consecutivas del partido de izquierda en la ciudad de México que tuvieron también mucho impacto entre los ciudadanos. Basta con revisar los periódicos de ese año para darnos cuenta de los hechos. En ese sentido el tránsito por la alternancia comienza a inundar 
los periódicos y a escucharse nuevas voces de ciudadanos que antes no participaban en los debates políticos.

En tanto, en este periodo surge una nueva tendencia, en especial, de la televisión y la radio, las cuales presentaban una lucha de discursos y acusaciones de personajes políticos, los cuales fueron ventilados a la opinión pública para su valoración.

Las elecciones del año 2000, como bien se comentó líneas arriba, dejaron consigo la esperanza de continuar con un proceso democrático. Los medios de comunicación, entre ellos la prensa escrita, experimentaron nuevas maneras de concebir una elección presidencial no simulada, o aparentemente no simulada, en donde los candidatos tenían la palabra y podían debatir sus posturas. Sin embargo, esta nueva apertura suscitó que los políticos acusaran a los medios de ayudar a ciertos personajes a presentarse positivamente y a desprestigiar a sus contrarios. Al respecto nos dice Fuentes-Beraín:

... No quiere decir que los periódicos no puedan contribuir a ventilar los abusos de los políticos, sino simplemente apunta hacia el dimensionamiento del supuesto poder mediático que tanto molesta a los políticos mexicanos y que, a mi juicio, no es tal si no va derivado de un "empoderamiento" de la ciudadanía o de una exigencia de rendición de cuentas horizontal, desde las instituciones mismas, o vertical, también desde la soberanía popular (2001, s.p.).

Los juicios de valor en negativo emitidos por los periódicos podrían manchar la imagen ética del político e invitar a los lectores a compartir tales opiniones; esa fue la principal preocupación de los actores, por ello se apoyó desde la clase política restricciones a los medios de comunicación, entre ellos la prensa, para que de esta manera se mantuviera el pacto de no agresión instituido décadas atrás. 


\section{Capitulado}

La tesis está estructurada en cuatro capítulos. El primero corresponde a la introducción; este apartado, en términos generales, se constituyó a través de la presentación de la problematización del tema, aquí se expuso la relevancia del discurso de los medios impresos en la presentación de los candidatos presidenciales del 2006 ante un nuevo contexto político, es decir, qué ocurría en esos momentos de elección con los diarios nacionales.

También de manera particular, se muestra la causa detonante de que la valoración de los personajes políticos por parte de la prensa se convirtiera en un problema necesario de controlar. En efecto, el exceso de libertad de opinión mostrada en los medios de comunicación que ventilaron la debilidad de los políticos en nuestro país y cómo la corrupción es el pan nuestro de cada día, ocasionó que surgiera un apartado en donde se restringía a los medios a no presentar con dolo a los personajes presidenciables en los lineamientos generales aplicables al proceso electoral federal 2006.

Asimismo, se describió el corpus del trabajo, los criterios y cuáles serían los objetivos a seguir.

Por último, este apartado muestra la relevancia del tema mediante los antecedentes; de manera general se narró qué relación entablaban los medios de comunicación con el poder político en nuestro país. Es decir, cuál fue el escenario previo y que pudo derivar todas las dificultades actuales.

El segundo capítulo expone los aspectos teóricos que hemos utilizado en el análisis del discurso de los periódicos. La teoría es tomada principalmente de los teóricos de la valoración, White y Martin.

Estos autores y un grupo más de científicos desarrollaron la Teoría de la valoración con el objetivo de obtener más información que pudieran demostrar que la semántica interpersonal es uno de los motores principales para comprender y escribir bien textos académicos. El trabajo, titulado Escríbalo bien, se desarrollo en Sídney, Australia. 
En este segundo capítulo se expone y explica la teoría de la valoración, aunque se trató de contextualizarla en el quehacer periodístico.

El tercer capítulo, analiza el corpus en términos de la presentación de los candidatos presidenciales y el sesgo ideológico a través de la evaluación. Por último en las conclusiones se muestra los resultados del análisis del discurso evaluativo (ideológico) de los periódicos mexicanos. 
Aspectos teóricos

Capítulo II 


\section{ASPECTOS TEÓRICOS}

\section{La ideología en los periódicos}

Los estudios de la ideología abarcan diversas posturas teóricas y, por tanto, metodológicas. En este caso, la Teoría de la Valoración me permitirá estudiar y analizar de manera directa la ideología del discurso periodístico.

En este capítulo expondré, brevemente, la relación que se establece entre la ideología, la lengua y el discurso periodístico. Por último, revisaré, desde la Teoría de la Valoración, cuáles son las estrategias lingüísticas posibles de manifestarse en el discurso periodístico.

Hodge y Krees (1993) establecen claramente la relación entre ideología y lengua; sus propuestas teóricas se derivan de la hipótesis de Whorf (1941) quien propone que el verdadero fenómeno del pensamiento se da, no en la idea universal del lenguaje, sino en las diversas lenguas. Por ello, hablar de la ideología necesariamente nos remite al pensamiento o la realidad social y sus vínculos con la lengua. Esto es, las estructuras semánticas y gramaticales conforman una guía para desarrollar la actividad mental y por tanto, una versión de la visión social.

La sociedad requiere de la lengua para materializar su realidad. De acuerdo con Hodge y Kress, la lengua posee un rol esencial para la construcción de la realidad: "Language fixe a world that is so much more stable and coherent than what we actually see take its place in our consciousness and become what we think we have seen." (1993.p.5).

Entonces, la lengua no es simple reproductora de ideas, si no una productora de ellas: "...are systems of categories and rules based on fundamental principles and assumptions about the world. These principles and assumptions are not related to or determined by thought: they are thought" (Idem). Los autores dirán que la Lengua además de ser un medio de comunicación también 
lo es de control y tiene sus formas para distorsionar el significado: "In this way hearers can be both manipulated and informed. Language is ideological in another, more political, sense of that Word: it involves systematization distortion in the service of class interest."(p.6)

Fowler (1994) en ese sentido dirá que el discurso de la prensa, como todos los de los medios de comunicación, se construye de los valores sociales que constituyen la esencia de los acontecimientos, estos no son reconocidos en la lengua puesto que pasan de manera natural, lo anterior indica que el pensamiento y la ideología se articulan sutilmente. Entonces, el periódico dependiendo de su naturaleza social elije las estrategias lingüísticas para presentar y valorar en positivo o negativo un hecho o, en este caso, a un candidato presidencial.

Van Dijk (1999), también, expone que "La valoración de las noticias está entre los muchos sistemas ideológicos que guían tales prácticas: ésta específica, por ejemplo, la preferencia por noticias sobre las elites, eventos negativos (especialmente los causados por otros), nuestro propio grupo cultural y nuestra región del mundo, etcétera". (p.237). Ante tal escenario, agregará "las ideologías son representaciones sociales compartidas que tienen funciones sociales específicas para los grupos".

Hogde y Kress (1993) ofrecen un concepto más extenso. Para ellos, la ideología es: "... as a systematic body of ideas, organized from a particular point of view. Ideology is thus a subsuming category which includes sciences and metaphysics, as well as political ideologies of various kinds, without implying anything about their status and reliability as guides to reality."(p.6).

Thompson introducirá al término de ideología un punto esencial al mencionar que ésta define directamente el papel de los medios de comunicación:

... la manera en que el significado se moviliza al servicio de los individuos y grupos dominantes, es decir, las maneras en que el significado construido y transmitido por las formas simbólicas sirve, en 
circunstancias particulares, para establecer y sostener relaciones sociales estructuradas donde algunos individuos y grupos se benefician más que otros, y que por lo mismo algunos individuos y grupos tienen interés en preservar, en tanto que los otros intentan combatirlas. (1993:109).

Fonte, comparte la visión de Thompson al describe que: "La prensa tiene una función de legitimación y sostenimiento de la estructura de poder de una sociedad"..., aunque, agregará líneas más adelante... "la prensa no funciona como pasiva reproductora de versiones de los grupos de poder. Mediante su propia construcción de hechos influye en la definición de la situación" (2002:25).

Por ejemplo, un personaje político corrupto, estafador, demagogo, etcétera, será un personaje no apto para ocupar la presidencia; en cambio, un personaje que demuestra ética, honradez, integridad y hasta carisma, será un buen candidato presidencial; sin embargo, el hecho no concluye ahí, sino cómo se muestra la información para que un personaje que no cumpla con tales valores socialmente sí los obtenga o no.

Así, "La distinción entre la presentación de los hechos y su evaluación es la base de los géneros de noticia y opinión. La presentación de hechos desprovista de su evaluación ha sido parte del criterio de objetividad de los periodistas. Sin embargo, como muestran numerosos estudios, los elementos de contenido que componen el texto de la noticia, la estructura sintáctica y la selección léxica suelen favorecer cierta interpretación ideológica." (Ídem).

Verón (2002) habla de la construcción social del discurso de la noticia y nos invita a reflexionar sobre el principio de objetividad que actúa como eje de la representación del mundo y sobre todo del mundo de las notas periodísticas, sin embargo, nos advertirá esta "objetividad" es sensible de ser evaluada. El discurso de la prensa, por tanto, es ideológico. 
A continuación mostraré, desde la Teoría de la Valoración, cuáles son las estrategias lingüísticas posibles de manifestarse en el discurso periodístico que hacen posibles medir el grado de subjetividad en los textos.

\section{TEORÍA DE LA VALORACIÓN}

\subsection{Los fundamentos}

El estudio de la evaluación comenzó con el trabajo del socio-lingüista Williams Labov en 1972. Este autor analizó las habilidades verbales que utilizaron los negros del sur-centro de Harlem que evaluaron sus experiencias en situaciones de peligro. Labov comenzó a ubicar la función de la evaluación, entre otros elementos no menos importantes, en lo que él llamó la sintaxis de la narración ${ }^{9}$.

Para este autor, la evaluación es un elemento fundamental que nos remite al terreno de la subjetividad: "es el medio más usado para indicar el objetivo de la narración, su razón de ser: por qué fue contada, y qué es a lo que quiere llegar el narrador". (Labov, 1972:19).

El legado que dejó Williams Labov, actualmente, lo nutren estudios de diferentes escuelas que, por sus argumentos teóricos, recurren a categorías diversas para enunciarla: "...Martin talks of appraisal, while Conrad and Biber talk of stance and our title attempts to hedge our bets by talking of evaluation and stance (we could have tied to fit in appraisal, but that would probably be a hedge too far)". (Hunston, 2003:2)

Entre los exponentes de las diversas corrientes de la evaluación encontramos: "a los denominados subjetivemas en la teoría de la enunciación (Kerbrat-Orecchioni 1980), de la evidencialidad (Biber y Finegan 1989), del estudio de la modalidad de los enunciados (Bybee y Fleischman 1995) o de la gramática local de la evaluación (Hunston y Sinclair 2000), entre otros." (López,

\footnotetext{
${ }^{9}$ Es importante acotar que Labov centró su investigación en la narración oral y espontánea.
} 
2010:4) ${ }^{10}$. En el discurso oral: Grimes 1975, Sinclair y Coulthard 1975, Shiro 1997; el escrito: Hoey 1983, Bolívar 1986, Tadros 1994, Winter 1994, entre otros. (Kaplan, 2004).

Por ejemplo, en Latinoamérica Adriana Bolívar es una importante representante de los estudios de la evaluación; ella ha publicado capítulos de libros y artículos de revistas enfocados a la temática, entre los que destacan: 'La expresión de evaluaciones en 'I thought' en el inglés hablado en Gran Bretaña" (1995); "The negotiation of evaluation in written text" (2001); "la función de la evaluación en artículos y ensayos humanísticos" (2006); La negociación de la evaluación en editoriales de periódicos(1997).

La más compleja de las teorías, nos dice Kaplan, es la denominada Teoría de la valoración: "Martin 1995a, 1995b, Christie y Martin 1997, Coffin 1997, Martin 1997, White 1998, Martin 2000, White 2000, White 2002, MackenHonrarik y Martin 2003, Martin y Rose 2003, White 2003, 2004, entre otros." (Kaplan, 2004:53). La teoría de la valoración se deriva de un gran proyecto denominado: Write it right, creado para ofrecer soluciones a los problemas, que presentan los estudiantes australianos, de lectura y escritura de textos académicos.

Para Kaplan esta teoría se alimenta de diversos autores con su respectiva base teórica, entre los que destacan como ya mencioné William Labov con su sintaxis de la narración, M.A.K. Halliday con su Lingüística Funcional Sistémica (LSF por sus siglas en inglés), Bajtín con su dialogismo y Kristeva con su intertextualidad, sientan las bases para fundar la Teoría.

Labov aporta al trabajo de la lingüística la oportunidad de analizar el lado subjetivo y emocional del discurso porque concibió, dentro de una estructura "sintáctica del texto", a la evaluación y éste como un elemento que fija el por

${ }^{10}$ Este artículo forma parte del simposio Prácticas letradas contemporáneas: análisis y aplicaciones, resultado del proyecto de investigación titulado La competencia receptiva crítica: análisis y propuesta didáctica (HUM2004-03772/FILO), que lleva a cabo el grupo Literacitat crítica (Literacidad crítica), de la Universitat Pompeu Fabra de Barcelona, coordinado por Daniel Cassany. Web del proyecto: http://www.upf.edu/dtf/recerca/grups/grael/LC/index.html 
qué y la importancia de narrar situaciones, es decir, tomar una actitud ante los hechos ocurridos. (1972).

Este autor clasifica cómo las personas incorporan la evaluación a su discurso. Así tenemos a la acción evaluativa de Labov: "lo que la gente hizo en vez de lo que la gente dijo" (p.29), y la evaluación por suspensión de la acción donde nos dice que "las emociones expresadas pudieron ser instantáneas o simultáneas con la acción en el momento, pero cuando se expresan en oraciones aparte, la acción se detiene" (Ídem). Todo lo anterior, es significativo para la teoría de la Valoración porque en ella, la evaluación no sólo forma parte de una estructura sintáctica del texto, sino también se incorpora a una situación de relación social porque crea vínculos entre el sujeto que evalúa y entre quienes son evaluados.

Hunston y Thompson (2003) en su libro evaluation in tex, nos afirman que la evaluación es un término de amplias dimensiones que expresa la actitud, la postura, los puntos de vista de los hablantes hacia determinadas entidades:

For us... evaluation is the broad cover term for the expression of the speaker or writer's attitude or stance towards, viewpoint on, or feelings about the entities to certainty or obligation or desirability or any of a number of other sets of values. (p.5). En ese sentido dirá White (2004)...Así como de los significados que hacen variar los términos del compromiso del hablante o autor con sus enunciados, tanto en el caso de las emisiones individuales como en el de aquéllas que se van acumulando a medida que el texto se despliega. Además, la evaluación representa el punto de vista que expresa una postura positiva o negativa ${ }^{11}$, es decir, ideológica.

\footnotetext{
${ }^{11}$ Asimismo, Susana Hunston y Geoff Thompson (2003) nos mencionan la importancia de los parámetros dentro de la evaluación porque de ellos dependen las formas en que se aborda la valoración: bueno-malo (good-bad); positivo-negativo (positive-negative). Hunston va más allá y propone evaluar a las opiniones canónicamente epistémicas, llamadas comúnmente las opiniones de proposición porque involucran los grados de certeza, de cierto, seguro (certain) e incierto, inseguro (uncertain. Véase páginas: 22, 23 y 24; también a Martin en The language of evaluation; appraisal in English.
} 
Como observamos, la evaluación se complejiza y ahora no sólo necesitamos de las superestructuras del texto para interpretar las cláusulas, sino también del sistema semántico que proporciona más elementos situacionales y relacionales.

El segundo autor Halliday aporta a la teoría de la valoración la concepción del texto como función sociosemántica y por tanto ofrece el análisis situacional del significado, esto es, el significado en contexto.

La SFL concibe al lenguaje no sólo para comunicar, sino también para que los seres humanos se relacionen, comprendan e interpreten al mundo, en eso radica la visión social del lenguaje.

La SFL considera que el sistema semántico tiene una organización en su interior que codifica las funciones sociales del lenguaje y es por medio de las metafunciones o funciones básicas del sistema semántico que se logra dar significados y concretar estas relaciones sociales: "La organización funcional de la semántica simboliza la estructura de la interacción humana (la semiótica de los contextos sociales) y las metafunciones son abstracciones basadas en un análisis de la situación social dentro de la cual se inserta el lenguaje, lo que técnicamente se denomina el contexto de situación, que es una abstracción de la situación comunicativa.". (Ghio, 2005:17).

Las metafunciones son representadas por cuatro componentes, de acuerdo con Halliday, estos son: El experiencial, el lógico, el interpersonal y el textual. Los dos primeros, dirá el autor, por su proximidad "pueden combinarse bajo el nombre de componente 'ideacional'." (1982: 169).

La primera, ideacional, contiene a la experiencial y a la lógica, se refiere al vínculo que se establece entre el hablante, su mundo, y el que lo rodea: "es la Interpretación y representación de la experiencia del mundo que nos rodea y del mundo interior" (2005:17). Así también en el nivel léxico-gramatical su representación será a través de la transitividad. 
La interpersonal que corresponde a la interacción entre el hablante y los oyentes, aquí se designan los roles de habla "y observaciones modalactitudinales" (p.17). "La representación en el nivel léxico-gramatical será el modo (modalidad) y las opciones de cláusulas disponibles serán: las declarativas, las interrogativa e imperativas.

Por último, la textual, organiza el "contenido ideativo e interpersonal como un texto cohesivo y coherente." (Ídem).

En palabras de Martin y White (2005):

...that language is a resource for mapping ideational, interpersonal and textual meaning onto one another in virtually every act of communication. Ideational resources are concerned with construing experience: what's going on, including who's doing what to whom, where, when, why and how and the logical relation of one going-on to another. Interpersonal resources are concerned with negotiating social relations: how people are interacting, including the feelings they try to share. Textual resources are concerned with information flow: the ways in which ideational and interpersonal meanings are distributed in waves of semiosis, including interconnections among waves and between language and attendant modalities (action, image, music etc.). (p.7).

Hunston y Thompson exponen en qué consiste la influencia de Halliday en la Teoría de la Valoración:

Halliday (1994) can be taken as a representative of a 'separating' approach: he deals with modality separately from attitudinal meaning. He explores modality at much greater length, establishing two main subcategories: modalization (relating to probability and usuality) and modulation (relating to obligation and inclination)... Martin (this volume; see also e.g. Egging and Slade 1997) follows this separating approach, but expands the account of attitudinal meaning greatly, using the term appraisal and establishing three sub categories: affect, judgment, and 
appreciation. (2003)...This formulation brings it close to Halliday's concept of modalization. (p.4-5).

El Tenor ${ }^{12}$ y la intersubjetividad, también, forman parte fundamental de la reflexión de Martin y White. En especial menciona White que el modelo que se desarrolla, adoptó un enfoque que asigna un rol más importante a la audiencia, o por lo menos, al modo en que los textos negocian significados con audiencias concretas y potenciales. "También considero que el significado se construye en términos sociales más que individuales y, por otra parte, no asigno prioridad al contenido ideacional y al valor de verdad que se asocia con él" (2004:19).

Martin escribe ${ }^{13}$ y define la Valoración de la siguiente manera: "The term appraisal will be used here for the semantic resource used to negotiate emotions, judgments, and valuation, alongside resource for amplifying and engaging with these evaluations". (2008: 145).

En ese mismo tenor, Kaplan parafrasea a White diciendo que la teoría de la valoración es la encargada de proporcionar los recursos lingüísticos para que los hablantes negocien ciertos puntos de vista y de los significados que hacen modificar los términos del compromiso del hablante con sus emisores (2004). En estas líneas observamos la influencia del dialogismo de Bajtín. Éste contribuyó a través de su concepción dialógica del lenguaje, ésta se concibe como el intercambio verbal y se apoya en la polifonía de discurso. Su clave es el enunciado y los enunciados tienen un destinatario que pueden ser respuestas a otros. (2004). También en dichos diálogos tiene lugar la

\footnotetext{
${ }^{12}$ El tenor, el campo y modo "son los conceptos generales necesarios para describir lo que lingüísticamente es importante en el contexto de la situación" (28). Halliday parafraseando a Jonh Pearce dice que: "El Campo se refiere al marco institucional en que se produce un trozo de lenguaje e incluye no sólo el tema de que se trata sino también toda la actividad del hablante o del participante en determinado marco. El tenor... se refiere a la relación entre participantes... no sólo a la variación de formalidad... sino... también a cuestiones como la permanencia o cosas por el estilo de la relación y el grado de carga emotiva que hay en ella... Modo se refiere al canal de comunicación adoptado: no sólo a la elección entre el médium escrito, sino a elecciones mucho más detalladas...". (28).

${ }^{13}$ Este artículo aparece en uno de los capítulos del libro evaluation in text, de Susan Hunston y Goeff Thompson.
} 
negociación que juega un papel fundamental en las emociones, juicios y valores. (2004).

Finalmente, la intertextualidad de Kristeva forma parte del marco teórico de la Valoración porque ésta concibe a la evaluación como una relación social que anticipa la reacción, la emoción, la actitud de otros. Es decir, para Kristeva el enunciado responde a una construcción dialógica, a propósito de Bajtín, y los hablantes lo construyen sobre la base de otros y lo reelaboran, asimismo está disponible para ser empleado nuevamente. (Kaplan, 2004), esto también ocurre con la Valoración.

\subsection{Los subtipos de la valoración}

Parafraseando a White, diré que la Teoría de la Valoración está encargada de las expresiones o recursos lingüísticos utilizado por los hablantes para negociar y establecer posiciones intersubjetivas. El interés de la teoría radica en el significado de la actitud, la valoración, por supuesto, y de las emocionales. Éstas últimas requieren un grado de compromiso del emisor y con lo que se derive de ello.

Esta teoría se compone de tres recursos valorativos, llamados: Actitud, Compromiso y Gradación. A continuación mostraré un esquema elaborado por Martin y White (2008): 


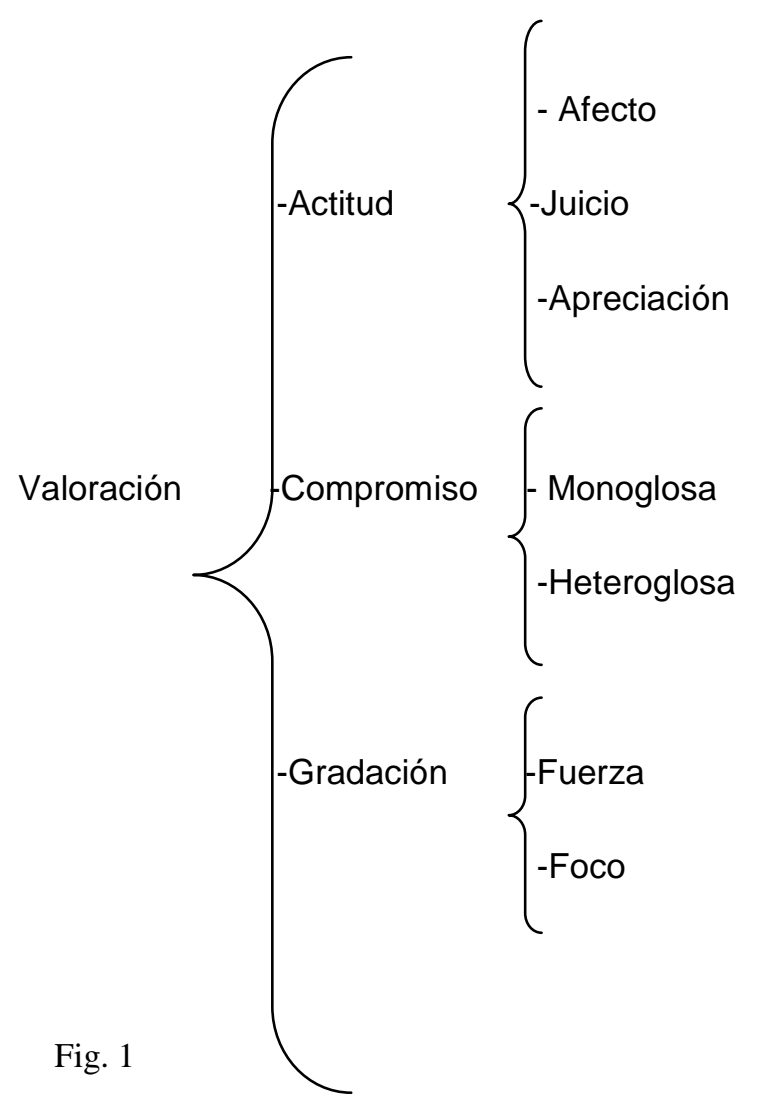

La actitud se refiere a la expresión de afecto, también hacia los objetos y procesos (apreciación) y de la valoración del comportamiento de las personas y de sus sentimientos (juicios). Es decir, "incluye los significados por los cuales los hablantes/textos atribuyen un valor o una evaluación intersubjetiva a los participantes y los procesos, ya sea relacionados con respuestas emocionales o con sistemas de valores culturalmente determinados." (Ibíd., 7).

El compromiso incluye los recursos lingüísticos utilizados para construir proposiciones: "Este conjunto de recursos retóricos se ocupa de aquellos significados que varían de acuerdo con el compromiso del hablante con sus emociones, y con los que hace variar lo que se pone en juego, tanto en las emisiones particulares como en lo que se va acumulando en los textos a medida que se despliegan." (Ibíd., 11). 
La gradación representa la manera en que los hablantes intensifican o disminuyen la fuerza de la enunciación y gradúan lo que semánticamente requieren destacar: "En la gradación, nos preocupan los valores que proporcionan escalas de grado, ya sea en términos de fuerza interpersonal que el hablante adjudica a una emisión como en términos de la precisión con que un elemento pone en foco una relación de valor". (Ibíd. p. 10-11).

En resumen, Attitude is concerned with our feeling, including emotional reactions, judgements of behavior and evaluation of things. Engagement deals with sourcing attitudes and the play of voices around opinion in discourse. Graduation attends to grading phenomena whereby feelings are amplified and categories blurred. (White y Martin, 2005:35).

\subsubsection{Categorizaciones semánticas}

Los tres dominios se dividen en subsistemas por ejemplo, la actitud en afecto, juicio y apreciación. El compromiso en monoglosia y heteroglosia, que al mismo tiempo se divide en extravocalización e intravocalización. Finalmente, La gradación en fuerza que, a su vez, se divide en intensidad baja y alta; foco tiene un estatus central o prototípico o un estado marginal.

\subsubsection{Actitud}

La actitud se divide en tres "áreas que comprenden los sentimientos": afecto, juicio y apreciación (Martin y White, 2005). 


\subsection{El afecto}

El afecto, de manera general, se define como los recursos lingüísticos necesarios para expresar un hecho que causa alguna emoción; por ejemplo un shock ante los eventos del once de septiembre de 2001. "The terrible events of the past week have left us with- in order of occurrence- of horror, worry, anger, and now, just a general gloom". (2005).

White nos dice que las características lingüísticas (semánticas y gramaticales) del afecto se pueden ubicar perfectamente: "El afecto tiene que ver con la respuesta emocional... y con la disposición, y se realiza de manera típica mediante procesos mentales de reacción... y mediante atributos de afecto...Mediante la nominalización, también puede realizarse con nombres..." (White, 2004:11).

El afecto puede expresar nuestras emociones (llamada autoral porque está dicho en primera persona) o la de terceros (llamada no-autoral porque está dicho en tercera persona) hacia cosas, situaciones o eventos en positivo o negativo, como lo muestra el ejemplo.

La función retórica de la llamada autoral indica una posición actitudinal hacia lo que desencadena la emoción: "Los hablantes aspiran a establecer un rapport interpersonal con sus interlocutores para que acepten, comprendan, o al menos simpaticen con su reacción emocional."(Kaplan, 2004:63).

En el caso de la función retórica de la llamada no-autoral nos indica Kaplan se describen no las emociones del autor, sino de otros individuos:

Podría decirse que el evaluador atribuido actúa como un sustituto del autor. Sin embargo, el fenómeno es más complejo de lo que aparenta. Por un lado, depende del grado con que la fuente del valor afectivo reportado se presenta como confiable o razonable en sus respuestas emocionales así como el grado con que la reacción emocional atribuida puede ser interpretada como coherente con la posición evaluativa general del texto. Por otro lado, cuando, los hablantes atribuye alguna 
emoción a un actor social, se espera que esto suscite una respuesta favorable o desfavorable hacía éste. (2004:63).

Además el afecto puede expresarse desde una cualidad: atributo, circunstancia; un proceso: afectivo mental o conductual y un comentario.

El afecto y su función retórica pueden ser una estrategia perfecta de evaluación de las notas periodísticas que presentan las campañas presidenciales, porque la nota invita a sus lectores a compartir esta respuesta emocional. Dice White que cuando se aprueba esa invitación, ocurre que la solidaridad o la simpatía aumenten entre los interlocutores, construyéndose una postura interpersonal.

Por tanto, esta categoría permite la inclusión de los valores de afecto de una determinada cultura, para negociar por lo menos ciertos espacios para la perspectiva de quien escribe, lo que finalmente nos habla de una postura ideológica.

Kaplan, nos ofrece una síntesis de las categorías de afecto en la presente tabla:

\section{AFECTO}

\begin{tabular}{|l|l|l|}
\hline Categoría & Ejemplos positivos & Ejemplos negativos \\
\hline Felicidad /infelicidad & $\begin{array}{l}\text { Feliz, alegre, jubiloso/a, } \\
\text { optimista }\end{array}$ & $\begin{array}{l}\text { Deprimido/a, } \\
\text { miserable, angustiado/a }\end{array}$ \\
\hline Seguridad/inseguridad & $\begin{array}{l}\text { Confiado/a, seguro/a, } \\
\text { tranquilo/a, sereno/a }\end{array}$ & $\begin{array}{l}\text { Ansioso/a, preocupado/a, } \\
\text { inseguro/a, intranquilo/a }\end{array}$ \\
\hline Satisfacción/insatisfacción & $\begin{array}{l}\text { Interesado/a, absorto/a, estar } \\
\text { enfrascado/a, gustar }\end{array}$ & $\begin{array}{l}\text { Cansado/a, aburrido/a, } \\
\text { exasperad/o, odiar }\end{array}$ \\
\hline
\end{tabular}

Cuadro 1. (Kaplan, 2004: 62) 
El juicio tiene que ver con los recursos para emitir una evaluación acerca de cómo deben o no de comportarse las personas (una forma de regulación) de acuerdo a las normas establecidas (socialmente aceptable o no: moral, inmoral legal o ilegal). Martin y White nos describen un ejemplo de una crítica al Primer Ministro de Australia, John Howards, por su gobierno conservador: "Worse, this is a men administration, a miserly, mingy, minatory, bunch if ever there was one. (2005).

Esta función se divide en dos subsistemas: Juicios de estima social que se refiere a la oralidad y sanción social, a la escritura.

A continuación, en el cuadro 2 , se resume y ejemplifica la categoría del juicio y sus subsistemas (2004):

\begin{tabular}{|c|c|c|}
\hline \multicolumn{3}{|c|}{ El Juicio } \\
\hline \multicolumn{3}{|c|}{ Estima Social } \\
\hline & $\begin{array}{l}\text { Ejemplos positivos } \\
\text { (admiración) }\end{array}$ & $\begin{array}{c}\text { Ejemplos negativos } \\
\text { (Critica, sin implicaciones legales) }\end{array}$ \\
\hline normalidad & $\begin{array}{l}\text { Corriente, común, normal, } \\
\text { Afortunado/a, moderno/a }\end{array}$ & $\begin{array}{l}\text { Excéntrico/a, extraño/a, raro/a, } \\
\text { desafortunado/a, anticuado/a }\end{array}$ \\
\hline capacidad & $\begin{array}{l}\text { Habilidoso/a, inteligente, intuitivo/a, } \\
\text { atlético/a, fuerte }\end{array}$ & Inhábil, lento/a, tonto/a, torpe, débil \\
\hline tenacidad & $\begin{array}{l}\text { Heroico/a valiente, confiable, infatigable, } \\
\text { perseverante }\end{array}$ & $\begin{array}{l}\text { Cobarde, apresurado/a, no confiable, } \\
\text { distraído/a, perezoso/a }\end{array}$ \\
\hline \multicolumn{3}{|c|}{ Sanción Social } \\
\hline & $\begin{array}{l}\text { Ejemplos positivos } \\
\text { (admiración) }\end{array}$ & $\begin{array}{l}\text { Ejemplos negativos } \\
\text { (Crítica, sin implicaciones legales) }\end{array}$ \\
\hline veracidad & $\begin{array}{l}\text { Sincero/a, honesto/a, genuino/a, franco/a, } \\
\text { directo/a }\end{array}$ & $\begin{array}{l}\text { Deshonesto/a, mentiroso/a, } \\
\text { inauténtico/a manipulador/a }\end{array}$ \\
\hline $\begin{array}{l}\text { integridad } \\
\text { moral }\end{array}$ & $\begin{array}{l}\text { Moral, bondadoso/a, respetuoso/a de la } \\
\text { ley, sensible, justo/a }\end{array}$ & $\begin{array}{l}\text { Inmoral, malvado/a, corrupto/a, cruel, } \\
\text { injusto/a. }\end{array}$ \\
\hline
\end{tabular}

Cuadro 2. 
En la tabla no aparece, pero también se habla de un juicio 'inscripto' (o explícito) y los 'indicios' (o implícitos). El primero nos señala una evaluación representada por un ítem lexical; por ejemplo, a través de algunos adverbios como honestamente; de atributos como la siguiente frase: la gente es conformista e irracional; de sustantivos como: un mentiroso, y de verbos como: engañar. (2004)

El segundo no se inscribe textualmente, sino que se reemplaza por juicios "superficialmente neutrales"; Kaplan (2004) muestra el siguiente ejemplo: si un periodista escribe que el gobierno no creó las bases para un crecimiento económico sostenido; directamente el periodista no acusa al gobierno de incompetente, pero sí evoca juicios de valor que lo muestra de manera indirecta que cobrarán sentido cuando el escritor comparte, con lectores conocedores de política, economía o simplemente de una determinada sociedad, esto significados. ${ }^{14}$

En especial, los juicios implícitos son muy comunes en las notas periodísticas porque el periodista o los periódicos tienden a moderar su postura.

White explica que las normas sociales que entran en juego pueden evaluar, a través del lenguaje, el comportamiento tanto moral como inmoral, legal o ilegal, socialmente aceptable, etcétera. (2004).

En la prensa escrita, la categoría del juicio y sus subsistemas puede servir de estrategia para evaluar el comportamiento lícito o ilícito, la integridad moral del pasado o del presente de un candidato presidencial. En ese sentido debemos tomar precauciones para elaborar un análisis del juicio porque como menciona White, está tan fuertemente determinado por los valores culturales e

\footnotetext{
${ }^{14}$ El texto, advierte Esla Ghio, puede considerarse entonces como un potencial de significados culturales que es actualizado por medios lingüísticos. (2005:27). Más adelante Elsa cita a Halliday: “Lo importante acerca de la naturaleza del texto es que, aunque cuando lo escribimos parece estar hecho de palabras y oraciones, en realidad, está hecho de significados. Por supuesto, los significados tienen que ser expresados en palabras y estructuras, que a su vez, tienen que volver a expresarse... en sonidos o símbolos escritos. Tienen que ser codificados de alguna manera para ser comunicados; pero en sí mismo, el texto es esencialmente una unidad semántica." (Ídem).
} 
ideológicos que por eso no se debe aplicar las mismas sub-categorías de manera universal.

\subsection{Apreciación}

La apreciación es un recurso mediante el cual se construyen valores en positivo o negativo alrededor de las cosas, incluyendo fenómenos naturales, procesos, entidades, hasta las personas sin sus actos, desde un marco institucional: "Con estos valores se evalúan la forma, la apariencia, la composición, el impacto y la importancia...Este sistema incluye...una evaluación estética”. (2004:66). También dice White que se representan significados tales como: "significativo" o "perjudicial". (White, 2004).

Asimismo, sus parámetros pueden ser medidos desde lo positivo y negativo. El juicio evalúa los comportamientos humanos, la apreciación evalúa textos, constructos más abstractos, tales como planes y políticas, y también manufacturas y objetos naturales. (White, 2004).

De acuerdo con Martin y White (2005), existen tres tipos de apreciación: la reacción, la composición y la valuación. En el siguiente cuadro 3 que transcribo de la traducción de Kaplan, aparece la síntesis de la apreciación:

\begin{tabular}{|l|l|}
\hline \multicolumn{2}{|c|}{ Apreciación } \\
\hline \multicolumn{1}{|c|}{ Positiva } & \multicolumn{1}{|c|}{ Negativa } \\
\hline $\begin{array}{l}\text { Reacción Impacto: Cultivador/a, llamativo/a } \\
\text { atractivo/a, agradable, conmovedor/a } \\
\text { Reacción calidad: } \\
\text { Hermoso/a, espléndido/a, encantador/a }\end{array}$ & $\begin{array}{l}\text { Aburrido/a, tedioso/a, ascético/a, } \\
\text { pedante, soso/a } \\
\text { Feo/a, repulsivo/a, repugnante }\end{array}$ \\
$\begin{array}{l}\text { Reacción Balance: Balaceado/a, armonioso/a, } \\
\text { simétrico/a, proporcionado/a } \\
\text { Reacción Complejidad: } \\
\text { Simple, elegante, detallado/a, preciso/a, } \\
\text { proporcionado/a }\end{array}$ & $\begin{array}{l}\text { Desbalanceado/a, } \\
\text { desproporcionado/a, asimétrico/a } \\
\text { Extravagante, monolítico/a, simplista, } \\
\text { impreciso/a }\end{array}$ \\
\hline $\begin{array}{l}\text { Valuación: Profundo/a, innovador/a, original, } \\
\text { único/a, exigente }\end{array}$ & $\begin{array}{l}\text { Superficial, } \\
\text { reaccionario/a, conservador/a }\end{array}$ \\
\hline \multicolumn{1}{|c|}{ Cuadro 3 }
\end{tabular}

Cuadro 3. 
En términos generales la reacción, el primer tipo de apreciación, se refiere a la impresión causada por un proceso, un texto, un objeto, etcétera.

La composición, el segundo tipo de apreciación, está representada por la percepción del detalle y la proporción, y la valuación, el tercer tipo de apreciación, por la valoración de lo social. (2004)

La condición estética de la evaluación, constituida por la apreciación, representa una herramienta útil para evaluar a los candidatos presidenciales en los periódicos. La importancia del instrumento radicaría en poder medir la reacción de los lectores, cómo lo perciben y dentro de las reglas sociales si lo que hace es relevante o no.

\subsubsection{Compromiso}

De acuerdo con Martin y White, el compromiso es el sistema de opciones lingüísticas que ocupa el hablante para posicionarse en el texto. También, bajo la perspectiva dialógica (Bajtín) se le pone especial atención a "los significados por medio de los cuales los emisores reconocen o ignoran los diversos puntos de vista que sus enunciados ponen en juego." (Kaplan, 2004:67). Esto nos indica que la llamada audiencia o los lectores son considerados en este aspecto. Dice White: “...O por lo menos, al modo en que los textos negocian significados con audiencias concretas y potenciales". (White, 2004:19) En ese sentido, los autores consideran que el significado se construye en términos dialógicos e interactivos.

El compromiso se refiere a los significados que legitiman o no las posturas que los emisores ponen en juego en sus enunciados (2004). Esta categoría o sistema representa la naturaleza dialógica del habla (Bajtín, Voloshinov). "De este modo, la modalidad no se concibe bajo una óptica epistémica sino heteroglósica; puede no estar conectada en absoluto con la duda o la vaguedad y usarse, en cambio, para señalar que un enunciado particular puede ser discutible, que el emisor desea negociar con quienes adoptan posturas diferentes o alternativas a la suya, para mostrar diferencias 
hacia dichas personas". (2004:68). Para White este aspecto heteroglósico de la semántica del compromiso es próxima a la función del modo (Halliday) porque "considera a la posición intersubjetiva en términos sociales" (2004:68).

Desde la perspectiva dialógica adoptada por la de la Valoración, se considera que los enunciados monoglósicos, equivalentea las aseveraciones declarativas absolutas (bare assertions), ignoran la diversidad de voces que se ponen en juego en todo acto de comunicación... Lejos de considerarlos neutros y no modalizados, como formas comunicativas "por defecto", este enfoque concibe a los enunciados no dialogizados como una manera de adoptar posturas socio-semióticas de gran fuerza retórica e impersonal... (Ídem)

En los enunciados heteroglósicos, se reconocen las voces contrario a la anterior, sí reconoce las voces de otros y posturas alternativas. Hay variantes de la heteroglosia: la primera introduce voces externas y la segunda, localiza a la voz interna del autor, quien asume la responsabilidad por los enunciados emitidos. (2004).

La visión dialógica de los textos, muestra la relevancia de considerar las distintas voces que aparecen en los mismos. Este se relaciona con el grado de compromiso que asumen algunos autores sobre las opiniones o los puntos de vista, que proponen en sus enunciados, que pueden ser propios o ajenos ${ }^{15}$.

La siguiente figura muestra de manera sintética el sistema de Compromiso (2004):

Compromiso

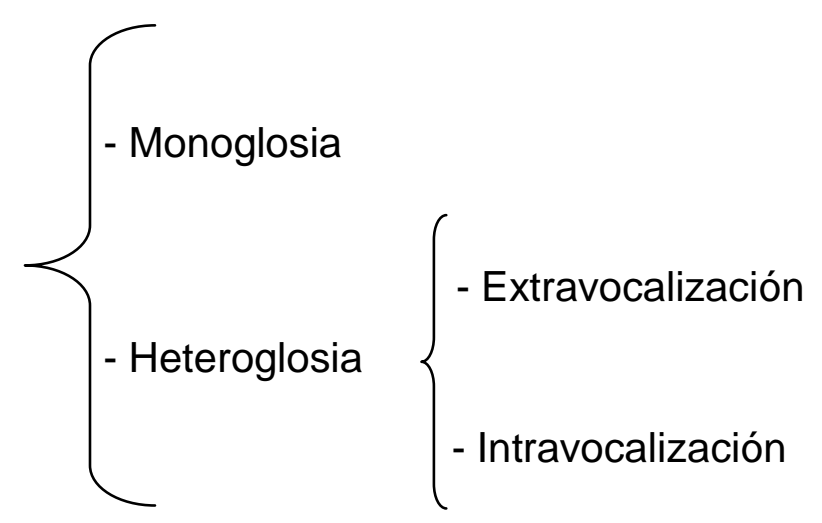

Fig. 4

${ }^{15}$ Véase en la metodología. 


\subsubsection{Gradación}

La gradación es la última categoría del sistema. Es un espacio semántico fundamental en la Teoría de la Valoración que influye en los otros sistemas. Martin y White (2005) dicen lo siguiente: "The semantics of graduation, therefore, is central to the appraisal system. It might be said that attitude and engagement are domains of graduation which differ according to the nature of the meanings being scaled". (136).

La gradación se refiere a la manera en que: “(1) los hablantes gradúan el impacto interpersonal, (aumentan o disminuyen) la fuerza o el volumen de sus emisiones, y (2) gradúan (desdibujan 0 agudizan) el foco de sus categorizaciones semánticas". (White, 2004:3).

Los intensificadores, amplificadores y enfáticos son los valores que expresan explícitamente la intensidad: "Esta semántica de escala de acuerdo con la intensidad se ejemplifica de manera más transparente con el conjunto de adverbios que han sido investigados como 'intensificadores', 'amplificadores' y 'enfáticos'. El conjunto incluye ligeramente, un poco, de alguna manera, bastante, totalmente, íntegramente, más bien, mejor, en realidad, verdaderamente, muy, extremadamente. Por medio de estos valores, el hablante aumenta o disminuye su intensidad de un amplio rango de categorías semánticas..." (Ibíd., 29).

Según, Martin y White (Ídem), la gradación opera con dos escalas: la fuerza y el foco. Los valores de la fuerza tienen la escala de baja a alta. Los valores del foco "operan para indicar que el valor representado tiene un estatus central o prototípico, o, por el contrario, un estatus marginal." (2004).

Se muestra un cuadro a manera de conclusión, en donde señalan que los valores altos y bajos pueden proporcionar valor en todos los subsistemas:

Tabla 1: Intensificación 


\begin{tabular}{|c|c|c|}
\hline & Baja intensidad & Alta intensidad \\
\hline Juicio & $\begin{array}{l}\text { Es un post-moderno } \\
\text { satisfactorio }\end{array}$ & $\begin{array}{l}\text { Es un brillante post- } \\
\text { moderno }\end{array}$ \\
\hline Afecto & $\begin{array}{l}\text { Le gustan los post- } \\
\text { modernos }\end{array}$ & $\begin{array}{l}\text { El adora a los post- } \\
\text { modernos }\end{array}$ \\
\hline Apreciación & $\begin{array}{l}\text { Un trabajo post-moderno } \\
\text { atractivo }\end{array}$ & $\begin{array}{l}\text { Un trabajo post-moderno } \\
\text { exquisito }\end{array}$ \\
\hline Extravocalización & $\begin{array}{l}\text { Ella dice que él es post- } \\
\text { moderno }\end{array}$ & $\begin{array}{l}\text { Ella insiste que él es un } \\
\text { post-moderno }\end{array}$ \\
\hline Foco & $\begin{array}{l}\text { Es un trabajo post- } \\
\text { moderno, o algo así }\end{array}$ & $\begin{array}{l}\text { Es genuinamente post- } \\
\text { moderno. }\end{array}$ \\
\hline
\end{tabular}

La teoría de la valoración, en resumen puedo decir que es un sistema conceptual que ofrece amplias posibilidades de análisis para estudiar los mecanismos del discurso en su dimensión interpersonal.

Por ejemplo, en las notas periodísticas de elecciones presidenciales, la evaluación cumple un importante en la presentación de los candidatos, de manera de favorecer que los lectores compartan la opinión del periódico. 


\section{La evaluación en los periódicos}

Capítulo III 


\section{EL INICIO DE CAMPAÑA}

\section{ANDRÉS MANUEL LÓPEZ OBRADOR}

\section{La Jornada}

\section{0 de enero de 2006}

Desde que el candidato Andrés Manuel López Obrador fue jefe de gobierno de la Ciudad de México entabló polémicos debates con el entonces presidente de la República.

La guerra de discurso se incrementó aún más, ante el destape de este jefe de gobierno como candidato presidencial; se construyó una campaña de desprestigio donde se cuestionaba la ética de su equipo de trabajo durante el periodo que gobernó la Ciudad de México.

Ésta campaña se la atribuyen a sus enemigos, los cuales se incluye al entonces presidente de la república, Vicente Fox. La batalla se desarrolló en todos los medios de comunicación. Por ello, es interesante, bajo este contexto, observar cómo se presentó y evalúo al candidato perredista.

La noticia de inicio de campaña que presenta La Jornada se conforma de veintitrés párrafos, además de los titulares.

El título de la noticia del inicio de campaña del candidato Andrés Manuel López Obrador se tituló: Progreso social y justicia indígena, ofrece AMLO. En este enunciado el periódico presenta en discurso seudo-directo las propuestas del candidato. Este tipo de discurso se caracteriza por posponer el verbo de "decir" y se separar con una coma del resto del discurso. Esto es, la voz del candidato ha sido reelabora (seudo-directo) y mostrada de tal manera que sea de impacto. 
Entonces el verbo, ofrece, cumple la función de indicadores evaluador en positivo porque aprecia las promesas que impactan, son las que más se carecen en el país.

Por otro lado, el antetítulo nos deja ver en la siguiente estructura oracional simple, la siguiente evaluación conocida como apreciación: Inicia su campaña en Metlatónoc, el municipio más pobre del país. La apreciación aparece marcada con itálicas y se ubica en el complemento circunstancial de lugar que valora negativamente el sitio en donde se dio inicio la campaña presidencial.

El periódico mostró, en el título, la promesa de campaña y en el antetítulo el escenario donde se ofreció dicha promesa. Esto indica que los dos titulares se corresponden para recrear el contexto y resaltar la importancia del discurso del candidato.

El subtítulo presenta una cita mixta: Promete acabar con la "hipocresía de los gobierno neoliberales", en éste se muestra la postura asumida por el candidato frente a la propuesta de los gobiernos actuales. Observemos:

La evaluación se ubica en el verbo performativo: prometer (sinónimo de ofrece), el cual muestra al lector un acto verbal atractivo porque propone acabar con la falsedad de los dirigentes y de paso liberarnos de los malos gobiernos. El objeto directo del verbo prometer, arriba señalado, focaliza en el sustantivo hipocresía, un juicio negativo de cómo actúan los gobernantes y no cumplen con sus obligaciones.

El periódico en los titulares, muestra, desde la apreciación, a un candidato presidencial con discursos y estrategias de campaña positivas, mientras por otro lado, resalta, a través del juicio, lo negativo del actuar de algunos políticos: PRI y PAN, en voz del candidato Andrés Manuel López Obrador. 
A continuación analizo el resumen (el lead en adelante) en la que detecté tres evaluaciones: Una elaborada por el periodista (locutor en adelante) y las otras dos efectuadas por el candidato presidencial.

1. Metlatónoc, Gro., 19 de enero. En la desolación mixteca y tlapaneca, el candidato presidencial de la Alianza Por el Bien de Todos, Andrés Manuel López Obrador, perfiló el eje de su plan de gobierno en seis puntos, y estableció: "Sí habrá economía de mercado, pero el Estado combatirá la desigualdad social; sí habrá orden macroeconómico y disciplina, aunque con crecimiento sostenido, generación de empleos y bienestar. Se acabará la hipocresía de los gobiernos neoliberales".

La primera evaluación la emite el locutor en voz narrada, describe el lugar donde se inició la campaña. Este lugar es presentado con una nominalización del adjetivo desolado (La desolación) que aparece en el complemento circunstancial que se anticipa al sujeto de la oración. Nuevamente, observamos que el locutor utiliza la apreciación para resaltar de manera negativa el lugar.

La singularidad de esta evaluación mostrada radica en que el discurso de campaña se emitió en un lugar poco poblado porque es una comunidad indígena, esa es su característica principal. Se pensaría que nadie está al tanto de la existencia de esa zona pobre, hasta que el candidato presidencial decide iniciar su campaña ahí.

Esta correspondencia de las evaluaciones tanto en el resumen como en los titulares es una guía importante para inferir que el discurso y la imagen del candidato son coherentes.

La segunda evaluación inicia al final del tercer renglón con la siguiente estructura oracional: "Sí habrá..., pero el Estado..." "sí habrá..., aunque con..." Los nexos adversativos pero y aunque (aquí cumple la función de adversativo) sirven de indicadores evaluativos, porque su función es oponer la primera parte de la oración con la segunda, diciendo que sí se puede lograr un crecimiento con economía de mercado. El tipo de valoración que se muestra es el juicio al exponer que el candidato actuará de acuerdo con la que marca la estima social. 
Lo anterior se reafirma con la siguiente y última evaluación del párrafo en discurso directo: Se acabará la hipocresía de los gobiernos neoliberales. Esto nos sugiere pensar que la estrategia neoliberal también puede incluir a los menos favorecidos. Como ya se había señalado anteriormente en el subtítulo.

Como bien observamos, aquí se evalúa de manera negativa, el comportamiento (el juicio de estima social) de los políticos al afirmar que son hipócritas.

En general, tanto las evaluaciones del candidato como del locutor presentadas en este primer párrafo recurren a la evaluación para tomar una postura positiva ante las promesas de campaña y negativa ante el gobierno.

De esta manera, como acabamos de leer, el periódico La Jornada presenta en positivo al candidato Andrés Manuel López Obrador en su primer día de candidatura.

En ese sentido, en el periódico La Jornada se reconoció la voz del candidato presidencial evaluando a otros personajes (del gobierno).

\section{INICIO DE CAMPAÑA}

\section{ANDRÉS MANUEL LÓPEZ OBRADOR}

\section{El Universal}

20 de enero de 2006

El Universal nos presenta la noticia del candidato Andrés Manuel López Obrador en 16 párrafos; siete menos que La Jornada.

Antes de comenzar es importante comentar que la noticia que a continuación se presenta tiene una importancia sustancial para el análisis, porque el texto construye 
una estructura, en su conjunto, evaluativa. Por tanto, serán contemplados los párrafos necesarios para recrear el contexto de dicha macro-evaluación.

Distante y restándole importancia al discurso del candidato, el periódico tituló en voz narrada lo siguiente: AMLO ofrece atender las exigencias de globalización.

Los elementos evaluadores del título son el verbo, ofrece, que evalúa en negativo la propuesta de gobierno del candidato y el nombre, las exigencias que evalúa a la globalización. En ella se muestra la apreciación negativa de los proyectos económicos del candidato.

Como mencioné al inicio del análisis, los titulares son de gran ayuda en la búsqueda de la evaluación de los acontecimientos y de los discursos citados.

En este caso, el periódico resume la propuesta principal del aspirante presidencial en el titular: atender las exigencias de la globalización, propuesta extraña para un candidato que siempre ha manifestado otra postura, por decirlo, en contra de la globalización. Esta formulación nos motiva a averiguar, leyendo más, por qué el candidato expresó tal ofrecimiento.

La primera respuesta la encontraremos en el contexto de la candidatura de este personaje, ¿Porqué presentar un discurso contradictorio a la imagen proyectada durante su trabajo como jefe de gobierno? En ese sentido cumple con su objetivo el periódico, llamar la atención del lector.

La otra respuesta la encontramos cuando Nieves, indígena de la región, cuestiona las promesas del candidato.

En tanto, observemos qué nos dice el subtítulo: Promete mantener una economía de mercado y disciplina para inflación. El elemento evaluativo es el verbo performativo, promete, que reporta a un candidato de izquierda proponiendo implementar una economía de mercado. De igual manera el nombre, disciplina, modifica a inflación para denotar la rigurosidad y la pureza de la economía de mercado. Nuevamente, se 
imprime la evaluación de apreciación, y el centro de la valoración es la economía de mercado incentivada por un candidato de "izquierda".

Por otro lado, en el lead se presenta a Nieves, la indígena que evalúa las promesas del candidato.

1. METLATÓNOC, Gro.- Nieves Castro, como cientos de indígenas mixtecos, escuchó a Andrés Manuel López Obrador, candidato a la Presidencia de la República de la alianza Por el Bien de Todos, comprometerse en favor de la economía de mercado, mantener el orden macroeconómico, disciplina en el manejo de la inflación y atender los fundamentos actuales que exige la globalización.

Como podemos leer en esta introducción, el locutor nos presenta a una indígena llamada Nieves Castro. Esta presentación a simple vista no tiene relevancia, pero ¿por qué presentar a este personaje en oposición a las propuestas? Nieves escucha a un candidato que se pronuncia en favor de la economía de mercado. ¿Qué significado tendría para ella, escuchar este discurso? ¿Cuándo esta política económica no ha respondido a las necesidades de los pueblos originarios?

Después de la presentación de Nieves, el verbo que introduce el discurso del candidato: comprometerse a favor, es un elemento que lo evalúa: El candidato se compromete a favor de una economía de mercado. El periódico contrasta la postura del candidato frente a la realidad y expectativas de los pueblos, donde la economía de mercado no ha dado respuesta a las demandas más básicas, como ya mencionaba. Por tanto, el periódico en realidad está presentando a un candidato en contradicción con intereses de aquellos a quienes dice defender y lo escuchan. El locutor recurrió a la evaluación de juicio de estima social para señalar el comportamiento contradictorio del candidato.

A continuación muestro el segundo párrafo:

2. Estas son las tesis de lo que será su gobierno en cuanto al combate a la pobreza, dijo el tabasqueño aquí, el municipio que gobierna el PRD desde hace nueve años, emblema de la pobreza en el país, 
según indicadores nacionales e internacionales que lo comparan con las naciones africanas más pobres y cuyos índices de analfabetismo rondan el $71 \%$.

En este párrafo, la evaluación aparece en la narración del locutor, quien nos dice que este municipio es emblema de la pobreza, comparada con las naciones africanas. En ésta misma hay dos evaluaciones marcadas por los siguientes elementos evaluativos: emblema de la pobreza y según indicadores. Estas frases califican, el primero, al perredismo y el segundo a la ubicación geográfica donde se dio inicio a la campaña del candidato. También hay una evaluación implícita al momento de mencionar que el Partido de la Revolución Democrática (PRD) gobierna desde hace tiempo este municipio: ¿es el PRD responsable de mantener esa pobreza? En este caso, también, el locutor recurre a la evaluación de juicio de estima social.

Ahora observemos el párrafo tres:

3. "Quiero que se escuche bien y se oiga lejos: sí habrá economía de mercado, pero el Estado y el gobierno promoverán con decisión el desarrollo social para combatir la desigualdad", exclamó.

En este párrafo el locutor nos muestra en discurso directo la voz del candidato, con la misma estructura observada en el periódico La Jornada. La evaluación se denota por la frase Quiero que se escuche bien y se oiga lejos y la adversativa pero. La primera es una frase evaluada por el discurso directo porque parece una provocación a aquellos que escuchan al candidato.

En la segunda, la adversativa, evalúa las condiciones para que estas políticas funcionen: mediante el desarrollo social; un enunciado paradójico. Por tanto, concluyo que las dos valoraciones son negativas, de apreciación y una gradación fuerte.

Más adelante, el locutor nos vuelve a traer al escenario a Nieves:

6. Nieves escuchó al candidato ofrecer restañar las viejas heridas porque es hora de hacer justicia a los pueblos indígenas, de no hacer a un lado a los pobres, a los más abandonados y olvidados, para quienes 
se aplicará un programa nacional para el desarrollo social contando con su opinión.

El locutor escenifica este discurso, instalando a dos personajes centrales: Nieves, mujer indígena de la zona, quien escucha el ofrecimiento, y el candidato, autor de ese ofrecimiento y quien es escuchado atentamente. A simple vista esta relación no tiene trascendencia; no obstante, el periódico recurre a esta presentación por una intención, observemos en el párrafo nueve:

9. Sin sorpresa por ser parte de su cotidiana realidad, Nieves, de 34 años y madre de seis hijos con edades desde los dos a los 14 años, siguió el discurso de López Obrador que, con base en un informe que le dieron sobre la región, enlistó los problemas de pobreza, marginación y abandono.

El locutor presenta de manera formal a Nieves, a quien según no le sorprendió el discurso del candidato, porque todo lo dicho forma parte de su cotidianidad, ofrecer "no empobrece", esta muestra una evaluación de juicio de estima social, es negativa. El elemento evaluativo es la frase clave: Sin sorpresa por ser parte de su cotidiana realidad. Nieves siguió escuchando las palabras del aspirante. El periódico nos indica que la información expresada no aporta nada extraordinario y los indígenas son escépticos a las promesas. Otro elemento evaluado importante es la frase "con base...región", que nos presenta un candidato ajeno a estos problemas, que conoce sólo por informes, las carencias de la zona. Estas dos evaluaciones no son positivas.

Con estos dos párrafos culmina la aparición de Nieves y de la evaluación del discurso del candidato:

10. En su gobierno, prometió López Obrador, la política social no será relegada, va a respetar a todos y a escuchar a todos, "pero la preferencia la van a tener los pobres".

11. "A ver si cumple. Yo ya no les creo porque siempre nomás vienen a prometer", dijo al final del discurso de López Obrador, quien estuvo acompañado de legisladores y de los líderes nacionales del PRD y Convergencia, Leonel Cota Montaño y Dante Delgado; ausentes los dirigentes del tercer aliado, el Partido del Trabajo, José Narro y Alberto Anaya. 
El párrafo diez de la nota presenta una cita mixta, en donde se exponen las promesas del candidato; además la enunciación comienza diciendo En su gobierno.... Es importante puntualizar aquí la función del verbo: prometer, pide un acto de fe a los escuchas, quienes estarán o no dispuestos a creer en sus palabras.

En la cita del siguiente párrafo, emerge una voz en discurso directo, la cual con el verbo pospuesto, dijo, se vierte un punto de vista, que el periódico no específico directamente quién la realizó. Aunque la única con autoridad para evaluar al candidato sería Nieves.

Nieves evalúa el discurso completo del candidato, utiliza el juicio para ponerlo en duda.

La significación de la nota se dirige a materializar una macro evaluación que sitúa a un personaje de la audiencia, a una mujer pobre indígena poniendo en duda las propuestas del candidato. Observamos que la nota de El Universal aunque menos extensa, resulta más compleja que el de La Jornada. La evaluación de Nieves enmarca la presentación del candidato presidencial, y porta la intención del periódico, valorar al candidato a través de una autoridad que sí sabe de pobreza.

Las evaluaciones emitidas por los dos periódicos son de grandes contrastes. Mientras La Jornada exalta al personaje político comprometido con los pobres y la justifica social; El Universal presenta a un candidato con discurso contradictorio y de poca credibilidad. Esto es, presenta a un candidato en negativo.

Finalmente intenta, el periódico El Universal, decirnos que todos los políticos que han llegado a esa comunidad independientemente de su corriente política representan los intereses del capital y no de los ciudadanos. 


\section{INICIO DE CAMPAÑA \\ FELIPE CALDERÓN HINOJOSA}

\section{La Jornada}

\section{0 de enero de 2006}

La noticia del diario comienza y termina relatando los disturbios y problemas que enfrentó el candidato Felipe Calderón en su primer día de campaña. El periódico dedicó a este personaje dos discursos directos, dos voces narradas y cuatro mixtos. La noticia se conformó de 26 párrafos y se dividió en tres partes.

La primera muestra, de manera general, las dificultades que sorteó el aspirante presidencial para presentarse en los tres sitios contemplados en su agenda de trabajo; la segunda aborda el "desangelado" encuentro que sostuvo con los habitantes de la delegación Iztapalapa (gobernada por uno de los partidos opositores) y la tercera nos relata el mitin en el Toreo de Cuatro Caminos.

La noticia se tituló: De pesadilla, el inicio de campaña de Calderón.

Esta frase aprecia el desafortunado inicio de campaña, un comienzo negativo.

En ese sentido, el antetítulo refuerza e intenta contextualizar porqué fue de pesadilla: Falta interés en Iztapalapa y división panista en El Toreo. La frase conforma dos evaluaciones. Por un lado, valora de manera negativa el comportamiento de los habitantes de la delegación Iztapalapa (ésta se caracteriza por su militancia perredista, el partido opositor). Por tanto, el lugar no fue indicado.

También el periódico señala veladamente la actitud desafiante del personaje, al programar una visita en tierras perredistas. 
También, en el antetítulo se comenta qué pasó en el Toreo de Cuatro caminos; sitio que representa, para los panistas, un símbolo de victoria porque alguna vez el candidato Cluthier cerró rodeado de un número importante de militantes y con mucho éxito. Sin embargo, las fracciones del Partido Acción Nacional (PAN) no llegaron a consensar como sería la presentación del candidato, puesto que no resulto lo que esperaban. En ese sentido, se valora el comportamiento de los miembros del partido de Acción Nacional en negativo.

Aunado a lo anterior, se desprende en el subtítulo: El repudio al líder de AN en el Edomex opacó su discurso. En este enunciado el periódico La jornada indica que la actitud de los ciudadanos del Estado de México no permitió que el discurso del candidato brillara, dejando entre ver que éste estratégicamente se equivocó y optó más por el desafío que por presentar sus propuestas. Además no hay que olvidar que el Estado de México milita por el Partido Revolucionario Institucional (PRI), por lo tanto quiénes asistieron a este recinto.

En el lead se muestra lo siguiente:

1. Desde el primer día de su campaña presidencial, Felipe Calderón intentó desafiar al perredismo en Iztapalapa, pero apenas reunió a un escaso auditorio, y en el estado de México se encontró con una militancia dividida que prodigó rechiflas e insultos al dirigente estatal y comenzó a abandonar El Toreo en plena intervención del abanderado blanquiazul.

En este párrafo, el locutor deja ver dos evaluaciones, señalada arriba con itálicas.

En la primera, nos habla del carácter de desafío del aspirante presidencial en una zona gobernada por el partido oponente, en voz narrada. Esta evaluación negativa corresponde al denominado juicio de estima social porque define a un aspirante provocador. 
La segunda evaluación, presentada en voz narrada, el locutor exhibe de manera negativa el comportamiento de la militancia que recibió al candidato; ésta se construye desde el juicio de estima social.

La evaluación se ubica en el objeto directo del verbo, se encontró; con qué se encontró el candidato: con las rechiflas y los insultos.

Podemos señalar que el periódico se centrará más en las provocaciones y acontecimientos de los hechos que en las propuestas del candidato.

Por tanto puedo señalar que la presentación del candidato presidencial Felipe Calderón Hinojosa en el periódico La Jornada presenta evaluaciones negativas, principalmente desde el juicio.

\section{El Universal}

\section{0 de enero de 2006}

El periódico El Universal muestra, en el inicio de campaña del aspirante presidencial, 19 párrafos, de los cuales sólo dos se lo dedica al discurso del aspirante y los demás se ofrecen a la narración de los acontecimientos.

El toreo otra vez se cimbró, este es el enunciado del título de la notica.

La evaluación se centra en la emoción manifestada por los militantes en este primer día de actividades proselitistas; también se resalta con la frase otra vez, al pasado para comparar este momento con otro en donde se sintió la misma emoción (con el candidato Clouthier). En el título se recurre a la valoración de afecto para resaltar el fervor de la militan por ese partido, emoción positiva. 
El periódico evalúa, entonces, mediante el entusiasmo de los militantes, un agradable inicio de campaña.

Esta noticia no cuenta con subtítulo y antetítulo. Así que pasaré al resumen.

En el lead nos muestra lo siguiente:

1. El Toreo, el recinto que se identifica con el Partido Acción Nacional, desde que Manuel J. Clouthier lo colmó en mayo de 1988 con miles de simpatizantes, anoche casi se llenó con una nueva generación panista, la mayoría, gente de colonias populares, que a gritos de "¡leeeerooo!" y rechiflas para el líder estatal del blanquiazul, marcó el inicio de la campaña presidencial de Felipe Calderón.

El resumen nos resalta dos elementos importantes dignos de evaluarse; por un lado, se menciona la nueva generación de simpatizantes del partido Acción Nacional reunidos en el Toreo, la nueva corriente de seguidores: gente de colonias populares; y esto justifica las rechiflas y groserías que recibió el candidato. También, apela al llamado de una nueva era del partido. En otras épocas al PAN se le conocía como un partido de empresarios y algunos sectores de la clase media, ahora, tal parece, se agregaron nuevos grupos a la militancia. Estos ciudadanos tienen una característica negativa, fueron groseros, su comportamiento no fue el adecuado.

Así en los subsiguientes párrafos (hasta el párrafo 7), las evaluaciones del locutor giraron en torno a este carácter popular de la corriente panista y su supuesto apoyo al candidato presidencial.

También, a lo largo de la nota, se comparó esta efervescencia observada con la ocurrida el 14 de mayo de 1988 cuando Clohutier fue candidato presidencial. Por ello, es importante puntualizar hacia dónde se dirigió la evaluación, no a las propuestas, sino al comportamiento. Por ello podemos concluir que la noticia en lo general evalúo, el comportamiento de la militancia pasada, en positivo y la nueva de manera negativa. 


\section{INICIO DE CAMPAÑA}

\section{ROBERTO MADRAZO PINTADO}

\section{La Jornada}

\section{0 de enero de 2006}

La Jornada presenta la nota de inicio de campaña del candidato Roberto Madrazo con quince discurso citados: 2 discursos directos, tres indirectos, cinco voces narradas y cinco citas mixtas dentro del cuerpo de la noticia. La nota se estructuró en veinticinco párrafos.

El título de esta noticia es el siguiente: Desaíran gobernadores y acarreados a Madrazo. En este enunciado se evalúa la actitud de los actores participantes en el mitin. Los colegas y amigos del candidato no respondieron a la invitación y los militantes no lo son tanto porque les dice "acarreados". En ese contexto es bien conocido por todos los mexicanos que el PRI se caracteriza por concentrar en sus mítines a acarreados y no militantes. El locutor recurre al juicio para evaluar el comportamiento de los gobernadores y de los acarreados.

Previamente, el antetítulo: Llama a contendientes a alejarse de la confrontación; advierte que el candidato no quiere confrontación como antiguamente los priistas concebían sus campañas presidenciales. Efectivamente, en la oración aparece el verbo en presente llama que alude a una petición y el verbo pronominal alejarse, representa de qué petición se trata, el cual nos invita a inferir que el candidato solicita una tregua en la guerra de acusaciones. Aquí, el candidato, evalúa de manera indirecta el comportamiento de sus contendientes.

El subtítulo muestra en esta oración a los numerales y al verbo como elementos de evaluación porque denotan, a través de ellos, la poca convocatoria que tiene el candidato: En Ecatepec, 15 mil personas; el PRI esperaba 54 mil. La evaluación utilizada por el locutor es la apreciación (reacción de balance). 
Veamos el primer párrafo lead:

1. La campaña de Roberto Madrazo Pintado difícilmente pudo arrancar en un escenario menos favorable. En Ecatepec, donde se dispusieron más de 42 mil sillas y 12 mil espacios en tribunas, el candidato presidencial del PRI logró reunir apenas a poco más de 15 mil personas, quienes lo esperaron más de cuatro horas para escuchar un discurso que el tabasqueño tuvo que cortar no bien habían pasado 10 minutos, porque los acarreados, aquellos que por decenas de miles llenaron ese mismo escenario para el hoy gobernador mexiquense, Enrique Peña Nieto, como ríos humanos buscaron la salida y abandonaron al tabasqueño.

En el párrafo, el locutor nos relata el escenario del inicio de campaña del candidato priista, y deja ver su punto de vista; sitúa en el adverbio (difícilmente) la evaluación que aprecia en negativo la acción pudo arrancar. Posteriormente, le continúa el adverbio menos que alude al lugar donde empezó su campaña proselitista: iniciar en un lugar menos favorable. Esta narración nos muestra lo difícil del primer día para el candidato. El locutor en este caso, utiliza la apreciación de calidad de baja intensidad.

Después, en la siguiente oración se valora en negativo, indirectamente, la impuntualidad del candidato.

Posteriormente, señala a través de los números y los estimados, la cantidad de personas esperadas: los acarreados, así como los ausentes y los que decidieron huir del lugar. Por consecuencia se valoró la rapidez de su discurso emitido (sólo diez minutos) comparado con la espera del público (cuatro horas) que fastidiado abandonó el lugar. En esta evaluación se recurrió a la apreciación de reacción de balance.

La siguiente valoración representativa, la ubicamos en el tercer párrafo del cuerpo de la noticia. En este se relata un dato curioso, el candidato priista organizó un homenaje al fallecido ex candidato presidencial, de su mismo partido, Luis Donaldo Colosio. Este candidato murió asesinado durante su campaña presidencial en 1994, en su momento se convirtió en un héroe. No 
es fortuito pensar que el evento se debe a una estrategia política para atraer militantes, además no debemos olvidar la "impopularidad" de Madrazo. Aunque la apuesta no le funcionó porque muy pocos compañeros de su partido acudieron al evento y las personas que pudieron haber legitimado el homenaje, tampoco lo hicieron:

3. Con la ausencia de Luis Colosio Fernández y Luis Donaldo Colosio Riojas, padre e hijo del malogrado sonorense, Madrazo se comprometió a realizar una campaña sin confrontaciones estériles, a conducirse con civilidad, madurez y privilegiar propuestas deseables y alcanzables.

El presente párrafo dejar ver, primero, el circunstancial de modo: Con la ausencia de Luis Colosio... En él se sitúa la evaluación que le resta importancia al evento organizado. Por tanto, el tipo de valoración efectuada fue de juicio porque el comportamiento del candidato en este evento es lo evaluado.

En general, el periódico La Jornada, evalúa de manera negativa el comportamiento del candidato, de los gobernadores y acarreados.

\section{Periódico: El Universal}

20 de enero de 2006

El periódico El Universal presentó nueve párrafos del inicio de campaña de Roberto Madrazo, asimismo presenta solo una cita mixta de la voz del candidato.

Por consiguiente, la nota del periódico está centrada en la narración de los acontecimientos más que en las propuestas de campaña.

El corporativismo administró hasta la alegría priista, es el título que le dio el periódico a este inicio de campaña. La oración simple valora mediante el verbo y la 
preposición, administró hasta, el entusiasmo de los militantes; mientras que el sustantivo, el corporativismo, a la acción verbal. También se utiliza la valoración de juicio de sanción social (integridad moral) en negativo.

1. ECATEPEC, Méx.- Cuando Roberto Madrazo comenzó a abrirse paso para llegar al templete donde ayer inició su campaña política por la Presidencia de la República, el grupo Mandarina Show estaba interpretando, accidental o azarosamente, una canción de Consuelito Velázquez:

"Si te vienen a contar

cositas malas de mí,

manda a todos a volar

y diles que yo no fui."

Los adverbios señalados, accidental o azarosamente, denotan una clara evaluación que recae en las normas sociales.

El locutor invita a reflexionar, desde la ironía, el significado de la canción esos dos contextos. Convenientemente, en el momento del arribo del candidato:

2. La voz del animador se alzaba entre la música, y entre las consignas lanzadas por una multitud que no alcanzó a llenar el Deportivo Tecnológico de Ecatepec, para anunciar "a toda la gente bonita que hoy nos acompaña", que el candidato de la Alianza por México (PRI-PVEM) "ya se encuentra saludando a todos nosotros".

Por otro lado, notamos, además, otra evaluación del locutor al referirse a la multitud que no alcanzó a llenar el deportivo.

3. Una pantalla gigante reveló entonces la imagen del candidato bajo una lluvia de confeti tricolor. Mientras Madrazo avanzaba -en esa sincronía extraña que desde La culebra en Lomas Taurinas tienen a veces los candidatos del PRI con la música-, Mandarina Show seguía cantando:

"Yo te aseguro que yo no fui, son puros cuentos que hay por ahí, tú me tienes que creer a mí..." 
La frase en cursivas retoma la evaluación iniciada en el primer párrafo: la empatía que tienen los priistas con la música popular. Aquí el locutor insinúa, en voz de otro, una evaluación negativa e irónica porque la canción que señalan (La culebra) estuvo de fondo cuando le dispararon al candidato Colosio.

Finalmente, podemos agregar que el periódico El Universal, presentó al candidato de manera negativa.

Ese fue el escenario del primer día de actividades de los candidatos presidenciales.

Ahora retomaré los titulares y el lead de los días 21, 22 y 23 de enero de los tres candidatos como inicio de campaña.

\section{Periódico: La Jornada}

\section{1 de enero de 2006}

\section{Candidato: Andrés Manuel López Obrador}

La notica se estructuró con veintidós párrafos, los cuales muestran ocho discursos directos, nueve voces narradas y siete citas mixtas del candidato. Esto indica que el discurso del mismo y sus acciones se equilibraron en la narración de la noticia.

El título, en cita mixta, es: Promete AMLO resolver 50 casos de "presos políticos".

Como bien se muestra, el periódico antepone al verbo para realzar la acción del candidato que consiste en resolver una problemática que nadie se ha atrevido, asimismo observamos, característica de la cita mixta, entrecomillas 
la frase presos políticos. También al mostrar las comillas se deslinda de la frase por su alto costo político. El título muestra una evaluación implícita; el enunciado en general nos menciona una propuesta honesta y por tanto positiva. La apreciación es el recurso utilizado.

Define ejes económicos durante su gira por Guerrero. En el antetítulo se distingue una oración en donde aparece, en primer lugar, la acción verbal en presente simple; posteriormente, el predicado contiene objeto directo y complemento. En este titular no detecté evaluación, simplemente representa el escenario de la evaluación que viene a continuación.

En el subtítulo aparece ya la oferta económica: Ofrece crear comisión de la verdad sobre el Fobaproa.

La propuesta del candidato se presenta en voz narrada, teniendo la siguiente estructura oracional; el verbo ofrece, inicia la oración; el sujeto es tácito y su objeto directo tiene una oración subordinada que comienza con el verbo en infinitivo crear. La evaluación se ubica en la presentación que hace el periódico en voz narrada de la oferta económica porque con esta cita la voz del candidato es poco prominente, esto indica, que el periódico quitó importancia a la oferta del candidato.

En el lead muestra lo siguiente:

1. Cuernavaca, Mor., 20 de enero. El candidato de la alianza Por el Bien de Todos (PRD, PT y Convergencia), Andrés Manuel López Obrador, definió los ejes para el financiamiento de su plan de gobierno: renegociación de la deuda pública; comisión de la verdad para el Fobaproa; combate a la corrupción, que ponga fin a privilegios, y gobierno austero para lograr un ahorro de 100 mil millones de pesos anuales.

El discurso del candidato muestra diversos elementos con función evaluativa. La primera instancia a evaluar es la renegociación de la deuda pública, el verbo denota que los ajustes pactados para la deuda no han resultado beneficiosos y que para ello se requiere hacer una comisión de la 
verdad para el Fobaproa. En estos renglones el locutor utiliza el recurso del juicio implícito de la integridad moral de los banqueros, empresarios, etcétera.

Más adelante y en correspondencia con la primera propuesta emitida, el candidato nos habla de atacar la corrupción, esto indica que el verbo combate está valorando a que hay corrupción y privilegios. Todo gira en torno de la renegociación de la deuda para financiar su propuesta económica. También en esta valoración se recurre al juicio implícito de la integridad moral de los deudores y acreedores.

En este segundo día el locutor evalúa las propuestas del candidato, desde el punto de vista ético, en positivo. Por otro lado, el candidato evalúa en negativo e indirectamente a los políticos que están en el poder.

\section{Periódico: El Universal}

\section{1 de enero de 2006}

La noticia del segundo día de campaña presentada en el periódico El Universal está constituida por nueve párrafos, también consta de un discurso directo, cuatro discursos indirectos, cuatro voces narradas y dos mixtos, haciendo un total de once discursos referidos acerca del candidato dentro del cuerpo de la noticia.

La noticia se titula: AMLO afirma 30 promesas a Morelos. Como bien leemos, aparece el sujeto con el nombre abreviado del candidato ( $A M L O)$, el verbo y su objeto directo. El verbo hace notar la seguridad del candidato justamente para evaluar su actitud, aunada a la función evaluativa del verbo, el recurso que utiliza el locutor es la fuerza y su representante es el verbo.

Po otro lado, el subtítulo dice: Enuncia cinco acciones para cumplir los compromisos adquiridos. El discurso de este titular se muestra en voz narrada, iniciando con el verbo y seguido de su predicado; mientras que el sujeto es tácito. El acto verbal en el subtítulo no es tan fuerte como en el título, es débil porque la voz narrada es la voz del candidato menos prominente. 
El lead retoma la información del subtítulo y la amplía. El locutor presenta el discurso del candidato mediante la voz narrada y lo introducen con el verbo en pretérito enunció; conjuntamente con el adverbio aquí. Esta combinación proporciona la evaluación del lugar y el contexto en donde fue mencionada sus acciones y le ofrece mucha fuerza al enunciado:

1. CUERNAVACA, Mor.- Andrés Manuel López Obrador, candidato de la alianza Por el Bien de Todos a la Presidencia de la República, enunció aquí cinco acciones que, según dijo, le permitirán cumplir sus promesas de campaña, y se dio tiempo para amarrar la alianza con Convergencia rumbo a la elección de gobernador de esta entidad, concurrente con la presidencial del próximo 2 de julio.

Posteriormente, a la presentación del candidato, aparece la preposición con el verbo de decir a manera de acotación, según dijo, interrumpiendo la voz del candidato. Dentro de esta frase observamos la valoración del locutor hacia las propuestas del candidato, las cuales pone en duda. Esta valoración corresponde a la de compromiso de atribución.

Básicamente las evaluaciones giran en torno a las promesas hechas por el aspirante presidencial, el contexto y la duda de que sean realizables.

\section{Periódico: La Jornada}

\section{1 de enero de 2006}

\section{Candidato: Felipe Calderón Hinojosa}

La presente nota periodística contiene cuatro discursos directos, siete discursos indirectos, cuatro voces narradas y un discurso mixto. Siendo el discurso indirecto el más requerido para mostrar las acciones y el discurso del aspirante presidencial. 
Comenzaré por analizar el título, el cual dice lo siguiente: Felipe Calderón critica ante queretanos problemas del DF. En el enunciado podemos leer el sujeto (que es el nombre del candidato), seguido del verbo en presente: critica, el complemento en donde se realiza tal acto y el objeto directo que está pospuesto. Es importante señalar que el complemento circunstancial denota la valoración del acto verbal; por ello se anticipa al objeto directo. El locutor utiliza la estrategia evaluativa llamada juicio porque nos comenta de manera implícita que el candidato no debió quejarse, sino exponer sus propuestas.

Por otro lado, el antetítulo dice lo siguiente: Aludió a panteras, policías de la GAM e inseguridad. En esta frase, el periódico, nos menciona cuáles son las problemáticas que el aspirante presidencial pronunció en el estado de Querétaro y no debió hacerlo. Presentado en voz narrada, el discurso que se abre con el verbo en pretérito aludió, seguido de los nombres, en este caso, el acto verbal evalúa el comportamiento del candidato.

Además, el subtítulo revela: En maratónica gira por tierras blanquiazules se reunió con transportistas y correligionarios, y encabezó mítines. Esta voz narrada abre con un complemento circunstancial, seguido del verbo pronominal y cierra con otro complemento. En el primer complemento yace el adjetivo maratónico, el cual evalúa negativamente la gira del candidato.

En las presentes líneas la voz del candidato es presentada en voz narrada, en ella se sintetizan sus preocupaciones y también elementos relevantes que constituyen el cuerpo de la cita referida: la conjunción ni. Esta conjunción aparece dos veces en la oración reiterando y negando dos aspectos significativos que bien podrían afectar la campaña del candidato presidencial:

1. Querétaro, Qro., 20 de enero. Ni los escándalos de los hijos de Marta Sahagún afectarán la campaña panista ni Andrés Manuel López Obrador es el enemigo a vencer; es el abstencionismo, declaró el candidato presidencial blanquiazul, Felipe Calderón.

La reiteración de la conjunción (ni) y su contenido de negación crean la imagen de un candidato combativo ante todos los obstáculos que deberá sortear. Al mismo, tiempo el locutor expone cómo el candidato compara 
hechos de corrupción junto con otros de diferente naturaleza. Desde esa perspectiva el locutor aprecia el discurso del candidato.

La información mostrada en los titulares dista mucho de la presentada en el lead.

Básicamente las evaluaciones giran en torno a las promesas hechas por el aspirante presidencial, el contexto y la duda de que sean realizables.

\section{Periódico: El Universal}

\section{1 de enero de 2006}

\section{Candidato: Felipe Calderón Hinojosa}

La noticia consta de veintiún párrafos que contienen un discurso indirecto, dos voces narradas y cuatro citas mixtas. Haciendo un total de seis citas referidas al aspirante presidencial.

El título de la noticia alude a una solicitud propuesta por el candidato: Calderón pide dejar atrás las divisiones.

En esta enunciado el periódico nos muestra en voz narrada el discurso promulgado por el candidato presidencial. En éste aparecen dos verbos uno principal pide y el otro subordinado dejar. El primero señala una solicitud a alguien; el segundo alude al acto solicitado. Se puede inferir que va dirigido a su partido. El candidato efectúa la evaluación y critica el comportamiento (juicio: estima social) de su partido.

Por otro lado, el subtítulo del periódico hace mención a los actos del candidato: Escucha los reclamos de taxistas y de camioneros en Querétaro. Demanda a sus adversarios propuestas serias. Como bien leemos, el subtítulo muestra dos oraciones. La primera narra el acto de escuchar el reclamo de los seguidores; en ese sentido el nombre (los reclamos) evalúa a taxistas y camioneros, aquí se utiliza el recurso de la apreciación. Mientras en la segunda 
enunciación el periódico en voz narrada nos cuenta cómo el aspirante solicita propuestas serias de sus adversarios. En esta segunda oración el candidato evalúa las propuestas de los otros, diciendo que no son sensatas, para ello utiliza la apreciación.

En el lead, el locutor nos presenta el discurso del candidato en cita mixta (vn y dd) e introduce su voz con un verbo prepositivo: convocó a dejar atrás:

1. QUERÉTARO, Qro.- El candidato presidencial del PAN, Felipe Calderón, convocó a dejar atrás "las divisiones y los enconos, a que dejemos atrás las envidias y los rencores, a que en esta campaña le demos la espalda a quienes llaman a odio, violencia o rencor, entre gente del campo y la ciudad, a rencor entre ricos y pobres, a rencor entre mexicanos de un credo u otro".

El locutor aprecia un aspirante conciliador.

Por otro lado, dentro de la cita referida el enunciador tiene la misión de calmar la inquietud de los queretanos al solicitar no crear rencores a pesar de que él expone que existe diferencia entre los ricos y pobres, gente del campo y la ciudad, etcétera. Asimismo, directamente alude con el pronombre relativo a quienes, a los contrincantes que promueven a tal división, principalmente la evaluación va dirigida al candidato Andrés Manuel López Obrador. Cuando habla en el título no a las divisiones eso indica que llama a los pobres no hacer caso a los discursos del candidato perredista.

El periódico en los titulares y el lead muestran a un candidato conciliador.

\section{Periódico: La Jornada}

21 de enero de 2006

\section{Candidato: Roberto Madrazo Pintado}


La presente noticia consta de siete discursos directos, dos discursos indirectos, una voz narrada y ocho citas mixtas. Asimismo, está constituida por diecinueve párrafos.

La nota se tituló: Buscará Madrazo a quienes ya han votado por PRIPVEM.

El título está construido en voz narrada. El locutor evalúa de manera negativa a través de esta oración simple, el discurso del candidato. La apreciación es la herramienta de evaluación, la cual en este caso, se utilizó para resaltar el sin sentido de la enunciación porque sabemos que la infraestructura existente no alcanzaría para buscar a quienes hayan votado por el PRI y PVE, las elecciones pasadas.

Asimismo, el antetítulo nos expone que el candidato presidencial: Presume que tiene los datos de 14 millones de electores. Como bien se observa el título y el antetítulo se corresponden, la información del segundo valora la del primero.

El elemento que los evalúa es el verbo, presume. Esto es el elemento que indica que el personaje político enaltece su trabajo de investigación poco confiable. De la misma manera, el locutor, se apoya de la apreciación para evaluarlo.

Por otro lado, el locutor dicta, en dos renglones el siguiente subtítulo: Los últimos meses de 2005, noche eterna para mí, por el Tucom y Gordillo, confía. En este renglón el periódico nos muestra en discurso seudo-directo la preocupación de este personaje; asimismo deja entrever que su partido está dividido.

El verbo performativo confía se pospone y el objeto directo se antepone. Podemos decir que en este enunciado se perciben dos evaluaciones; la del candidato presidencial que está acotada por las comas; ésta expresa el sentimiento que le ocasionó la reacción de Elba Esther Gordillo, de tal manera que entrecorta la narración. Por otro lado, la valoración del locutor está 
localizada en el verbo, confía, el cual valora la confesión del candidato para causar un efecto negativo porque indirectamente se resalta el conflicto del partido.

El segundo renglón del subtítulo nos muestra: "El tricolor, uno a partir de hoy". El decir del candidato tiene gran relevancia para el periódico porque se muestra un discurso directo. Aquí remarca la división de su partido, con una declaración en presente. De igual forma recurre al efecto negativo.

El primer párrafo de la noticia el locutor presenta la voz del candidato en discurso directo:

1. Saltillo, Coah., 20 de enero. Noviembre y diciembre "fueron los meses más largos de mi vida política; parecían una noche eterna, por los terribles problemas que enfrentó el partido", confió ayer, en privado, el candidato de la alianza PRI-PVEM, Roberto Madrazo Pintado, a un grupo de propietarios de medios de comunicación, con quienes se reunió por la mañana en el comienzo de su gira proselitista por esta entidad. "En ese momento el partido tocó fondo", les expresó.

La evaluación de tal acontecimiento por parte del locutor se centra en el pretérito perfecto del verbo confió, el significado en contexto de éste devela un elemento que evalúa la actitud del candidato.

En el discurso citado encontramos, al igual que en el subtítulo, otra acotación que bien funciona como oración evaluativa: parecía una noche eterna. El candidato muestra el verbo en copretérito, parecía, y sujeto tácito con su objeto directo. En general la oración es el elemento que evalúa los meses más largos de la vida política del candidato, además de comparar una situación con otra. La valoración se plantea desde el afecto en negativo.

Posteriormente, el locutor también resalta otra oración elaborada por el candidato: "En ese momento el partido tocó fondo", les expresó. Se demuestra en estas últimas líneas del primer párrafo cómo el candidato reconoce el problema que enfrentó su partido en esos años. En este apartado el candidato hace una autoevaluación que le hace ubicarse en el subsistema de actitud, en específico el de apreciación. 
En términos generales, el tema de la evaluación del locutor fue el sentimiento de desventaja que sintió el candidato. Por tanto, podemos decir que es una evaluación negativa.

\section{Periódico: El Universal}

\section{1 de enero de 2006}

\section{Candidato: Roberto Madrazo Pintado}

La nota periodística de este primer día de actividades se construyó con veintiún párrafos y por las siguientes citas referidas del candidato: tres discursos directos, ocho discursos indirectos, seis voces narradas y tres discursos mixtos en el cuerpo de la noticia.

El título manifestó en voz narrada lo siguiente: Madrazo ofrece abrir Pemex a la IP.

El locutor con la abreviatura IP intenta crear polémica porque a primera vista pareciera que Madrazo intenta privatizar Pemex, sin embargo, IP significa para el candidato Inversión Pública, así se explica en el subtítulo y en el lead.

Si algunos lectores se quedan con la lectura del titular y no están de acuerdo con la privatización, se quedarían con esa impresión. También puede ocurrir que éste les llame la atención y lean toda la nota para enterarse.

El subtitular enuncia los ejes de su propuesta: Destaca que inversión pública, infraestructura productiva y mejor educación serán el eje de su política social. En este apartado mediante la frase inversión pública puede esclarecer el sentido de la abreviatura, sin embargo, el periódico en este espacio no lo aclara. Por tanto, es ambiguo el título.

En el siguiente párrafo el locutor presenta al candidato con discurso seudodirecto: 
1. SALTILLO Coah.- Más inversión pública, infraestructura productiva y la educación como eje de la buena política social de la gente comprometió el candidato presidencial de la Alianza por México, Roberto Madrazo Pintado, en un acto celebrado en el centro de convenciones.

Las mismas propuestas ya habían sido expuestas en el subtítulo. Sólo que en el lead se utiliza el discurso seudo-directo para presentarlas. Asimismo, el verbo en copretérito: comprometió; lo convierte en un verbo con alta responsabilidad.

La nota en términos globales, contiene pocas evaluación negativa y las que muestran no son enérgica, prácticamente podemos decir que el locutor fue muy sutil o más imparcial.

\section{Periódico: La Jornada}

\section{2 de enero de 2006}

\section{Candidato: Andrés Manuel López Obrador}

El periódico La Jornada presentó la nota con catorce citas, de las cuales cinco corresponden a los discursos directos, uno al discurso indirecto, seis a voz narrada y dos a citas mixtas. En total la narración de los hechos se estructuró en veinticuatro párrafos.

El titular de la nota muestra en voz narrada la propuesta del aspirante presidencial, y esta es introducida por el verbo en pretérito perfecto: Cambiará la política económica aunque ellos no quieran: $A M L O$.

Se muestra la oración subordinada y en ella una evaluación. Ésta se ubica desde la conjunción, aunque, hasta el verbo, quieran; el sentido de la evaluación alude al desafío de cambio; denota a un candidato combativo. En el titular se aprecia el discurso en positivo.

El antetítulo propone la siguiente frase: Austeridad y honestidad, las enseñanzas de Juárez, dice. Aquí el periódico nos expone bajo qué filosofía se rige el candidato; Benito Juárez representa un presidente con honestidad; en 
ese sentido tanto el candidato como el locutor aprecian de manera positiva los principios de su campaña.

Los nombres en la frase, Austeridad y honestidad, conforman el elemento evaluador no sólo de sus propuestas, sino también de su discurso.

A continuación, en el subtítulo se expone: Promete en Oaxaca que habrá libertad de expresión; es vergonzoso que en el estado se persiga a periodista, señala.

Lo que aquí se despliega son dos discursos referidos, cada uno con oraciones subordinadas que contienen a su vez dos evaluaciones. Una de ellas la situamos en la oración subordinada de la primera cita en voz narrada: habrá libertad de expresión..., otra, en la siguiente oración copulativa del discurso seudo-directo, en el adjetivo vergonzoso. Por ejemplo, la libertad de expresión, si se dice que habrá, esto también indica que no la hay.

En el caso del adjetivo, califica una entidad importante, la gubernamental; el candidato acusa al estado de coartar la libertad de expresión de los periodistas, además de hostigarlos.

De esta manera se muestra en los titulares de este periódico una clara evaluación negativa hacia los otros gobiernos (como el PRI). Se evalúa el comportamiento, juicio de estima social.

El lead presenta al candidato entre ovaciones juaristas. El párrafo abre sus renglones con el complemento circunstancial que evalúa, por un lado, el entusiasmo de los seguidores del aspirante presidencial $y$, por otro, las acciones negativas del gobernador de Oaxaca:

1. Guelatao, Oax., 21 de enero. Entre evocaciones juaristas y las provocaciones del gobernador Ulises Ruiz, quien ordenó levantar el adoquín de la plazoleta de este pueblo, el candidato presidencial de la alianza Por el Bien de Todos, Andrés Manuel López Obrador, estableció que la mayor enseñanza del Benemérito es su austeridad y honestidad, sobre todo cuando el país ha padecido corrupción y abuso de poder.

El lead contextualiza dos eventos importantes, ya observados en los titulares: a) La bienvenida al candidato por parte de los Oaxaqueños, recrea un escenario agradable porque el pueblo lo compara con Benito Juárez. 
b) Que el gobernador hiciera coincidir los trabajos de remodelación justo en la fecha de presentación de campaña presidencial en la plaza de Oaxaca, presupone un escenario negativo para el candidato perredista porque se traducen en un obstáculo para presentar adecuadamente su candidatura.

Asimismo, líneas más abajo, el discurso emitido por el candidato se constituye desde una perspectiva evaluativa, retoma a la ideología juarista, austeridad y honestidad; para llamar gobiernos corruptos y abusivos a aquellos quienes no se rijan bajo estos principios.

En esta nota se muestra a un candidato crítico y combativo de quienes no se rigen por los principios de la justicia, por ello, podemos aducir que se presenta al candidato de manera positiva.

\section{Periódico: El Universal}

22 de enero de 2006

\section{Candidato: Andrés Manuel López Obrador}

La noticia de este día estuvo conformada por diecisiete párrafos y nueve citas referidas del candidato presidencial, de los cuales, cuatro son discursos directos, una voz narrada y cuatro citas mixtas.

La noticia presentó el título con un discurso mixto (voz narrada y discurso directo). Asimismo, la oración se estructura con un sujeto, seguido del verbo y un objeto directo que introduce a una oración subordinada: AMLO asegura: conmigo no habrá "medicinas amargas".

El verbo que está en presente, asegura, denota la firmeza con que se emite tal discurso, por lo que se deduce que el locutor indirectamente hace una evaluación del 
candidato comprometiéndolo con discurso. Posteriormente, encontramos la oración simple que pertenece ya a la voz del aspirante presidencial; en ella notamos parte de la voz narrada y el discurso directo que hace alusión a que si votan por él, no tendrán medicinas amargas. La negación es un elemento que está comparando las posturas o propuestas de otros aspirantes con la propia: con los otros aspirantes el aumento de las medicinas es inminente y con él no hay tal propuesta.

En el subtítulo se manifiesta la cita mixta (discurso directo y voz narrada), otra propuesta que el periódico le interesa proyectar: "Hay que conocer bien la historia", dice a Fox en referencia a Juárez.

El adjetivo bien, hace alusión no al total desconocimiento de la historia por parte del presidente, sino a la parcialidad con que éste hace referencia del personaje, Benito Juárez. En ese sentido sí podemos hablar de una evaluación emitida por el candidato hacia el presidente, ésta se ubicada en discurso directo, en donde el locutor se deslinda del comentario y compromete al candidato con su discurso.

El siguiente es el primer párrafo de la noticia; en él encontramos que la voz del candidato presidencial no está presente, sólo se hace mención de la actividad que realizó:

1. GUELATAO, Oax.- Andrés Manuel López Obrador, candidato de la alianza "Por el bien de todos" a la Presidencia, caminó un centenar de metros a la entrada de este poblado, para colocar una ofrenda floral en el obelisco a Benito Juárez, pero se topó con que todo el adoquín de la plaza fue levantado anoche por orden del gobernador Ulises Ruiz, hombre cercano al abanderado del PRI, Roberto Madrazo, según el testimonio de pobladores.

En general en este párrafo, se ubican dos evaluaciones; la primera está centrada en el comportamiento del gobernador de Oaxaca, el cual no permitió que se desarrollara bien la ceremonia en honor a Benito Juárez, presenciada por el candidato perredista, lo cual vivió como un boicot. Todo lo anterior, el locutor, lo describe después de la adversativa, pero, ubicada en la oración coordinada.

La segunda valoración la ubicamos en la acotación que hace referencia al gobernador como un hombre cercano al candidato priista (del partido 
opositor), insinuando que tal situación poco afortunada fue provocada para arruinar la presentación del candidato de oposición

En resumen, se muestra a un candidato crítico, combativo y ético, a partir de resaltar las acciones negativas de otros políticos que están gobernando.

\section{Periódico: La Jornada}

\section{2 de enero de 2006}

\section{Candidato: Felipe Calderón Hinojosa}

El cuerpo de la noticia consta de veintitrés párrafos, de tres discursos directos, dos discursos indirectos, dos voces narradas y dos citas mixtas del candidato presidencial Felipe Calderón Hinojosa.

El periódico nos presenta un título espectacularmente evaluativo: EI PAN acarrea pepenadores en SLP; como bien se puede apreciar, el titular despliega una oración simple; el sujeto de la oración es el PAN, seguido de su verbo, acarrea, y su objeto directo, pepenadores; por último su complemento. En esta oración del titular se ubica una evaluación, su elemento es el verbo que introduce la acción del partido político: acarrea; esto es, evalúa con el verbo el comportamiento deshonesto del candidato (juicio de estima social).

El significado de la palabra acarrea, en el contexto de campaña presidencial, indica llevar a conjunto de personas a un mitin político con la promesa de proporcionarles algunos privilegios económicos, políticos 0 sociales.

El antetítulo hace mención del acompañante del candidato presidencial: Acompañado por Vázquez Mota, Calderón recuerda que ella manejó Oportunidades.

Estos renglones muestran la presencia de Vázquez Mota, personaje muy allegada al candidato, además coordina su campaña. La presentación ante los 
medios de tal personaje puede tener diversas interpretaciones. Sin embargo, hay una que muestra el propio discurso del candidato: ella manejó Oportunidades. Con tal aseveración se puede inferir que Felipe Calderón Hinojosa persigue implementar la misma política social y que sus promesas de campaña están fundamentadas sobre esta línea. El candidato evalúa sus propuestas a través de la apreciación del trabajo de la ex secretaria de desarrollo social.

En tanto, el subtítulo hace referencia a: No pudo deslindarse ante severas críticas de empresarios al gobierno de Vicente Fox. Estas líneas hacen evidenciar que en esa entidad el candidato presidencial no pudo evitar las críticas hacia el partido que representa y está en el poder.

La negación emitida en el subtítulo funciona como una apreciación de los pocos resultados de su compañero de partido.

A continuación presento este primer párrafo de la noticia:

1. Aguascalientes, Ags. 21 de enero. Felipe Calderón se enfrentó a los avatares de un candidato presidencial de partido en el gobierno. El panista escuchó severos reclamos del empresariado por la falta de resultados en materia económica, pero no pudo deslindarse de esta administración. "Las críticas a Fox corresponde hacerlas a mis adversarios, no hago campaña para perder", justificaría después ante reporteros.

En el discurso directo del candidato, ubicado en los últimos tres renglones del párrafo, percibimos la negación y el verbo en presente, hago, para insinuar que el candidato no habló mal del presidente porque de hacerlo perdería la candidatura. Además de informarnos indirectamente que el gobierno del actual presidente y del candidato, a pesar de pertenecer al mismo partido, se nota que son de la misma fracción.

En resumen, el periódico a través del discurso del candidato muestra a quiénes aprecia y a quiénes no, es decir, define a sus aliados y sus adversarios dentro del Partido. 


\section{Periódico: El Universal}

\section{2 de enero de 2006}

\section{Candidato: Felipe Calderón Hinojosa}

El cuerpo de la noticia del periódico El Universal está constituida por quince párrafos, cinco discursos directos, tres indirectos y cinco mixtos. En total sumaron trece citas referidas del personaje político.

El periódico presenta el título de la noticia con la postura del candidato en discurso seudo-directo: Calderón: fin a tabúes sobre inversión de IP en energía. El periódico muestra con la frase: fin a tabúes, que el candidato va exponer y promover el tema de la inversión de la iniciativa privada en los energéticos, principalmente el petróleo. Una de las propuestas más relevantes y apetitosa para los empresarios nacionales y extranjeros. El periódico compromete al candidato con su dicho porque lo muestra en discurso directo.

En el subtítulo, el periódico muestra una propuesta en voz narrada: IVA, fuera de su agenda, pero agrega que buscará ampliar la base gravable.

La adversativa evalúa la postura del candidato en cuanto al tema de impuestos: fuera de su agenda, que sirve de elemento evaluativo de la propuesta mencionada. El candidato propone al tema de impuestos, excluir el IVA, aunque, no descarta otra forma de recaudación tributaria.

El siguiente análisis está centrado en las evaluaciones del primer párrafo (lead), el cual está constituido por una cita referida en voz narrada de las propuestas del candidato:

1. SAN LUIS POTOSÍ, SLP.- El candidato del PAN a la Presidencia de la República, Felipe Calderón Hinojosa, escuchó propuestas y reclamos que vinieron desde un ama de casa hasta de la clase empresarial de la entidad, con 
quienes el aspirante se comprometió a permitir la inversión de la iniciativa privada en la generación de energía, pero sin que signifique, dijo, una privatización.

En la primera parte del párrafo, encontramos la intervención discursiva del locutor que narra lo acontecido durante la estancia del candidato en San Luis Potosí, aquí se muestra un verbo en pretérito que introduce al acto del candidato: escuchó, después se relata lo escuchado que fueron desde propuestas hasta reclamos. Pareciera que aquí declara una apreciación negativa frente a los reclamos que le hacen; sin embargo, puede mostrar, también todo lo contrario a un candidato dispuesto a responder las preguntas de todas las personas: desde a una ama de casa hasta un empresario. El periódico muestra a un candidato con actitud positiva ante los reclamos.

Más adelante, ya en su discurso, que muestra el periódico, en voz narrada, se expone la diferencia entre los conceptos de inversión privada y privatización. Para el personaje no son sinónimos ni perjudiciales para la vida económica del país. La adversativa, pero, en el penúltimo renglón ayuda a reforzar esta idea.

Finalmente, podemos observar que el periódico muestra a un candidato con evaluaciones en positivo, a través de la prominencia del discurso de este personaje, aunado a la apreciación de la actitud del candidato.

\section{Periódico: La Jornada}

\section{2 de enero de 2006}

\section{Candidato: Roberto Madrazo Pintado}

El periódico dedicó al cuerpo de la noticia del candidato Roberto Madrazo, diecinueve párrafos, tres discursos directos, dos discursos indirectos, cuatro voces narradas y siete discursos mixtos. Haciendo un total de dieciséis citas referidas.

La noticia que presenta el periódico se titula: Madrazo afirma que dará seguimiento a la política de Fox en materia de vivienda. El enunciado nos alude a una de las propuestas que presenta el candidato. En ella el periódico 
introduce mediante una voz narrada el verbo performativo: afirma, antes se muestra el sujeto y posteriormente el objeto directo que lleva una oración subordinada. En la oración subordinada aparece la evaluación del candidato en positivo a favor de las políticas del presidente.

La fuerza que el periódico le asigna aparece justo con el verbo: afirma.

En el antetítulo el periódico presenta lo siguiente: Señala que el reto es vencer "la desesperanza" de una sociedad" decepcionada". El discurso nos advierte cuál es el objetivo del candidato en sus propuestas, recuperar la confianza en una sociedad decepcionada por el gobierno del PAN. La oración está compuesta por un verbo que introduce al pensamiento del candidato: señala. Posteriormente, el objeto directo contiene una oración subordinada que su función es evaluar cuál es el reto del candidato. En estos reglones el locutor recurre al efecto para evaluar cómo está la sociedad en voz del candidato.

A continuación presento el análisis del primer párrafo de la noticia. Este párrafo contiene en su interior sólo la narración de los acontecimientos de este tercer día de actividades; por tanto, las evaluaciones estarán realizadas por el locutor.

1. Monterrey, NL, 21 de enero. Luego del fallido paso de Roberto Madrazo por el estado de México, cuyo gobernador, Enrique Peña Nieto, fue incapaz de cobijarlo en el acto masivo con el que arrancó su campaña, ahora el abanderado tricolor no sólo contó con escenarios colmados de militantes, sino que estuvo acompañado por el mandatario estatal, Natividad González Parás -quien en su momento le disputó al tabasqueño la directiva de su partido y la candidatura presidencial-, además del alcalde de Monterrey, Ricardo Canavatti.

La primera evaluación se localiza en el primer renglón de este párrafo: Luego del fallido paso de Roberto Madrazo por el estado de México. En esta línea aparece la frase: luego del fallido, la cual estima de manera negativa el paso del candidato por el estado de México.

Posteriormente, localicé otra evaluación negativa, ésta alude a la acción del gobernador del estado de México: Enrique Peña Nieto, fue incapaz de cobijarlo en el acto masivo con el que arrancó su campaña. La evaluación se centra en el elemento 
verbal: fue incapaz. En ese sentido el locutor refiere al comportamiento del gobernador.

Por otro lado, la siguiente frase también contiene carga evaluativa: ahora el abanderado tricolor no sólo contó con escenarios colmados de militantes, sino que estuvo acompañado por el mandatario estatal, Natividad González Parás -quien en su momento le disputó al tabasqueño la directiva de su partido y la candidatura presidencial-, además del alcalde de Monterrey, Ricardo Canavatti. El locutor en este enunciado presenta al candidato rodeado de adeptos y apoyos. Aquí los elementos evaluadores son la negación junto con el adverbio de modo no sólo y el nexo adversativo sino que dan la impresión de asombro porque es la primera vez que se le ve con militantes y acompañantes de su partido.

En esta nota nos percatamos que el locutor muestra a un candidato con propuestas evaluadas en negativo.

\section{Periódico: El Universal}

\section{2 de enero de 2006}

\section{Candidato: Roberto Madrazo Pintado}

El periódico presentó la noticia del candidato Roberto Madrazo en diecinueve párrafos. Se apoyó de dos discursos directos, tres discursos indirectos y dos voces narradas. En total las citas referidas del cuerpo de la noticia del aspirante presidencial sumaron siete. Un poco más, comparada con la presentación del primer día de candidatura. Aunque observamos que todavía el periódico dedica más a la narración de los hechos que a la presentación del discurso del candidato, por supuesto, en comparación con los otros dos candidatos.

La noticia se tituló: Afirma Madrazo que sacará las reformas estructurales. Esta cita se muestra en voz narrada la propuesta del candidato. El periódico nos introduce a esta propuesta mediante el verbo performativo: afirma, seguido del sujeto y de objeto directo, el cual lleva una oración subordina. La evaluación se centra justo en esta oración subordinada, es decir, 
en la propuesta que ofrece el candidato; el locutor aprecia el discurso de manera positiva.

Ahora, en el subtítulo se expone otra de las propuestas en voz narrada: Plantea bajar las tarifas eléctricas, y el costo de diesel, gas y gasolina. La anterior oración se presenta con un verbo de decir en presente simple: Plantea; el cual valora a su objeto directo. Esta es una propuesta muy atractiva para los ciudadanos, en ese sentido el locutor estima en positivo el discurso del candidato.

Con lo que respecta al primer párrafo de la noticia, nos dice:

1. MONTERREY, NL.- El candidato presidencial de la Alianza por México, Roberto Madrazo (PRI-PVEM), se comprometió ante los empresarios más importantes de México a impulsar la competitividad, a sacar avante las reformas estructurales que requiere el país y no dar bandazos económicos, de llegar a la Presidencia de la República.

Este párrafo presenta, el locutor en voz narrada, las propuestas del candidato. Del mismo modo detecté que la primera parte del apartado, el locutor realiza una evaluación a través del verbo de decir: se comprometió. Este verbo evalúa el grado de compromiso que estableció el candidato con algunos sectores de la sociedad.

Finalmente, podemos aducir que el locutor muestra a un candidato comprometido y con interesantes propuestas.

\section{Periódico: La Jornada}

\section{3 de enero de 2006}

\section{Candidato: Andrés Manuel López Obrador}

El periódico dedicó a la nota de este candidato presidencial veintitrés párrafos; nueve discursos directos, un discurso indirecto, ocho voces narradas y siete discursos mixtos. Esto suma un total de veinticinco citas referidas del 
candidato presidencial en el cuerpo de la noticia, una cantidad de importancia porque las citas directas superan a las otras. La voz del candidato es más prominente.

El título se presenta en discurso directo y está estructurado en dos oraciones: "El pueblo no es tonto, ciudadano Presidente", advierte López Obrador. La primera oración comprende el discurso directo del candidato, quien manifiesta de manera categórica un reclamo al presidente Fox. La negación modifica no al verbo, sino al adjetivo, quedando de esta manera un discurso que efectivamente, reclama y evalúa el comportamiento del presidente de la república, se observa una valoración directa, así como la cita.

En ese sentido, el periódico presenta a un candidato desafiante e irrespetuoso por dirigirse sin protocolos al presidente. También puede interpretarse como el típico candidato de "izquierda" irreverente que defiende los ideales del pueblo y confronta al enemigo abiertamente. Esta presentación como evaluación es ambigua.

Por su parte el antetítulo: En gira por Puebla y Tlaxcala califica a Madrazo de "cínico y desfachatado", aquí se vuelve a retomar la imagen de un aspirante presidencial desafiante, al estimar su discurso, también es ambigua esta presentación. El antetítulo se construyó de voz narrada y un discurso directo. En este titular el candidato evalúa el comportamiento de su adversario Madrazo con dos adjetivos: cínico y desfachatado.

El subtítulo enuncia lo siguiente: El mandatario anda apurado en busca de votos, dice el candidato de PRD-PT-Convergencia. El periódico, como bien se muestra, presenta en primer lugar la voz del candidato en discurso seudodirecto, posponiendo el verbo de decir y el sujeto. El periódico en voz del candidato le atribuye un comportamiento negativo al presidente Fox.

El siguiente párrafo contiene las acciones y reacciones del candidato ante ciertas situaciones acontecidas durante su último día de la gira (primera etapa). Las voces y reacciones fueron presentadas en voz narrada como a continuación se lee: 
1. Puebla, Pue., 22 de enero. Un estado gobernado por el priismo (Puebla) y otro por el panismo (Tlaxcala) integraron el último día de la gira del candidato de la Alianza Por el Bien de Todos, Andrés Manuel López Obrador, en la que cuestionó el anuncio presidencial de las pensiones a adultos mayores, y calificó de cínico y desfachatado al aspirante priista, Roberto Madrazo Pintado.

El locutor nos introduce al discurso del aspirante con voz narrada y con el verbo performativo cuestionó. Este acto verbal remite a la duda impuesta por el candidato presidencial a la propuesta publicada por el presidente Fox; valorándolo de "copión" (no abiertamente). En ese sentido el candidato evalúa su comportamiento (juicio) en negativo.

Después, con el verbo calificó, el locutor evalúa el comportamiento del candidato Andrés Manuel al enunciar algunos calificativos referentes a Madrazo Pintado.

Por último, también aprecia a su contrario aludiendo a dos adjetivos: cínico y desfachatado cuando propone políticas.

En general se muestra a un candidato confrontador y crítico de manera positiva.

\section{Periódico: El Universal}

23 de enero de 2006

\section{Candidato: Andrés Manuel López Obrador}

El periódico El Universal construyó la noticia en quince párrafos, dos discursos directos, dos discursos indirectos, dos voces narradas, siete mixtos. En total se generaron once citas referidas del candidato en el cuerpo de la noticia. En donde la voz del candidato fue menos prominente. 
Con lo que respecta al título podemos observar que se presenta el decir del candidato en discurso seudo-directo: Copian Fox y Madrazo mis ideas, acusa $A M L O$. El título plantea en dos oraciones en primer lugar, la postura del candidato y, posteriormente, la del periódico.

En este apartado ocurren dos evaluaciones; la primera, negativa, la centramos en el locutor al presentar al candidato presidencial, Andrés Manuel, víctima de un asalto de ideas a través de los verbos: copiara y acusar, el locutor evalúa el comportamiento inoperante del candidato.

En segundo lugar, la postura del candidato, dentro de su discurso, es de enojo y señalamiento hacia quienes actúan de manera inadecuada, esto es, dentro de la ilegalidad, del plagio. El candidato utiliza el juicio de estima social para evaluar el comportamiento de antiético.

El subtítulo está estructurado bajo una cita mixta: Asegura que reactivará la economía; "Puebla, con gobiernos autoritarios".

La primera parte de este subtítulo comienza con el verbo asegura, un objeto directo con oración subordinada, y un sujeto tácito. El acto verbal muestra la certeza de la propuesta del candidato; el locutor recurrió al subsistema de apreciación para evaluar el discurso del candidato. En tanto, el nombre y el adjetivo, de la segunda parte del subtítulo, evalúan, mediante la apreciación del locutor, las condiciones del estado Puebla.

En este primer párrafo de la noticia, el locutor expone el discurso del candidato presidencial en voz narrada:

1. PUEBLA, Pue.- Andrés Manuel López Obrador, candidato a la Presidencia de la alianza Por el Bien de Todos, acusó a su adversario priista Roberto Madrazo y al presidente Vicente Fox de actuar con cinismo al plagiar sus propuestas de bajar los precios de energía eléctrica, gas y gasolinas, y de otorgar apoyos económicos a adultos mayores. 
El locutor muestra a través de la siguiente estructura oracional, el discurso del candidato: inicia con el verbo performativo, acusó; un sujeto, Andrés Manuel...; el complemento prepositivo, de actuar..., y sus oraciones subordinadas (al plagiar... otorgar...); el objeto indirecto, a sus adversario... La estructura es compuesta, sin embargo, nos ayuda a descifrar los elementos que evalúan a simple vista; esto es la evaluación cae directamente al candidato priista y al presidente Fox. La voz narrada que diseñó el locutor para presentar el discurso del candidato, puede ayudarnos a ir más allá, porque no sólo nos muestra la voz del personaje de la nota, sino también la del locutor, entonces puede suceder que éste también evalúe indirectamente. Ambos recursos, el sintáctico y el discursivo, complementan el análisis.

El verbo acusó y la palabra cinismo en términos sintácticos se ubican en una relación gramatical a simple vista de evaluación; el primero tiene como argumentos un objeto indirecto y un complemento de preposición, en el cual se incluye el adjetivo, cinismo, que califica a dos personajes, esta evaluación la elabora el candidato presidencial porque es el sujeto que acusa. Más allá, el discurso nos ofrece el análisis de las citas, en este caso la voz narrada nos muestra una característica peculiar, diluir la voz del otro y resaltar la del que narra. En este párrafo ocurre que el candidato realiza evaluación y el locutor la legítima. Veamos cómo ocurre.

El candidato aprecia el comportamiento negativo de su contrincante y del presidente de la república porque copian sus ideas y eso culturalmente en México, aunque no se castiga severamente con el desprecio de los demás y advirtiendo que es antiético, si se puede señalar y acusar de no originalidad.

Asimismo, el adjetivo y el verbo, diseñados por el locutor, sirvieron para evaluar indirectamente, el comportamiento del candidato, al mostrar en voz fuerte y acusadora estas palabras que señalaron a los dos personajes. 


\section{Periódico: La Jornada}

\section{3 de enero de 2006}

\section{Candidato: Felipe Calderón Hinojosa}

El cuerpo de la noticia que nos presenta La Jornada se estructura en veintiséis párrafos. Estos párrafos contienen, dos discursos directos, cinco discursos indirectos, dos voces narradas y una cita mixta que en total sumaron diez citas referidas del candidato presidencial en el cuerpo de la noticia.

Las oraciones del título de la noticia permiten percibir la postura del candidato. Éstas se presentan en discurso seudo-directo, como a continuación se muestra: Honraré la memoria de Juárez, asegura Calderón.

Efectivamente, el locutor refiere a la voz del candidato abriendo su discurso con el siguiente acto verbal: honraré. El verbo muestra la postura del personaje.

Después, el periódico presenta el discurso mediante el verbo performativo: asegura, este acto verbal dibuja claramente la postura de certeza del discurso del personaje que le atribuye el locutor, asimismo nos muestra el compromiso adquirido con los principios del Benemérito.

Por su parte, el antetítulo centra su atención en otra actividad realizada por el candidato en esa ciudad: Realiza una "visita de cortesía" al cardenal de Guadalajara. La cita es mixta (vn y dd).

Asimismo, la frase entre comillas nos alude a diversas interpretaciones; bien podría decirse que la visita de cortesía está puesta en duda, necesariamente un candidato no está en posición de hacer este tipo de visitas, además si honra la memoria de Benito Juárez ¿Por qué visita la Iglesia? Se supone que por eso luchó el ex presidente por mantener a la iglesia alejada del poder. Entonces ¿no lo honra? En ese sentido el locutor evalúa a través de esta frase la veracidad del discurso. 
Sin embargo, la enunciación de esta actividad refleja una postura con respecto al comportamiento del candidato y su relación con el clero.

Lo mismo ocurre con el subtítulo; en éste encontramos la presentación de un discurso en forma de pregunta y entre comillas (por tanto discurso directo): “¿Qué diría el Benemérito de los departamentos de Madrazo?”.

La función de la pregunta es evaluar los bienes del candidato opositor. En este caso, el periódico, indirectamente comparte esta evaluación. La paradoja vertida en la pregunta que se prende sea resuelta por el Benemérito, quien es recordado por sus reformas equitativas en la repartición de las tierras durante una parte del siglo XIX, sin embargo, se olvida que algunas propiedades expropiadas eran del clero.

El primer párrafo del cuerpo de la noticia se presenta la voz del candidato en discurso indirecto:

1. Guadalajara, Jal., 22 de enero. En este bastión blanquiazul, Felipe Calderón se sumó a los homenajes a Benito Juárez al decir que honrará su memoria siendo un presidente que aplicará la ley, a diferencia de sus adversarios, y se preguntó qué diría el Benemérito, defensor de la honrada medianía de los gobernantes, si supiera de los departamentos "off shore" del priista Roberto Madrazo.

El locutor expone el singular homenaje a Benito Juárez brindado por el candidato panista al reconocerlo en su discurso: Felipe Calderón se sumó al decir que...Esta evaluación refiere al comportamiento del candidato al sumarse a los festejos, siendo que su corriente ideológica no comparte los principios que el personaje pregonó, eso se refuerza con la visita al cardenal.

Posteriormente, a esa evaluación, el locutor introduce ya la voz del candidato, en discurso indirecto, y dice que honrará la memoria de Benito Juárez siendo un presidente que aplicará la ley, a diferencia de sus adversarios. Esta última frase de la cita referida, muestra la evaluación negativa del comportamiento poco ético de sus contrincantes frente al cumplimiento de la ley. 
En el lead el locutor reitera, la pregunta evaluadora del subtítulo; con ello se pregunta o evalúa sobre la ética del candidato del Partido Revolucionario Institucional (PRI): qué diría el Benemérito, defensor de la honrada medianía de los gobernantes, si supiera de los departamentos "off shore" del priista Roberto Madrazo.

Las evaluaciones emitidas refieren en gran medida al comportamiento ético y al compromiso del discurso efectuado.

\section{Periódico: El Universal}

\section{3 de enero de 2006}

\section{Candidato: Felipe Calderón Hinojosa}

El periódico el Universal presenta en el cuerpo de la noticia del candidato quince párrafos, de los cuales contienen tres discursos directos, dos discursos indirectos y una voz narrada. En total se generaron seis citas referidas del candidato presidencial. Las citas directas son pocas comparadas con las que muestra la Jornada; por tanto, El Universal le da menor prominencia a la voz del candidato.

El discurso del candidato en el título es presentado en cita mixta, esto es, está constituido por una voz narrada y un discurso directo: Calderón refrenda compromisos con "libertad de todos". El verbo, refrenda, alude a una reiteración del discurso y evalúa al compromiso emitido.

En el subtítulo el periódico retoma otro asunto de interés: Los encuentros han sido para dar a conocer su plataforma política, aclara. Se presenta esta actividad del candidato mediante el discurso seudo-directo; asimismo esta cita alude a unos encuentros efectuados con ciertas personalidades; sin embargo, el periódico aclara a través del verbo el porqué. Efectivamente, en este párrafo se amplía la información: 
1. GUADALAJARA, Jal.- La tierra en donde fue destapado el 29 de mayo de 2004 como candidato a la Presidencia de la República por el gobernador Francisco Ramírez Acuña, fue el punto final de esta primera gira de Felipe Calderón Hinojosa en la que visitó el llamado "corredor azul", compuesto por entidades gobernadas por el PAN y en donde sostuvo sus primeros contactos con la jerarquía católica como candidato, entre ellos el cardenal Juan Sandoval Íniguez y el ex presidente del Episcopado, Luis Morales Reyes, el sábado en San Luis Potosí.

La presentación del candidato en este primer párrafo no contiene cita referida, se narra el contexto de los acontecimientos. A grandes rasgos se dice que en la ciudad de Guadalajara ocurrió el destapa del candidato presidencial y de vuelta meses más tarde se organizó una visita poco común, desde esa perspectiva nos hace inferir, el periódico, que el candidato llegó a dar cuentas a quienes lo apoyaron para su candidatura.

El locutor valora el comportamiento extraño del candidato, anti juarista.

\section{Periódico: La Jornada}

\section{3 de enero de 2006}

\section{Candidato: Roberto Madrazo Pintado}

Dentro de los doce párrafos dedicados al cuerpo de la noticia del candidato, se distinguen siete discursos directos, dos discursos indirectos, siete voces narradas y cinco citas mixtas. En total se generaron veintiuna citas referidas del candidato.

El título que le dio vida a la presentación del aspirante, en esta nota, fue: Madrazo imprime tinte salinistas a su campaña.

El periódico le atribuye al candidato una cualidad negativa a los mecanismos que ha adoptado la campaña política; si analizamos la connotación que tiene para la economía mexicana el nombre de Carlos Salinas de Gortari ex presidente de México. Por ello, puede convertirse en una desafortunada presentación. 
El antetítulo enuncia otro tema no menos evaluativo. Se presentaron las actividades y las promesas del candidato mediante un contexto poco peculiar, una carrera atlética: Carrera atlética y promesas en varios rubros. En esta frase se expuso el contexto donde fueron emitidas las promesas para esa entidad. Por tanto, vemos qué postura tiene el periódico con respecto al comportamiento del candidato: Tal evaluación nos abre cuestionamientos: ¿será que las propuestas emitidas por el candidato bajo este escenario son poco serias o que el candidato ve a la contienda política como una carrera de maratón?

El subtítulo nos expone una propuesta concreta: Voy con todo contra el crimen, dice en Ciudad Victoria. El periódico presenta la voz del candidato en discurso seudo-directo porque afirma que esta ciudad existe el crimen, una afirmación que el periódico comparte. El mensaje es muy claro; aquí denota una evaluación directa porque considera a Tamaulipas un lugar de criminales; desde este punto de vista se aprecia de manera negativa, la situación en ese territorio.

En este párrafo (lead), el locutor relata y describe el contexto en donde se emitió el discurso del aspirante presidencial:

1. Ciudad Victoria, Tamps., 22 de enero. En uno de los estados con mayor presencia del crimen organizado, donde fueron ejecutadas 178 personas en 2005 y 17 tan sólo en este mes, el candidato de la Alianza por México (PRI-PVEM), Roberto Madrazo Pintado, advirtió que va "con todo" en la lucha contra el narcotráfico. "Ha llegado el tiempo en que son ellos o nosotros, y no me temblará la mano para sacarlos del país", dijo al delinear su oferta en materia de seguridad, uno de los proyectos más acabados.

Ante este escenario de presentación de datos e información acerca de la problemática del estado, se presenta la voz del candidato en discurso mixto; el locutor lo introduce mediante el verbo de decir: advirtió, el cual denota un tinte de amenaza para a todos aquellos que colaboran con el narcotráfico. 
Posteriormente, se muestra un discurso directo: no me temblará la mano. Esta acción negada representa en términos concretos una imagen de intimidación hacia el crimen organizado, y una comparación con otros aspirantes que no se han atrevido a comprometerse con lucha de tal problemática social.

De igual forma, el locutor evalúa, en las últimas líneas, las propuestas del candidato: uno de los proyectos más acabados. Desde la percepción del locutor ésta es una propuesta acabada, en donde se denota la seguridad del candidato frente a su propuesta central de campaña: la inseguridad y el crimen organizado; asimismo, esta propuesta se expone en un contexto maratónico. Tal vez nos invita a inferir que para el candidato el combate contra el crimen organizado es su mejor apuesta de campaña o de competencia de maratón que lo hará ganar la presidencia.

En general, muestra a un candidato con propuestas negativas porque lo compara, en algunos aspectos, con Carlos Salinas de Gortari ex presidente de México; sin embargo, en el lead muestra una propuesta, de inseguridad, y evalúa que es la más acabada (en positivo).

\section{Periódico: El Universal}

23 de enero de 2006.

\section{Candidato: Roberto Madrazo Pintado}

La estructura de la noticia del candidato presidencial Roberto Madrazo se pública de la siguiente manera: Para esta nota se disponen dieciséis párrafos, y ocho citas referidas del candidato presidencial: un discurso directo, cinco voces narradas y dos citas mixtas. La voz del candidato es menos prominente que en el periódico La Jornada. 
El título se presentó en discurso seudo-directo, Madrazo: habrá ley contra el narcomenudeo. En esta oración el candidato evalúa la falta de legislación sobre esta problemática social.

A continuación en el subtítulo aparece la siguiente oración: Señala que legisladores de su partido aprobarán la iniciativa. Como podemos leer, el periódico muestra un fragmento de la propuesta del aspirante, ésta es mostrada en discurso indirecto. El verbo en futuro resalta claramente una evaluación de gradación (de fuerza) que garantiza la aprobación de la ley y que es necesaria.

El primer párrafo de la noticia:

1. CD. VICTORIA, TAMAULIPAS.- El candidato presidencial de la Alianza por México (PRI-PVEM), Roberto Madrazo, aseguró, ante representantes de medios de comunicación, que diputados y senadores del $P R I$, aprobarán una ley contra el narcomenudeo y otra que permita la extradición de quien tenga vínculos contra el narcotráfico.

En este párrafo observamos la información del título y subtítulo ya ampliada. El discurso del candidato se muestra en discurso indirecto y se señala (el verbo en futuro), nuevamente, que se aprobará la ley contra el narcomenudeo. El candidato presidencial evalúa que actualmente no existe una ley de tal naturaleza y que su corriente partidista la está impulsando.

Sobre la misma línea el locutor señala que la propuesta del candidato también contempla a quien tengan vínculos con el narcotráfico. La oración contiene la evaluación porque evalúa la situación actual del estado, del país y también se incluye en la reacción emocional que le causa el evento.

En conclusión, se muestra a un candidato con propuestas en positivo. 


\section{Periódico: La Jornada}

\section{9 de junio de 2006}

\section{Candidato: Andrés Manuel López Obrador}

En el cierre de campaña del candidato Andrés Manuel López Obrador, el periódico La Jornada dedica veinte párrafos a la nota, en los cuales se concentraron cinco discursos directos, ocho discursos indirectos, cinco voces narradas y seis citas mixtas. En total sumaron veinticuatro citas referidas del candidato presidencial.

Por otro lado, el título nos muestra en discurso seudo-directo al candidato: Impulsaré el desarrollo sin endeudar el país: AMLO.

En la oración aparece el verbo en futuro: impulsaré; también contiene un sujeto tácito, un objeto directo y un circunstancial de modo con una oración subordinada por la preposición: sin; si observamos este nexo su significado denota la carencia o falta, en este caso, de la deuda.

Esto hace inferir que las políticas propuestas por otros partidos políticos sí llevan a la deuda. Por tanto, esta preposición se convertirá en el elemento de apreciación, no solo de su propuesta, sino indirectamente la de sus opositores.

El siguiente titulado que a analizar es el antetítulo, que promulga lo siguiente: Actuaré con responsabilidad y sensatez, sostiene. En este enunciado se conciben dos evaluaciones simultáneas: La primera que viene del candidato y la segunda del periódico.

La del candidato se ubica en el verbo de preposición: actuaré con. Este elemento califican a los nombres: responsabilidad y sensatez. Así nos indica que el candidato actuará bajo ciertos valores; aquí nos muestran un juicio.

Por otro lado, el periódico a través del verbo sostiene, valora en positivo el compromiso del candidato. 
La voz narrada del subtítulo relata la acción que pretende realizar el candidato una vez ganada las elecciones: Convocará a todos los sectores a un pacto nacional.

El discurso presenta un verbo en futuro perfecto que emite una evaluación anticipada, es decir, cómo actuará el candidato una vez obtenida la presidencia. Lo relevante de esta presentación es que pospone el motivo de la convocatoria y anticipa a quienes invitará; resaltando a los actores sociales por encima de su propuesta.

Por otro lado, si relacionamos el subtítulo con los otros titulares podemos deducir que: El actuar con responsabilidad y sensatez indica actuar incluyendo a todos los sectores y emprendiendo un desarrollo sin endeudarlos.

El lead de esta nota nos muestra, primero, en discurso indirecto y, segundo, en mixto los actos y el discurso del candidato presidencial:

1. Frente a la multitud que no se movió del Zócalo capitalino a pesar de la Iluvia, Andrés Manuel López Obrador advirtió que la guerra sucia no le funcionó a sus adversarios, y envió un mensaje a empresarios y financieros: "Ni vamos a actuar de manera irresponsable, ni vamos a provocar ninguna crisis, nadie debe preocuparse".

Ante tal escenario podemos recuperar las distintas evaluaciones que hizo el candidato presidencial, así como el locutor. En primera instancia, dividiremos en cuatro los momentos evaluativos encontrados en el lead:

Primer momento: "Frente a la multitud que no se movió del Zócalo capitalismo a pesar de la lluvia”... El I elemento evaluativo de esta oración lo ubicamos justo en el renglón donde el locutor describe el lugar donde se presentó el aspirante presidencial: Frente a la multitud que no se movió del Zócalo capitalino a pesar de la lluvia. En estas líneas preliminares apreciamos una negación: no se movió, y una adversativa: a pesar. La cuales impactan de manera positiva al contexto de cierre de campaña del candidato presidencial.

El segundo momento evaluativo lo ubicamos en el verbo performativo advirtió, el cual evalúa la forma amenazante que dirige su discurso. 
Por otro lado, el siguiente momento evaluativo lo localizamos cuando el candidato enuncia que la guerra fría no funcionó, convirtiéndose esta frase en la evaluación de la acción de sus adversarios.

Finalmente, visualizamos el cuarto momento evaluativo, cuando en discurso directo se presenta la voz del candidato: "Ni vamos a actuar de manera irresponsable, ni vamos a provocar ninguna crisis, nadie debe preocuparse".

La estructura de la oración nos muestra dos negaciones con la conjunción ni. Esta conjunción evalúa dos veces de manera directa al acto verbal. Además, el pronombre indefinido también aparece evaluando la acción. En ese sentido tanto las negaciones como el pronombre nos intentan mostrar que las propuestas políticas del candidato han sido ya evaluadas por otros; por lo tanto, desmiente y contesta de manera directa aquellos que sí lo piensan, evalúa lo ético de su discurso.

En este cierre de campaña, se presenta a un candidato con propuestas evaluadas en positivo.

\section{Periódico: El Universal}

29 de junio de 2006

\section{Candidato: Andrés Manuel López Obrador}

La noticia del cierre de candidatura de Andrés Manuel López Obrador mostrada por el periódico El Universal consta de dieciséis párrafos, dos discursos directos, dos voces narradas y siete mixtas. En total se sitúan once citas referidas en el cuerpo de la noticia y el lead.

El título de la noticia se presenta en voz narrada: AMLO descarta una crisis económica. En la presente oración, el verbo descarta alude a una situación posible.

El periódico mediante el título rechaza que algo así suceda. Por otra parte, el subtítulo expone una propuesta del candidato: Insiste que desde el lunes se iniciará la construcción de un pacto nacional. El discurso del candidato 
es presentado en voz narrada y el verbo evalúa lo importante que es para el candidato trabajar en la construcción de un pacto nacional. Por otro lado, en la oración subordinada del objeto directo aparece un circunstancial de tiempo que evalúa la postura de triunfo anticipado del candidato.

El lead presenta dos discursos referidos del candidato presidencial:

1. En su última oportunidad para convencer al electorado, Andrés Manuel López Obrador dijo a los empresarios que en su gobierno no habrá crisis económica y aseguró que a partir del lunes comenzará la construcción de un pacto nacional en donde esté representada toda la sociedad.

El anterior párrafo alude básicamente a desmentir todos los rumores que de él se desprendieron durante la contienda presidencial y que crearon una imagen equivocada de sus propuestas de gobierno, veamos como lo muestra el periódico. La primera intervención del candidato en el lead, presentada en discurso directo, desmiente con la siguiente oración: no habrá crisis económica; la posibilidad de una crisis si ganara la presidencia. La segunda intervención manifiesta la importancia de convocar a un pacto, de lo cual indirectamente, desmiente que sólo sean los pobres el eje de su política.

Aparentemente, el periódico deja espacio para que el candidato de izquierda se exprese, sin embargo, veamos la frase con la que comienza el lead: En su última oportunidad para convencer al electorado, esta voz narrada sugiere que el candidato tuvo la oportunidad de convencer que no es una persona conflictiva y deshonesta, aunque según el periódico insiste mucho en demostrarlo. Por tanto, existe una evaluación implícita, porque a partir de las anteriores notas, en donde El Universal puntualiza en la necesidad de decir que el candidato no es bueno como parece, ahora con esta frase se reitera.

Por tanto, sí hay una evaluación: El candidato de izquierda no es lo que parece ser. 


\section{Periódico: La Jornada}

\section{6 de junio de 2006}

\section{Candidato: Felipe Calderón Hinojosa}

El total de párrafos construidos para el cierre de campaña del candidato Felipe Calderón Hinojosa fueron de dieciocho. Asimismo se presentaron seis discursos directos (dd), cuatro indirectos (di), una voz narrada (vn) y cuatro en citas mixtas $(\mathrm{cm})$. En total sumaron quince citas referidas del candidato presidencial incluidas en el cuerpo de la noticia y el lead.

El título de la noticia fue presentado en cita mixta (vn y dd) y versa sobre el contenido del discurso del candidato presidencial en su cierre de campaña: Los dos "López", eje del discurso calderonista; la estructura enunciativa del título es peculiar porque no existe un verbo de decir que introduzca la voz del aspirante.

La primera parte, del discurso, contiene un determinante, su adjetivo seguido del nombre, posteriormente aparece una coma que rompe con el posible verbo y a continuación se visualiza la misma estructura de frase de la primera parte. Conforme a lo anterior, podemos decir que el nombre que aparece en la primera parte del discurso referido tiene la función de elemento evaluativo. Éste aprecia el último discurso del candidato en campaña presidencial.

Por otro lado, el antetítulo nos dice: Rosario de ataques al perredista, la constante

El periódico presenta en voz narrada esta frase. Como bien observamos el enunciado nos anticipa el desarrollo de la nota que mostrará la lista de insultos hacia su contrincante, directamente, con ello, el periódico está evaluando el discurso del cierre.

A continuación analicemos la estructura de la frase del antetítulo. Esta frase funciona como una oración porque el verbo de decir está elidido; sin 
embargo, el nombre y su modificador representa al acto verbal, esto es, la función de este elemento: Rosario de ataques sustituye al verbo dijo; también podemos observar que es una manera modalizada de presentar la acción verbal. De la misma forma, el periódico introduce a la voz del candidato un nombre que hace la función de verbo, este es pospuesto, la constante. Por tanto, el elemento evaluador del antetítulo se centra en los sustantivos que estiman como el discurso del candidato se centró en hablar mal del opositor.

El subtítulo redondea la información de los otros titulares y desarrolla mejor el escenario del candidato: El extinto López Portillo, a escena; ninguna mención a Fox

En este apartado apreciamos, nuevamente, otro fragmento del eje del discurso del candidato y se agrega a la mención la figura del ex presiente López Portillo; en ese sentido el periódico implícitamente está evaluando por qué menciona a este ex presidente y no al actual, a manera de auto reflexión.

En el año de 1982, el presidente priista López Portillo dejó al país endeudado, sumergido en una gran crisis. De esta manera argumenta por qué nos es conveniente votar por un priista, y luego porque no es conveniente votar por un candidato que se apellida de igual manera. Evalúa a través del comportamiento de uno, el del otro.

El primer párrafo de la noticia describe lo siguiente:

1. Con la figura de Andrés Manuel López Obrador en el centro de su discurso, Felipe Calderón cerró su campaña en el Distrito Federal pidiendo a los panistas que no se rindan ni den un paso atrás en la búsqueda del voto en esta "hora crítica".

Este primer párrafo amplía la información encontrada en los titulares.

Si bien en los anteriores apartados la idea eje del discurso del candidato estaba centrada en los dos personajes con el mismo apellido, en el lead ya se aborda el ataque al candidato perredista. De hecho inicia el párrafo con el complemento circunstancial: Con la figura de Andrés Manuel López Obrador en el centro de su discurso; a través de este elemento el periódico reitera la 
evaluación sobre la estrategia de convencimiento que efectúa el candidato a través de la presentación negativa de sus opositores.

Posteriormente, en la siguiente oración, el periódico muestra en cita mixta (vn y dd) otra evaluación. Inicia con el verbo performativo en gerundio pidiendo, seguido del objeto indirecto y posteriormente del objeto indirecto: pidiendo a los panistas que no se rindan ni den un paso atrás en la búsqueda del voto en esta "hora crítica". La frase entre comillas nos alude a una situación tensa, la cual depende ganar las elecciones presidenciales, por ello, lanza una petición a sus seguidores para que voten. En este pequeño apartado nos percatamos, también, que el candidato contempla la problemática del abstencionismo.

La nota presenta el discurso del candidato centrado en opacar la propuesta de su contrincante y no a través de reiterar sus propuestas.

\section{Periódico: El Universal}

\section{6 de junio de 2006}

\section{Candidato: Felipe Calderón Hinojosa}

La noticia consta de diecisiete párrafos, dentro de ellos localizamos dos voces narradas y tres citas mixtas; haciendo un total de cinco citas referidas del candidato presidencial. Los discursos directos e indirectos no se localizaron a lo largo de la nota; sin embargo, en algunas de las citas mixtas se concentran.

El título que acompaña a la nota del cierre de campaña del candidato Felipe Calderón se presenta en discurso seudo-directo: Calderón: ganaré por 1.5 millones de votos.

Si prestamos atención al acto verbal en futuro, notaremos que éste es un elemento evaluativo, y en él se alude a una predicción en verdad sabe cuántos militantes existen en su partido, entonces la será de dónde obtuvo la 
cifra. Entonces mediante el discurso del candidato, el periódico presenta la valoración de la información que ofrece en cifra.

En cambio en el subtítulo se hace mención en discurso seudo-directo de los adversarios del candidato: "Indestructibles son mitos; rivales quieren estafar a mexicanos". Como bien leemos el subtítulo está constituido por dos oraciones; la inicial se construye de un verbo copulativo, el adjetivo y un nombre. Por lo que se percibe en él un sentimiento de preocupación por sus contrincantes. En la segunda oración menciona a los rivales y les atribuye una acción criminal. Por un lado, se manifiesta miedo y, por el otro, recriminación. Determinándose así un comportamiento negativo de sus opositores.

El locutor, en el lead, narra el escenario de su presentación que equivale a una evaluación: ante miles de simpatizantes reunidos... seguido nos introduce a la voz del candidato mediante el acto verbal: aseguró, otra evaluación en donde el verbo representa el elemento que va a evaluar el compromiso del discurso que después le sigue:

1. Ante miles de simpatizantes reunidos en el estadio Azteca, el candidato presidencial del PAN, Felipe Calderón Hinojosa, cerró campaña en la capital y aseguró que está preparado "profesional y espiritualmente" para gobernar el país, después de "haber enfrentado y superado la adversidad".

El locutor muestra, en este primer párrafo, el discurso del candidato en cita mixta. Ésta hace referencia al sentir del aspirante ante la llegada de las votaciones presidenciales, su emoción, su afecto.

En este enunciado el candidato se reconoce preparado para gobernar, el acto verbal valora su capacidad y la refuerza con los adverbios entre comillas; es decir, lo intensifica. Asimismo, en el complemento circunstancial aparece entre comillas otra oración que está evaluando el por qué está preparado, la apreciación en positivo de su capacidad para gobernar al país.

En general, la nota presenta a un candidato confiado y ganador. 


\section{Periódico: La Jornada}

\section{8 de junio de 2006}

\section{Candidato: Roberto Madrazo Pintado}

La noticia se conformó de diecisiete párrafos dentro de los cuales se observan tres discursos directos, dos voces narradas, dos discursos indirectos, once citas mixtas. En total se generaron para la noticia de cierre de campaña, dieciocho citas referidas del candidato presidencial en el cuerpo de la noticia.

El título de la noticia nos muestra en discurso seudo-directo la opinión del candidato presidencial: El PRI, en la antesala de la Presidencia, confía Madrazo. Como bien indica el periódico introduciendo el verbo confía; el candidato presidencial concibe a su partido dentro de los primeros lugares del juego de las elecciones presidenciales. Por tanto, el verbo estima la opinión y el sentir del candidato sobre las elecciones.

Ahora bien, en el antetítulo el periódico muestra el discurso del candidato mediante una cita mixta: México no aguanta más "la aventura" de la derecha. En este apartado no hay diferencia entre la voz del candidato y la del periódico porque no hay un verbo que introduzca a la presentación de la voz y se reconozca la del periódico. .

La estructura oracional de este antetítulo comprende un sujeto, un verbo acompañado de una negación y cuantificador, seguido aparece el objeto directo. En este caso, la acción verbal es negada e intensificada, esto revela una clara evaluación con respecto a la situación actual de México: si siguen con los experimentos de gobierno, no resistirá y caerá en crisis económica. La apreciación recae sobre el gobierno de Vicente Fox el actual presidente de la República.

El subtítulo está compuesto por dos oraciones que indican en qué sitio aconteció el cierre de campaña. Por ejemplo, el primero fue en el distrito federal: El priista cerró campaña en el Monumento a la Revolución. La acción del candidato se presenta en voz narrada. Este enunciado no revela claramente una evaluación, cuyo 
significado lo podemos advertir sólo por el contexto: Monumento a la Revolución descubrimos que este lugar simboliza el legado de la revolución y el PRI también es uno de ellos, fue muy simbólico.

Por otro lado, la siguiente oración menciona, también, el cierre de campaña efectuado en otro estado de la república: Tabasco. Aquí denota que por causa de la lluvia se aceleró el discurso del candidato: La lluvia obligó a acelerar el discurso en su natal tabasco. Asimismo, el estado de Tabasco representa el triunfo para este personaje porque en 1995 "ganó" las elecciones para gobernador, en donde compitió con Andrés Manuel López Obrador actual candidato. Entonces, aquí, indirectamente, nos muestra el reto expuesto.

El primer párrafo de la noticia presenta una cita referida del candidato en discurso seudo-directo; antes, el locutor, relata el contexto del discurso, como se observa en las primeras líneas:

1. Roberto Madrazo tuvo que pronunciar en su tierra el discurso más breve de toda su campaña. En apenas ocho minutos dijo a sus paisanos que ganará las elecciones del próximo domingo y que honrará el compromiso democrático de su padre, Carlos Alberto Madrazo, y el de Luis Donaldo Colosio.

El locutor nos introduce al candidato mediante la acción verbal en pretérito: tuvo que pronunciar, el auxiliar denota la necesidad de la acción verbal, sin embargo, está condicionado a su vez por un evento que lo impactó. Seguido se muestra el complemento circunstancial, lo que hace que se intensifique la acción: en su tierra natal, lo relevante es que fue en ese lugar su discurso más corto. A continuación se evalúa el discurso con el adjetivo y el cuantificador, intensificando tal propiedad. Por otro lado, continúa otra oración que específica el tiempo que le tomó al candidato dictar su perorata. Con la anterior oración abre la presentación del discurso del candidato. 
Efectivamente, esta frase: en apenas ocho minutos; el adverbio aprecia lo realmente relevante de decir para el candidato: que ganará las elecciones y también mediante una oración subordinada deja claro que lo hará honrando a su padre y a Luis Donaldo Colosio, es decir, a dos muertos; que tal parece agregarle, con esto, a su discurso el sentimiento de honradez.

La nota muestra en términos generales desde un punto imparcial al candidato. Sin embargo, podemos inferir que Madrazo no tenía la certeza de ganar.

Periódico: El Universal

28 de junio de 2006

\section{Candidato: Roberto Madrazo Pintado}

La noticia generada en el cierre de campaña del candidato Madrazo, en el periódico El Universal se conformó de catorce párrafos, dos discursos indirectos, cuatro voces narradas y dos citas mixtas. En total se generaron 8 citas referidas del candidato presidencial en el cuerpo de la noticia.

El título de la nota está presentada por una cita en discurso indirecto: Madrazo pide que no lo descarten como vencedor. En esta oración se aprecia el verbo en presente que introduce al discurso del candidato, el cual refiere una petición: pide. El objeto directo de este verbo: que no lo descarten, evalúan la preocupación del candidato porque los medios no lo consideran entre el posible ganador.

En el subtítulo se enuncia: Asegura que ganará con el voto leal. Hoy cerrará campaña en Veracruz. Por una parte el periódico proyecta en el título a un candidato preocupado y desangelado, y posteriormente, en el subtítulo, el discurso enuncia que ganará bajo ciertas condiciones: sí ganará (asegura), pero (con el voto leal), si esa combinación no se realiza, entonces no obtendrá la presidencia. 
En cuanto al primer párrafo de la noticia, el locutor muestra una cita mixta:

1. El candidato presidencial de la Alianza por México, Roberto Madrazo, pidió no ser descartado como posible ganador de la contienda electoral: "El pleito es de dos, la elección es de tres", sentenció el candidato en un cierre de campaña regional realizado en el monumento a la Revolución, en memoria de Luis Donaldo Colosio.

El lead recupera la información del título y el subtítulo, ampliando más los datos y también la evaluación. La primera parte de la cita ya fue analizada en el subtítulo, así que seguiré con la segunda parte que está en discurso directo: El locutor pospone el verbo performativo en pretérito que presenta el discurso del candidato: sentenció; el cual indica un fallo, advertencia de que el candidato no está fuera de la contienda, aunque no responda a las agresiones de sus adversarios.

Presenta a un candidato perdedor e inseguro con pocas propuestas. 


\title{
Conclusiones
}

\section{Ideología y evaluación}

\author{
Capítulo IV
}


La repentina democracia, un poco tardía en nuestro país, de los medios de comunicación que trajo consigo el uso excesivo de la toma de palabra para referir y exhibir a personajes políticos, sobre todo, negativamente, desentraño una problemática que el Instituto Federal Electoral tuvo que resolver poco antes de la llegada a las elecciones del 2006: ¿Cómo regular los comentarios que apuntaban a una evaluación de desprestigio de los personajes políticos en las noticias televisivas y por supuesto en las notas periodísticas ante un proselitismo? La respuesta la conocimos porque publicaron en enero de ese año los lineamientos de cómo deberían actuar la radio, televisión y periódicos en sus notas.

Bajo ese tenor, qué pasó realmente en la notas de los periódicos, ¿fue posible no considerar la presentación de los candidatos prescindiendo de la postura ideológica? La respuesta no fue simple, sin embargo, en el texto hallamos una guía para responder: las estrategias lingüísticas, la estructura del texto y el significado en contexto (principalmente los implícitos) nos ayudaron a construirla.

El análisis de la presentación de los candidatos en las notas me permitió observar muy de cerca la ideología, tal vez más directamente de lo que pensaba. Ahora me atrevo a decir que toda evaluación en forma de presentación contiene indudablemente la postura ideológica.

Presentación de los candidatos en las notas periodísticas

El periódico La Jornada y El Universal mostraron en sus evaluaciones claramente su postura ideológica.

\section{La Jornada y el candidato Andrés Manuel López Obrador}

Ciertamente, La Jornada presentó las noticias del candidato Andrés Manuel López Obrador (AMLO), en su mayoría, de manera positiva. El periódico resaltó las propuestas del candidato y los lugares donde las emitía, 
relacionando situación-lugar-propuesta. Por otro lado, las evaluaciones emitidas tanto del candidato como del periódico giraron en torno a la ética, fundamentalmente se centraban en el juicio de estimación social para dirigirse a los actos de los "otros político"; mientras que el periódico valoraba al presidenciable desde la apreciación y del juico de estima social positiva.

Un claro ejemplo de ello, lo observamos en el primer día del inicio de campaña: el periódico muestra a un candidato con propuestas justas, considerando a los pobres; además describe el lugar donde se emitió este primer discurso: el municipio más pobre del país.

De entrada estos aspectos resaltados en los titulares y el lead significan mucho para el contexto general que desea mostrar el periódico. La valoración como presentación de ciertos aspectos denotados en la macroestuctura del texto como: los titulares y el lead nos ofrecieron las pistas para interpretar qué de las propuestas emitidas por el candidato, qué de su ética como político y qué ofrece para votar por él.

\section{El Universal y el candidato Andrés Manuel López Obrador}

El periódico El Universal mostró, en la apertura de la candidatura de AMLO, a un personaje contradictorio y por tanto deshonesto. Para muestra un botón, el locutor evalúa las promesas de gobierno dudando de ellas; en primer lugar por el sitio donde fueron emitidas, una comunidad desolada Metlatónoc, la más pobre de México en donde se supone fue gobernada por los perredistas ${ }^{16}$ y no es palpable el progreso. En segundo lugar, a través de Nieves, una habitante de esta comunidad, que se refiere al candidato con un comentario que pone en duda las promesas: "haber si cumplen". El periódico recurre en gran medida a la evaluación de juicio de estima social para señalar al candidato en negativo, mientras que a Nieves la convirtió en una evaluadora pertinente porque sí sabe del tema y hasta podemos concluir que el periódico se reemplazó por ella para valorar.

\footnotetext{
${ }^{16}$ Así se les dice a los afiliados y seguidores del Partido de la Revolución Democrática. Andrés Manuel López Obrador es candidato a la presidencia por ese partido.
} 
Además en la nota existen más elementos que construyen a una, como yo la mencioné, macroevaluación, esto es, un texto totalmente dedicado a evaluar a un personaje político. Así, en este caso la evaluación representa el elemento organizador de esta nota periodística.

La presentación del último día de campaña describe a un candidato testarudo que insiste en que ganará la presidencia, las frases evaluadoras son principalmente: Insiste que desde el lunes se iniciará la construcción de un pacto social; En su última oportunidad por convencer al electorado, etcétera. Efectivamente, el periódico tiene la misión de revelar que Andrés Manuel López Obrador no es quien aparenta ser, es un político como los demás, con una historia llena de corrupción.

A continuación muestro un cuadro del resume de las evaluaciones emitidas:

\begin{tabular}{|c|c|c|}
\hline \multicolumn{3}{|c|}{$\begin{array}{l}\text { Parámetros de evaluación de las noticias } \\
\text { López Obrador }\end{array}$} \\
\hline $\begin{array}{l}\text { La Jornada } \\
\text { Parámetros }\end{array}$ & $\begin{array}{l}\text { El Universal } \\
\text { Parámetros }\end{array}$ & Fecha \\
\hline $\begin{array}{c}\text { Positivo (el personaje y su } \\
\text { discurso) }\end{array}$ & $\begin{array}{c}\text { Negativo (el discurso del } \\
\text { personaje y el partido político) }\end{array}$ & 20 de enero de 2006 \\
\hline $\begin{array}{l}\text { Positivo (el personaje y su } \\
\text { discurso) }\end{array}$ & $\begin{array}{c}\text { Negativo (las promesas del } \\
\text { candidato; la evaluación se hace } \\
\text { desde la gradación, es muy sutil. }\end{array}$ & 21 de enero de 2006 \\
\hline $\begin{array}{l}\text { Positivo (candidato } \\
\text { combativo y evaluador) }\end{array}$ & $\begin{array}{l}\text { Evaluó en negativo al gobierno } \\
\text { priista de Oaxaca } \\
\text { Fue imparcial en la presentación } \\
\text { del candidato. }\end{array}$ & 22 de enero de 2006 \\
\hline $\begin{array}{l}\text { Positivo (candidato } \\
\text { combativo, crítico y } \\
\text { evaluador) }\end{array}$ & $\begin{array}{c}\text { Negativo (acusar) } \\
\text { Negativo (indirectamente califica } \\
\text { al candidato priista y al } \\
\text { presidente de la República) }\end{array}$ & 23 de enero de 2006 \\
\hline Positivo (propuestas) & Imparcial & 29 de enero de 2006 \\
\hline
\end{tabular}

La Jornada y el candidato Felipe Calderón Hinojosa 
Con lo que respecta a Las notas del candidato Felipe Calderón Hinojosa elaboradas por La Jornada, éstas tienden a valorara de manera negativas. Por ejemplo, la no correspondencia de sus propuestas de gobierno con el sitio donde fueron emitidos: lugar-propuesta, muestra a un candidato fue poco coherente.

Otro, fue la de mostrar a un político provocador no conciliador, un ejemplo de ello está representado en la nota de inicio de campaña en donde el periódico puntualizó sobre la decisión de organizar los mítines en lugares gobernados por los partidos opositores. Otro ejemplo, es el último día de campaña; en esta nota el periódico reitera las anteriores evaluaciones porque deja a la vista a un personaje preocupado por desprestigiar al contrario y no aprovechar la oportunidad para convencer a los ciudadanos a través de sus propuestas. Por lo que hace inferir que no hubo propuestas.

\section{El Universal y el candidato Felipe Calderón Hinojosa}

En el caso del candidato Felipe Calderón Hinojosa, en general, se mostró en estas notas de inicio y final de campaña, a un hombre conciliador, seguro y con buenas propuestas de gobierno.

En el primer día, el titular fue: El toreo otra vez se cimbró, aquí notamos una evaluación en positivo porque el candidato provocó gritos y agitación. La evaluación está dirigida a aquellos militantes que brindaron un agradable inicio. Por lo que diré que el locutor utiliza la valoración de afecto en positivo, principalmente para presentar este inicio de campaña.

La noticia no cuenta con subtítulo así que pasa al lead directamente, en él se denota que el Toreo (lugar de inicio de la campaña) es un símbolo que identifica al Partido Acción Nacional (PAN), describe que hay miles de simpatizantes y la mayoría de colonias populares por ello se escucharon rechifla y silbidos, salvo este detalle todo lo demás marchó bien.

En el último día de campaña es importante recuperar parte de la frase del título porque allí se revela una fundamental evaluación: Calderón: ganaré 
por... y da una cifra notable de 1.5 millones de votos. Esta frase invita a saber que Calderón tiene a un importante número de seguidores, justos los que cimbraron el Toreo.

En general El Universal muestra a un candidato ganador y confiado, para ello utiliza la valoración de juicio de estima social en positivo para referirse al candidato y de afecto para los militantes. Así lo observamos en el resumen que muestra el siguiente cuadro:

\begin{tabular}{|c|c|c|}
\hline \multicolumn{3}{|c|}{$\begin{array}{c}\text { Parámetros de evaluación de las noticias } \\
\text { Felipe Calderón Hinojosa }\end{array}$} \\
\hline $\begin{array}{c}\text { La Jornada } \\
\text { Parámetros }\end{array}$ & $\begin{array}{c}\text { El Universal } \\
\text { Parámetros }\end{array}$ & Fecha \\
\hline $\begin{array}{c}\text { Negativo (el } \\
\text { comportamiento del } \\
\text { candidato y principalmente } \\
\text { de juicio) }\end{array}$ & $\begin{array}{c}\text { Positivo al candidato y su mitin } \\
\text { Negativo ( se centró a evaluar a la } \\
\text { militancia) }\end{array}$ & 20 de enero de 2006 \\
\hline $\begin{array}{c}\text { Negativo (del discurso del } \\
\text { candidato ) }\end{array}$ & $\begin{array}{c}\text { Positivo (un candidato conciliador } \\
\text { que pide se hagan las cosas bien, } \\
\text { sin divisiones) }\end{array}$ & 21 de enero de 2006 \\
\hline $\begin{array}{c}\text { Negativo ( Comportamiento } \\
\text { del candidato por acarrear } \\
\text { pepenadores) }\end{array}$ & $\begin{array}{c}\text { Positivo (la actitud del candidato } \\
\text { frente a reclamos) }\end{array}$ & 22 de enero de 2006 \\
\hline $\begin{array}{c}\text { Positivo (al candidato) } \\
\text { Negativo (Madrazo) }\end{array}$ & $\begin{array}{c}\text { Deja la duda del comportamiento } \\
\text { del candidato. }\end{array}$ & 26 de enero de 2006 \\
\hline $\begin{array}{c}\text { Negativo (al discurso de ese } \\
\text { cierre de campaña) }\end{array}$ & Positivo (al candidato) & 2006 \\
\hline
\end{tabular}

\section{La Jornada y el candidato Roberto Madrazo Pintado}

El candidato Roberto Madrazo Pintado se le evalúo, en el periódico La Jornada, en la gran mayoría de las veces por medio de ironías.

Las evaluaciones pronunciadas sobre este personaje se dirigieron a la forma de conducirse, sus propuestas de gobierno, a la militancia (acarreados) y la organización de los mítines. Aquí vemos, de igual manera, que el periódico retoma lo situacional, el lugar y las propuesta para evaluar también de manera global a la campaña. Asimismo, se mostró las pocas posibilidades que tuvo el 
candidato para ganar la presidencia porque representaba la fracción más débil del priismo, esto es, no simpatiza con Elba Esther Gordillo. ${ }^{17}$

En general La Jornada no evalúa positivamente al candidato del Partido Revolucionario Institucional (PRI).

\section{El Universal y el candidato Roberto Madrazo Pintado}

El candidato Roberto Madrazo Pintado lo dibujan, literalmente, en las notas del periódico El Universal como un hombre inseguro y con actitudes excéntricas que lo llevan a mirarlo con desconfianza.

En el primer día de campaña, por ejemplo, el titular es categórico porque muestra en todo su esplendor cómo el corporativismo (acarreados) administraron hasta la alegría priista. El titular hacen énfasis en valorarlos porque el PRI se le caracteriza por acarrear a personas y hasta pagarles por su presencia en mítines, etcétera. Por tal motivo el periódico valoró a través del juicio de sanción social esta práctica.

El último día de campaña se muestra a un candidato inseguro y con pocas propuestas, por ejemplo, en el titular aparece casi rogándole a la sociedad no lo descarte como un posible ganador, de entrada ya se asumió como perdedor, claramente lo pone en evidencia el periódico. Esto mismo se reitera en el lead, cuando dice que el pleito es de dos, pero la elección es de tres.

Tanto La Jornada como El Universal evalúa de manera negativa al candidato:

\footnotetext{
${ }^{17}$ Elba Esther Gordillo es la Secretaria vitalicia del Sindicato Nacional de Trabajadores de la Educación (SNTE) su afiliación al Partido Revolucionario Institucional (PRI) es conocido por todos, también el poder político que ostenta en México.
} 


\begin{tabular}{|c|c|c|}
\hline \multicolumn{3}{|c|}{$\begin{array}{c}\text { Parámetros de evaluación de las noticias } \\
\text { Roberto Madrazo Pintado }\end{array}$} \\
\hline $\begin{array}{c}\text { La Jornada } \\
\text { Parámetros }\end{array}$ & $\begin{array}{c}\text { El Universal } \\
\text { Parámetros }\end{array}$ & Fecha \\
\hline $\begin{array}{c}\text { Negativo (el } \\
\text { comportamiento del } \\
\text { candidato y gobernadores) }\end{array}$ & $\begin{array}{c}\text { Negativo (candidato, mitin y } \\
\text { acarreados) }\end{array}$ & 20 de enero de 2006 \\
\hline $\begin{array}{c}\text { Negativo (sentimiento de } \\
\text { desventaja) }\end{array}$ & $\begin{array}{c}\text { Más imparcial (cuando muestra IP } \\
\text { en un subtítulo) }\end{array}$ & 21 de enero de 2006 \\
\hline Negativo (propuestas) & Positivo (propuestas) \\
\hline $\begin{array}{c}\text { Negativo (propuestas, tintes } \\
\text { salinistas) Positivo } \\
\text { (propuesta de inseguridad) }\end{array}$ & $\begin{array}{c}\text { Positivo (propuesta del } \\
\text { narcomenudeo) }\end{array}$ & 22 de enero de 2006 \\
\hline Imparcial & $\begin{array}{c}\text { Negativo (el discurso de fin de } \\
\text { campaña, no quiere que lo vean } \\
\text { como perdedor) }\end{array}$ & 28 de enero de 2006 \\
\hline
\end{tabular}

De acuerdo a los cuadros, el periódico La Jornada muestra a través de sus evaluaciones una inclinación por el candidato de izquierda (López Obrador), en cambio por el candidato de derecha (Calderón Hinojosa) se observa una clara postura crítica.

El periódico El Universal simpatiza por el candidato de derecha ya que la mayoría de sus evaluaciones los hace en positivo, mientras que por el candidato de izquierda muestra una actitud crítica, así lo reflejan las evaluaciones que emitió.

Con lo que respecta al candidato Roberto Madrazo Pintado se observa que los dos periódicos lo evalúan con ironías.

El siguiente cuadro resume la postura de los periódicos:

\begin{tabular}{|l|l|l|}
\hline Candidato & \multicolumn{1}{|c|}{ La Jornada } & \multicolumn{1}{c|}{ El Universal } \\
\hline $\begin{array}{l}\text { Andrés Manuel López } \\
\text { Obrador }\end{array}$ & $\begin{array}{l}\text { Tiende a la evaluación } \\
\text { positiva }\end{array}$ & $\begin{array}{l}\text { Tiende a la evaluación } \\
\text { negativa }\end{array}$ \\
\hline Felipe Calderón Hinojosa & $\begin{array}{l}\text { Tiende a la evaluación } \\
\text { negativa }\end{array}$ & $\begin{array}{l}\text { Tiende a la evaluación } \\
\text { positiva }\end{array}$ \\
\hline Roberto Madrazo Pintado & $\begin{array}{l}\text { Tiende a la evaluación } \\
\text { negativa }\end{array}$ & $\begin{array}{l}\text { La evaluación está } \\
\text { repartida, pero el inicio y el }\end{array}$ \\
\hline
\end{tabular}




\begin{tabular}{|l|l|l|}
\hline & & $\begin{array}{l}\text { fin de campaña fueron } \\
\text { negativos. }\end{array}$ \\
\hline
\end{tabular}

La presentación de los candidatos en los medios de comunicación más allá de representar un fin publicitario, debemos de atribuirle el ideológico porque muestra y evalúa de acuerdo a los siguientes criterios: ¿con qué corriente coincido y cuál es su candidato? los discursos y las propuestas de gobierno. En ese sentido se estructura una nota que indudablemente promueva y resalta los beneficios de las promesas, sin ser necesariamente una publicidad, sino una evaluación que puede persuadir a otros de votar o no por ellos. A esto conduce a que la evaluación se proyecte de manera indirecta en una nota, ayudada estratégicamente por los recursos lingüísticos de la valoración.

Por otro lado, es importante destacar que el juicio y el valor son los subtipos más utilizados para evaluar a los candidatos en las notas de inicio y final de la campaña presidencial del 2006 del periódico La Jornada y El Universal.

La evaluación como bien hemos apreciado se convirtió en un elemento esencial en la estructuración de las notas y presentación de los personajes políticos pese a las restricciones del gobierno. 


\section{Obras citadas}

Caletti Kaplan, Rubén, 1989, "Las políticas de comunicación en México: Una paradoja históricas en palabras y en actos", en Medios de comunicación y política en América Latina, Elizabeth Fox (Ed.), México, pp. 52-78.

Cruz Soto, Rosalba, "La historia de la prensa en México durante el siglo XX", Instituto de Investigaciones Históricas de la UNAM, enero 2011: cdoc.iteso.mx/acervo/cat.aspx?cmn=download\&ID=2474\&N...,

Fernández, Nuria, 1978, "La reforma política: orígenes y limitaciones" en Cuadernos Políticos, número 16, México: Era, abril-junio, pp. 16-30.

Fonte Irene, 2000, "Parte I: Marco general: Teoría, Método, Contexto Histórico", en La nación cubana y Estados Unidos: Un estudio del discurso periodístico (1906-1921). México: El Colegio de México/UAM-I, pp. 17-40.

Fonte, Irene. 2008. "Un estudio pragmático del conflicto político mexicanocubano (2004) en la prensa", en Discurso y Sociedad. Revista multidisciplinaria de Internet, 2(1), 2008:http://www.dissoc.org/

Fuentes-Berain, Rossana, 2001, "Prensa y poder político en México", en Razón y Palabra. No. 23: http://www.razonypalabra.org.mx/anteriores/n23/23 rfuentes.html, enero de 2011.

Ghio, Elsa y María Elena Fernández, 2005, "Antecedentes y fundamentos de la LSF" en Manual de lingüística sistémico funcional: el enfoque de MAK Halliday y R. Hasan Aplicaciones a la lengua española. Argentina: Universidad del Litoral, pp. 9-21. Recuperado en abril del 2012: http://books.google.ca/books?id=5rrE2FyFXJ0C\&pg=PA9\&dq=Antecedentes+y +fundamentos+de+la+LSF\%E2\%80\%9D\&hl=es\&sa=X\&ei=1QflT8r-KO-u2gXC$8 \mathrm{HZCQ} \& \mathrm{ved}=0 \mathrm{CC} 4 \mathrm{Q} 6 \mathrm{AEwAA} \mathrm{v}=$ onepage $\& \mathrm{q}=$ Antecedentes $\% 20 \mathrm{y} \% 20$ fundame ntos\%20de\%20la\%20LSF\%E2\%80\%9D\&f=false

Hodge, R. Y G. Kress, 1993, "The scope of linguistics, en Language as ideology, London: Routledge, pp. 1-14.

Halliday, M.K.A., 1982,"La sociosemántica del texto" en El lenguaje como semiótica social. México: Fondo de Cultura Económica, 169-193.

,1982,"Una interpretación sociosemiótica del lenguaje" en El lenguaje como semiótica social. México: Fondo de Cultura Económica, 143160. 
Hunston, Susan y Geoff, Thompson, 2003, "Evaluation: An Introduction", en Evaluation in Text; authorial Stance and the Construction of Discourse. New York: Oxford, pp. 1-27.

, 2003, "Evaluation: An Introduction", en Evaluation in Text; authorial Stance and the Construction of Discourse. New York: Oxford, pp. 142175.

Instituto Federal Electoral (ed.), 2006, "Disposiciones adicionales sobre la cobertura y el uso de los medios", en Régimen Jurídico y Financiero de los Partidos Políticos y condiciones de equidad en la competencia electoral, México, pp. 14-15. Recuperado en mayo del 2011: http://www.ife.org.mx/docs/Internet/FAQ/Docs ES PDF/regimen-juridicofinanciero.pdf

Kaplan, Nora, 2004, "Nuevos desarrollos en el estudio de la evaluación en el lenguaje: La teoría de la valoración". Boletín de Lingüística. Julio -diciembre, Vol. 22. 52-78.

Karam, Tanius, 2000, "Comunicación y democracia en México: una introducción general", en Razón y Palabra, No.18, mayo-julio: http://www.razonypalabra.org.mx/anteriores/n18/editorial.html.

Labov, Williams, 1972, (Traducción: Ricardo Mendívil Rojo), "The transformation of experiencia in narrative syntax", en Language in the inner city, University of Pensnsylvania Press, Pennsylvania, pp. 345-396

López Ferrero, Carmen, 2004, "La valoración y la emoción en español en discursos especializados". En el simposio: Prácticas letradas contemporáneas: análisis y aplicaciones, Universitat Pompeu Fabra de Barcelona, coordinado por Daniel Cassay: http://www.upf.edu/dtf/recerca/grups/grael/LC/index.html

Malinowski, Bronislaw, (2008[1923]), "The Problem of Meaning in Primitive Language", en Maybin, Janet, Language and Literacy Social Practice, Gran Bretaña: Open University, pp. 1-10.

Martin, J.R. y P.R.R. White, 2005, The language of evaluation; appraisal in English.USA: palgrave.

Thompson, John B., 1993, "Réplica a algunas objeciones posibles" en Ideología y cultura moderna. México: Universidad Autónoma Metropolitana. 102-110.

Van Dijk Teun A., 1999, "Estructuras ideológicas del discurso", ideológica; Una aproximación multidisciplinaria. España: Gedisa. pp. 328-344. 
,1983, "Las estructuras del discurso de la noticia ", en Estructuras textuales de las noticias de prensa, Análisis. Quadernos de comunicación y cultura, Març. pp. 85-90.

1980, "Algunas notas sobre la ideología y la teoría del discurso". Semiosis (Jalapa, Mexico) 5, 37-54. Recuperado en mayo de 2012: http://bajofuego.org.ar/textos/Algunas notas sobre la ideologia y la teoria $\mathrm{d}$ el discurso.pdf

,1993, "Información explícita e implícita en el discurso", en Texto y Contexto; Semántica y pragmática del discurso, México: Red Editorial Iberoamericana, pp. 169-177.

Vasilachis de Gialdino, Irene, 1998, "La construcción discursiva y política de la realidad social (allegro)". en Discurso político y prensa escrita, Barcelona: Gedisa, pp.25-86.

Verón, Eliseo, 2002, Construir el acontecimiento; los medios de comunicación masiva y el accidente en la central nuclear de Three Mile Island. España: Gedisa.

White, Peter R.R. Un recorrido por la teoría de la valoración (Teoría de la valoración). Traducido por Elsa Ghio. Recuperado el 6 de junio de 2010: http://www.grammatics.com/appraisal/SpanishTranslation-AppraisalOutline.pdf

Williamson, Rodney y Zúñiga Cortés Karla, 2005, "Citas Mixtas en la Prensa: una comparación de periódicos en español y en inglés", en Signos Lingüísticos, Julio-diciembre, pp. 9-24.

Whorf, B., (1956 [1941.b]), Language, Thought, and Reality, Massachusetts: Institute of Technology Cambridge. 


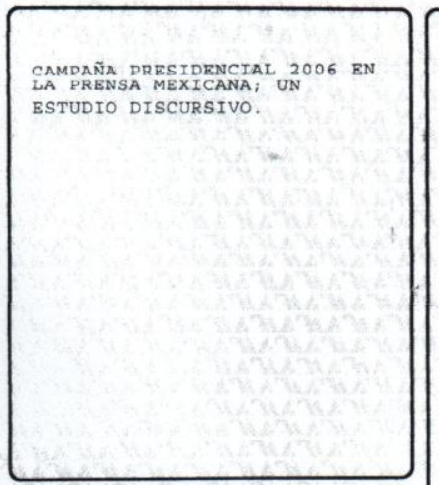

En México, D.F., se presentaron a las 11:00 horas del día 13 del mes de noviembre del año 2012 en la Unidad Iztapalapa de la Universidad Autónoma Metropolitana, los suscritos miembros del jurado:

DRA. LUISA IRENE FONTE ZARABOZO

DRA. LAURA ADRIANA HERNANDEZ MARTINEZ

DR. HECTOR AMADOR MUÑOZ CRUZ

Bajo la Presidencia de la primera y con carácter de Secretario el último, se reunieron para proceder al Examen de Grado cuya denominación aparece al margen, para la obtención del grado de:

MAESTRA EN HUMANIDADES (LINGUISTICA)

DE: CLAUDIA JALIFE MONTALVO

y de acuerdo con el artículo 78 fracción III del Reglamenta de Estudios Superiores de la Universidad Autónoma Metropolitana, los miembros del jurado resolvieron:

\section{APROBAR}

Acto continuo, la presidenta del jurado comunicó a la interesada el resultado de la evaluación $y$, en caso aprobatorio, le fue tomada la protesta. LIC. JULO CESTR DE LARA ISASSI DIRECTOR DE SISA MAS ESEOLARES

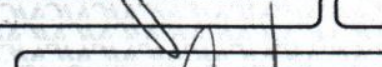

DIRECTOR DE LA DIVISION DE CSH

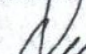

DR. JOSE OGTAVIONATERASTOOMINGUEZ

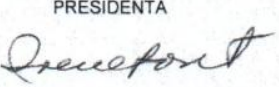

DRA. LUISA IRENE FONTE ZARABOZO

VOCAL
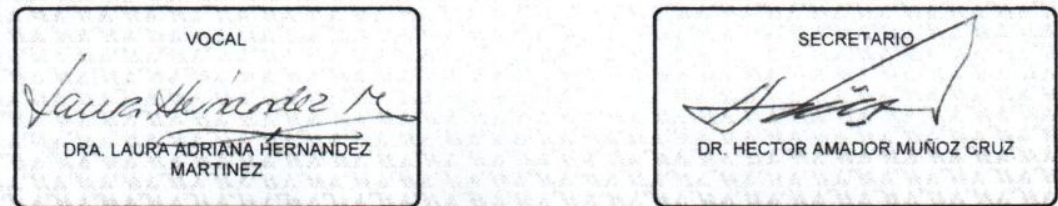